\title{
Remesas y migración internacional en América Latina: Simulación de los efectos en la pobreza y la desigualdad ${ }^{1}$
}

\author{
Diego Battistón \\ dbattiston@cedlas.org \\ CEDLAS-CONICET \\ Facultad de Ciencias Económicas \\ Universidad Nacional de La Plata
}

Director: Pablo Acosta (World Bank)

\begin{abstract}
Resumen $^{2}$
Este trabajo realiza un estudio comparativo del impacto de las remesas y la migración internacional sobre la pobreza y la desigualdad en cuatro países latinoamericanos con importantes procesos migratorios (Ecuador, El Salvador, Honduras y Nicaragua). A partir de encuestas de hogares se estiman los cambios producidos sobre estas dos dimensiones utilizando diferentes microsimulaciones. La metodología utilizada también permite descomponer los cambios totales en efectos directos e indirectos. Los cambios directos están relacionados con la salida del migrante del hogar y la sustitución de ingresos laborales por remesas. Los efectos indirectos (no observables) operan sobre el resto de los miembros del hogar y entre ellos se incluyen restricciones a la liquidez o cambios en las decisiones laborales. La incorporación de un doble mecanismo de selección muestral permite tener en cuenta arreglos intra-hogar que usualmente son excluidos del análisis empírico pero que han recibido fuerte soporte teórico en la literatura. Los resultados indican que en los cuatro países el proceso de migraciones y remesas reduce la desigualdad y en Ecuador, El Salvador y Honduras también se reducen significativamente las tasas de pobreza. La importancia relativa de los canales directos e indirectos depende entre otros factores de las características de los hogares involucrados en el proceso y el tipo de selección que opera sobre los mismos. En términos generales, la sustitución directa de ingreso laboral por remesas tiende a ser más importante cuando los hogares son más pobres mientras que los efectos indirectos se concentran en los hogares con ingresos medios.
\end{abstract}

\footnotetext{
1 Trabajo presentado como tesis final de la Maestría en Economía, Facultad de Ciencias Económicas, UNLP.

2 El Autor agradece los valiosos comentarios de Javier Alejo, Sergio Olivieri y Guillermo Cruces.
} 
Battistón, Diego Ezequiel

Remesas y migración internacional en América Latina : simulación de los efectos en la pobreza y la desigualdad . - 1a ed. - La Plata : Universidad Nacional de La Plata, 2011. E-Book.

ISBN 978-950-34-0780-6

1. Migración Internacional. 2. Tesis de Maestría. I. Título CDD 304.8

Fecha de catalogación: 01/11/2011 


\section{Introducción}

En los últimos años, las remesas se han convertido en una de las fuentes más importantes del ingreso familiar en muchos países de Latinoamérica y el Caribe. De acuerdo a las estimaciones de Ratha y Xu (2008) en 1995 la región recibía aproximadamente 13 mil millones de dólares anuales en concepto de remesas. Para el año 2007 este flujo se incrementó a casi 60 mil millones de dólares anuales. De acuerdo al mismo estudio, en algunos países como Honduras, Haití y Guyana, las remesas representan un porcentaje mayor al 20\% del PBI anual. Los flujos recibidos por los hogares, además de incrementarse en forma continua en cuanto su volumen, han revertido su característica extraordinaria para convertirse en una fuente relativamente estable de ingreso (Neyapti (2004))

El presente trabajo realiza un aporte en la discusión acerca del impacto que el proceso de migración ha tenido en Latinoamérica, avanzando al mismo tiempo sobre una serie de interrogantes y debilidades metodológicas que se observan en la literatura actual. Aunque los efectos de este proceso se extienden a un gran número de variables y dimensiones, el análisis se limita en este caso a la pobreza y la desigualdad.

Una característica que se observa en la literatura es cierta separación metodológica entre los estudios relacionados con el proceso de migración internacional y los que analizan los efectos de las remesas. En este sentido, el trabajo realiza un esfuerzo metodológico para incluir dentro del análisis ambos fenómenos permitiendo al mismo tiempo la posibilidad de que tengan consecuencias diferentes. Esto permitiría tener en cuenta que pueden existir diferentes arreglos intra-hogar entre el migrante y el resto de los miembros del hogar que no necesariamente implican flujos monetarios. Además, si bien existe una extensa literatura empírica vinculada al impacto de las remesas sobre la pobreza y la desigualdad, con fuente macroeconómica y microeconómica, existen pocos estudios que comparan entre países ${ }^{3}$.

El trabajo también se encuentra en línea con otros que durante los últimos años han criticado la visión de que las remesas puedan analizarse como flujos exógenos de ingreso. Bajo la visión tradicional, los efectos de las remesas sobre la pobreza son completamente triviales porque se ignoran las decisiones involucradas en el proceso de migración y el comportamiento del resto de los miembros del hogar. Por otro lado, los efectos sobre la desigualdad han sido vinculados tradicionalmente a las brechas de salarios y varianzas del

\footnotetext{
3 Algunos de los trabajos que realizan una comparación internacional de los efectos de las remesas sobre la pobreza o la desigualdad se pueden citar Acosta et.al. (2007) y Adams y Page (2003)
} 
ingreso laboral entre el país receptor de remesas y el país de residencia de los migrantes. Borjas (1987) por ejemplo, establece que estos factores son los que determinan el grado de calificación o educación de los migrantes. Sin embargo, son pocos los estudios que han hecho referencia la relación entre estas características del mercado laboral y de los migrantes con la desigualdad resultante en los ingresos familiares. Como se resume en la Tabla 1, los estudios empíricos han mostrado en general que el efecto de las remesas sobre la desigualdad no es concluyente.

Tabla 1

Estudios empíricos del impacto de las remesas sobre la desigualdad

\begin{tabular}{lclc}
\hline \hline Autor & Año & Data set & $\begin{array}{c}\text { Efecto s/ } \\
\text { desigualdad }\end{array}$ \\
\hline Acosta et.al. & 2008 & 10 países LAC & $+/-$ \\
Adams & 1989 & Egipto Rural & + \\
Adams & 2006 & Ghana & + \\
Barham y Boucher & 1998 & Bluefields, Nicaragua & + \\
Mora Rivera & 2005 & México Rural & $\mathbf{( - )}$ \\
Rodriguez & 1998 & Filipinas & $\mathbf{+}$ \\
Stark, Taylor y Yitzhaki & 1986 & México Rural & $\mathbf{( - )}$ \\
Stark, Taylor y Yitzhaki & 1988 & México Rural & $\mathbf{( - )}$ \\
Taylor & 1992 & México Rural & $\mathbf{( - )}$ \\
\hline
\end{tabular}

Fuente: elaboración propia

Desde el punto de vista teórico, tampoco existen desarrollos que indiquen que los efectos de las remesas sobre la desigualdad o la pobreza deben seguir una sola dirección. La complejidad de las decisiones detrás del proceso de migraciones ${ }^{4}$, al igual que la gran cantidad de parámetros que intervienen en los modelos teóricos, determinan que distintas combinaciones de condiciones iniciales (Borjas, 1987; Hanson y Chiquiar, (2005)) puedan generar impactos distintos sobre los niveles de ingreso de los migrantes y los no migrantes, y por lo tanto, sobre la desigualdad y la pobreza.

Otro tipo de aporte que se realiza tiene que ver con identificar algunos mecanismos a través de los cuales las remesas afectan el ingreso de los hogares. Si bien no es posible identificar todos estos canales utilizando encuestas de hogares tradicionales, se propone un marco analítico que permitirá diferenciar entre algunos efectos directos relacionados con el ingreso laboral de los migrantes de otros efectos indirectos relacionados con el resto de los miembros del hogar.

\footnotetext{
${ }^{4}$ Ver por ejemplo Docquier y Rapoport (2003) quienes desarrollan un modelo dinámico donde intervienen complejas decisiones sectoriales, de oferta laboral y de acumulación de activos.
} 
El resto del trabajo se estructura de la siguiente forma. La sección 2 describe el set de datos utilizados en el trabajo. La sección 3 realiza un análisis descriptivo de las características más importantes de los migrantes, las remesas y las familias receptoras dentro de la economía doméstica. También se analiza el "impacto aritmético" de las remesas sobre la desigualdad y la pobreza. La sección 4 discute los argumentos teóricos actuales más influyentes sobre los cuales se derivan las hipótesis más importantes del trabajo. La sección 5 introduce la metodología empírica que se utiliza para las simulaciones. La sección 6 describe los hallazgos más importantes y finalmente la sección 7 concluye.

\section{Países y encuestas incluidas en la muestra}

El trabajo compara 4 países de Latinoamérica: Ecuador, El Salvador, Honduras y Nicaragua. Estos países fueron seleccionados por dos razones. En primer lugar se trata de países con una larga historia de migración y grandes flujos de remesas que se han incrementado notablemente en los últimos 20 años. De acuerdo a Orozco et al. (2006) los cuatro países pueden clasificarse dentro de los 10 países con mayor impacto de las remesas en la región si se tiene en cuenta el impacto de las mismas sobre una serie de indicadores económicos. El mismo estudio estima que en Ecuador la tasa de crecimiento de las remesas fue del 35\% anual en promedio entre 1990 y 2003 alcanzando más de 1700 millones de dólares anuales, lo que representa más del 6\% del PBI. En Nicaragua, la importancia de las remesas tampoco es menor si se tiene en cuenta que las mismas representaron cerca del $75 \%$ de las exportaciones anuales durante el 2003, más del doble de la inversión extranjera directa dentro del país y un $12 \%$ en términos del PBI. En el caso de Honduras, Ratha y Xu (2008) estiman que durante el 2006 la participación de las remesas en el PBI superó el 25\%, ubicándose en el primer lugar del ranking entre los países de la región y en el quinto lugar a nivel mundial. La tasa de crecimiento anual de las remesas durante la década del 90 fue superior al 25\% anual de acuerdo a lo estimado por Orozco et al (2006) en base a cifras del Banco Mundial. Finalmente, El Salvador es uno de los países que mayor cantidad de remesas recibe en términos absolutos con más de 2500 millones de dólares recibidos durante el 2004 y un crecimiento promedio mayor del 10\% durante la última década. En términos del PBI este valor supera el 14\% y representa más del $60 \%$ de las exportaciones desde hace ya varios años.

La segunda razón para incluir estos países dentro de la muestra tiene que ver con la disponibilidad de encuestas, que además de proveer información básica sobre el hogar, 
contienen un cuestionario específico sobre características de antiguos miembros del hogar que emigraron. Para estimar los ingresos que el migrante hubiese recibido dentro de la economía, se necesita cierta información sobre educación, edad y género de los migrantes que estas encuestas poseen.

Estos 4 países, además, tienen la ventaja de contar con patrones e historias de migración muy heterogénea. Por ejemplo, en países como Nicaragua y El Salvador los acontecimientos políticos explican gran parte del proceso migratorio mientras que en otros países como Ecuador los motivos económicos suelen mencionarse como principal argumento. Además, como se verá posteriormente, existen diferencias muy importantes al momento de migrar que determinan impactos diversos sobre la pobreza o la desigualdad.

Los datos utilizados corresponden la "Encuesta de Condiciones de Vida" (ECV) 2006 de Ecuador, la "Encuesta de Hogares de Propósitos Múltiples" (EHPM) 2007 de El Salvador, la "Encuesta de Condiciones de Vida" (ECV) 2004 de Honduras y la "Encuesta de Medición de Niveles de Vida" (EMNV) 2005 de Nicaragua 5 .

\section{Perfil observado de las remesas y la migración internacional}

Una primera aproximación para estimar el efecto distributivo de las remesas consiste en estudiar la importancia de estos flujos de ingreso dentro de la estructura de ingresos familiares y su relación con la posición de los hogares dentro del ranking de ingresos. Si los flujos de remesas son contabilizados como exógenos, el impacto sobre la pobreza siempre es positivo o cero y su magnitud dependerá de dos factores: la cantidad agregada de remesas y la distribución de las remesas de acuerdo a la distribución del ingreso neto de remesas. Al comparar las tasas presentadas en la Tabla 2 para cada línea de pobreza, se obtiene este impacto "aritmético" de las remesas. Se observa que en El Salvador la pobreza cae varios puntos para todas las líneas cuando mientras que en el resto los países las disminuciones varían entre uno y tres puntos porcentuales dependiendo de la línea utilizada.

\footnotetext{
5 Todas las encuestas han sido homogeneizadas y son comparables de acuerdo a la metodología de la base de datos SEDLAC. La base SEDLAC es un proyecto conjunto entre CEDLAS- Universidad Nacional de La Plata y World Bank Group. Para mayor información consultar http://www.cedlas.org/sedlac.
} 
Tabla 2

Impacto aritmético de las remesas en la pobreza y la desigualdad

\begin{tabular}{|c|c|c|c|c|c|}
\hline & $\begin{array}{c}\text { Pobreza } \\
\text { Moderada }\end{array}$ & $\begin{array}{l}\text { Pobreza } \\
\text { Extrema }\end{array}$ & $\begin{array}{c}\text { Pobreza } \\
2 \text { usd }\end{array}$ & $\begin{array}{l}\text { Pobreza } \\
1 \text { usd }\end{array}$ & Gini \\
\hline \multicolumn{6}{|l|}{ ECUADOR 2006} \\
\hline Ingreso observado & 31.60 & 16.23 & 22.15 & 9.58 & 0.539 \\
\hline Ingreso neto de remesas & 33.03 * & 17.39 * & 23.45 * & 10.42 * & 0.544 \\
\hline \multicolumn{6}{|l|}{ EL SALVADOR 2007} \\
\hline Ingreso observado & 32.37 & 9.81 & 27.49 & 9.49 & 0.468 \\
\hline Ingreso neto de remesas & $40.27^{*}$ & 15.81 * & 34.59 * & $15.13^{*}$ & 0.496 * \\
\hline \multicolumn{6}{|l|}{ HONDURAS 2004} \\
\hline Ingreso observado & 63.37 & 43.53 & 39.40 & 20.25 & 0.625 \\
\hline Ingreso neto de remesas & 66.33 * & 46.82 * & 42.51 * & 22.37 * & 0.623 \\
\hline \multicolumn{6}{|l|}{ NICARAGUA 2005} \\
\hline Ingreso observado & 40.65 & 16.67 & 38.58 & 13.21 & 0.522 \\
\hline Ingreso neto de remesas & 42.66 * & 17.32 * & 40.39 * & 13.71 * & 0.518 \\
\hline
\end{tabular}

A diferencia de la pobreza, los cambios en la desigualdad pueden operar con distinto signo dependiendo de la cantidad agregada de remesas y la distribución de las mismas en relación al ingreso neto de remesas ${ }^{6}$. Para caracterizar la distribución de las remesas en relación a las otras fuentes de ingreso, en el Gráfico 1 se presentan las curvas de concentración de las mismas en relación al resto de los ingresos del hogar. El Salvador y Nicaragua son casos claramente opuestos, siendo las remesas marcadamente progresivas en el primer caso y regresivas en el segundo. Honduras y Ecuador en cambio, muestran una distribución más igualitaria de las remesas, con cruces de la curva de concentración y la línea de perfecta igualdad7. La última columna de la Tabla 2 muestra este "impacto aritmético" de las remesas sobre la desigualdad de cada país. Puede notarse que en El Salvador y Ecuador la inclusión de las remesas dentro del ingreso familiar reduce la desigualdad mientras que en Nicaragua y Honduras produce un leve aumento de la misma, sin embargo, el cambio es estadísticamente significativo ${ }^{8}$ solamente para El Salvador.

Como se analizará en secciones posteriores, existen una serie de decisiones dentro del hogar relacionadas con el proceso de migración y otros efectos indirectos que pueden incluso revertir la dirección de estas conclusiones. A lo largo de las siguientes secciones, se propone y discute una metodología que tiene en cuenta todos estos factores y permite

\footnotetext{
6 A partir de esta idea, Stark, Taylor y Yitzhaki (1986) proponen una fórmula de cálculo para el impacto marginal de las remesas sobre el índice de Gini que ha sido ampliamente difundido en diversos trabajos que relacionan la desigualdad con las remesas.

${ }^{7} \mathrm{El}$ cruce se produce en ambos países porque existe una importante cantidad de hogares cuyo principal ingreso son las remesas y por lo tanto el ingreso neto de remesas se ubica en los primeros percentiles.

8 Para establecer la significatividad de los cambios se obtuvieron intervalos de confianza al 95\% mediante bootstrap
} 
estimar en forma más realista el verdadero impacto del proceso de remesas incluyendo aquellos efectos relacionados con la migración de algunos miembros del hogar.

\section{Gráfico 1}

Curvas de concentración de las remesas en relación al ingreso neto de remesas
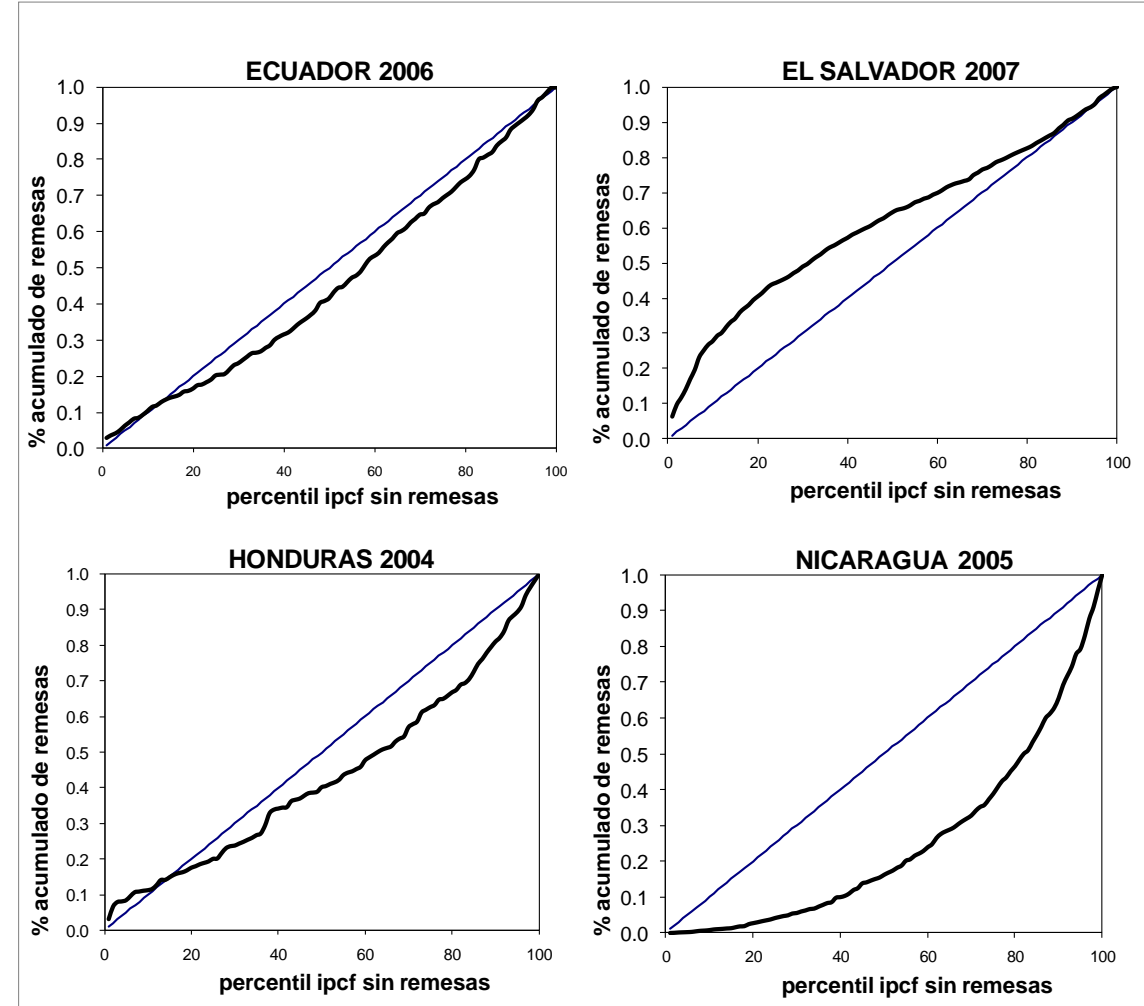

Fuente: elaboración propia en base a SEDLAC (CEDLAS-Banco Mundial)

\subsection{El perfil de los hogares perceptores de remesas y de los hogares con migrantes}

Si el flujo de remesas fuese completamente exógeno y aleatorio y no existieran cambios en el comportamiento de los hogares producto de las remesas, las diferencias observadas anteriormente podrían atribuirse exclusivamente a las remesas. Sin embargo, uno de los principales argumentos de la literatura más reciente (Tunali (2000), McKenzie et al (2006)) está relacionado con las diferencias ex - ante de los hogares con migrantes respecto del resto, ya sea en características observables como no observables. Es igualmente resaltado por algunos autores (Amuedo-Dorantes y Pozo (2006), Görlich et al (2007), Cox y Ureta (2003), Yang (2008)) el cambio en el comportamiento de los hogares producto de la recepción de remesas. La complejidad de esta situación introduce un serio problema de identificación: las diferencias observadas en variables socioeconómicas o laborales podrían responder a diferencias en características de los hogares registradas antes del proceso migratorio o bien ser consecuencias de dicho proceso. Diferencias sistemáticas en algunas 
variables pueden reforzar la hipótesis de selección frecuentemente mencionada por la literatura, ya sea a nivel individual (Borjas (1987), Hanson y Chiquiar (2005)), como de los hogares a los que pertenecen (Adams (2006)), particularmente cuando las variables bajo estudio sean difíciles de modificar en el tiempo.

Por otra parte, algunos trabajos usualmente asocian unívocamente la recepción de remesas con la migración internacional, es decir, asocian el flujo de remesas con la migración de algún integrante del hogar. Sin embargo, el análisis de las encuestas de hogares muestra que existen hogares que reciben remesas sin tener algún antiguo integrante fuera del país, y opuestamente, hogares que declaran tener algún miembro fuera del país y no reciben remesas durante un periodo considerable ${ }^{9}$.

\section{Perfil demográfico y regional}

En la Tabla A.1.1 del Apéndice 1 se resumen las principales variables demográficas y la distribución urbano-rural de los grupos de hogares para los cuales se dividió la muestra. Los países con mayor presencia de hogares con migrantes y hogares perceptores son El Salvador y Nicaragua. La estructura etaria sigue algunos patrones similares en los cuatro países. El rasgo más sobresaliente es que el porcentaje de población entre 26 y 40 años de edad es significativamente menor entre los hogares receptores de remesas y los hogares con migrantes respecto del resto de los hogares ${ }^{10}$. En cambio, el porcentaje de población entre 41 y 64 años, es superior en casi todos los casos para el set de hogares receptores o con migrantes y lo mismo sucede para el grupo de población de 16 a 25 años. El porcentaje de menores de 15 años es también menor para el grupo de hogares receptores y de hogares con migrantes, mientras que el porcentaje de mayores de 65 años es mayor para estos hogares. Las diferencias en el grupo de 26 a 40 años pueden estar conducidas principalmente por la emigración de individuos en este rango etario. Para otros grupos, como niños y adultos mayores, este argumento se debilita ya que por ejemplo las decisiones de fertilidad y otras variables socioeconómicas, que modifican esta estructura, pueden ser condiciones previas del proceso migratorio o consecuencias del mismo.

\footnotetext{
${ }^{9}$ Dos aclaraciones son necesarias en este punto. En primer lugar una consideración de carácter empírico es que algunas encuestas de hogares registran la salida de un miembro del hogar en un periodo de referencia determinado como es el caso de Ecuador. En segundo lugar, un argumento teórico analizado por Wouterse y Taylor (2006) y Katz y Stark (1986) sostiene que la migración puede asociarse a una estrategia de diversificación del hogar. En este caso la promesa del migrante de enviar dinero frente a una caída temporal de otras fuentes de ingreso del hogar puede ser suficiente para producir efectos en algunas variables de comportamiento del resto de los miembros del hogar (Yang y Choi (2007), Amuedo-Dorantes y Pozo (2002), Cox y Jimenez (1998))

${ }^{10}$ En las tablas del Apéndice 1, se reportan los correspondientes niveles de significatividad.
} 
En todos los países, el tamaño de los hogares con migrantes o con remesas tiende a ser significativamente mayor al tamaño del resto de los hogares excepto en el caso de Nicaragua donde los primeros hogares tienen menor cantidad de miembros en promedio.

Los hogares con migrantes o remesas se concentran principalmente en zonas urbanas. En todos los países el porcentaje de población urbana dentro del grupo de hogares con migrantes o remesas es superior al porcentaje de población urbana para los otros tipos de hogares, excepto en El Salvador, donde el porcentaje de hogares rurales es superior.

\section{Perfil educativo}

El perfil educativo de los hogares con remesas y de los hogares con migrantes es útil no sólo para comparar estos hogares con el resto en términos de características observables sino porque en algunos grupos etarios, las decisiones educacionales pueden ser bastante exógenas al proceso migratorio. Es particularmente interesante el grupo de mayores a 41 años, donde el proceso migratorio es mucho más leve o bien la tasa de retorno de migrantes al país de origen es elevada. Como se observa en la Tabla A.1.3, todos los países presentan diferencias en términos de años de educación formal que favorecen los hogares con remesas o migrantes, excepto el caso de El Salvador donde se da una diferencia muy importante: en los grupos etarios menores a 41 años los hogares con remesas o migrantes parecen ser más educados, sin embargo el resultado se revierte cuando se analizan los mayores de 41 años. Este tipo de conclusiones puede reforzar la hipótesis de selección negativa en el caso de El Salvador ${ }^{11}$ y positiva para otros países como Nicaragua. En esta misma dirección, se puede observar que para todos los países de la muestra, las variables de asistencia escolar infantil favorecen a los grupos con remesas o migrantes. En relación a este punto, una serie de trabajos entre los que se destacan Cox-Edwards y Ureta (2003), Amuedo-Dorantes et al (2008) y Kandel y Kao (2001), resaltan el impacto de las remesas y la migración en las variables educativas de los niños.

\section{Infraestructura del hogar}

Si bien en algunos casos como El Salvador los hogares con migrantes o remesas se concentran en percentiles más bajos de la distribución del ingreso neto de remesas, es interesante analizar lo que sucede cuando se examinan las características de la vivienda y acceso a servicios por parte de los diferentes hogares como se muestra en la Tabla A.1.2.

${ }^{11}$ Es necesario destacar que el resultado también podría ser producido por un "efecto cohorte" provocado por la mejora en las condiciones de acceso a la educación de los grupos de menor ingreso. 
En casi la totalidad de las variables analizadas y para los cuatro países, las diferencias favorecen a los hogares con remesas o migrantes. Si bien algunos autores enfatizan que la acumulación de activos suele ser un requisito previo o una "barrera" para la migración (Adams (1991), De Brauw (2007)), pueden existir también algunos efectos importantes de las remesas sobre los activos y la inversión del hogar ${ }^{12}$ como evidencian Yang (2008), Briere et al (2001) y Adams (1998).

\section{Status laboral}

En la Tabla A.1.4 se presentan las diferencias estimadas en una serie de variables de status laboral para los grupos de hogares bajo estudio, desagregadas para diferentes grupos de edad. El primer grupo de filas analiza las tasas de participación laboral de distintos grupos etarios y por género. En general, los hogares con migrantes y con remesas registran menores tasas de participación para cualquier rango de edad, salvo excepciones donde la diferencia es no significativa. Como analizan algunos autores, (Acosta (2006), AmuedoDorantes y Pozo (2006), Rodriguez y Tiongson (2001)) este resultado podría deberse a que las remesas elevan el salario de reserva del resto de los integrantes del hogar reduciendo la oferta laboral, aunque deben realizarse las mismas consideraciones de la selectividad por parte de los hogares con migrantes. Es interesante también analizar el grupo formado por mujeres entre 25 y 55 años, quienes a diferencia de los grupos etarios analizados anteriormente registran siempre tasas de participación mayores en hogares con remesas y con migrantes. Aunque esta diferencia podría explicarse por la reducción en la fuerza laboral dentro del hogar, puede observarse que las diferencias entre hogares con y sin migrantes son menores que las diferencias entre hogares con remesas y hogares sin remesas, lo cual puede reforzar la hipótesis de selección sobre el tipo de migración que produce mayor flujo de remesas. En otras palabras, los hogares donde la migración del jefe de hogar produce un aumento de la participación laboral femenina, pueden tener una mayor propensión a recibir remesas por parte del migrante. En casos donde el migrante es muy joven, hijo del jefe de hogar o migrante por motivos educativos, el efecto esperado sobre la oferta laboral femenina dentro del hogar es mucho menor y al mismo tiempo el envío de remesas es menos probable.

\footnotetext{
${ }^{12}$ Se puede mencionar también que en los últimos años una serie de trabajos (Ellis (2003), de Haan (1999)) han expresado cierto escepticismo sobre este punto, argumentando que los costos y barreras iniciales para migrar son usualmente sobreestimados arribando a la conclusión a veces errónea de que los individuos provenientes de familias pobres o vulnerables no pueden migrar.
} 
Cuando se analizan la cantidad de horas trabajadas, se observa que los individuos que habitan en hogares con remesas o con migrantes tienden a trabajar menos cantidad de horas semanales. Si bien para algunos países y algunos rangos de edad las diferencias son no significativas, en ningún caso la cantidad de horas trabajadas es mayor para los hogares con remesas o con migrantes.

\subsection{El perfil de los migrantes. Tipos de migración}

Una de las ventajas de contar con un análisis comparativo entre países es que cada uno de ellos cuenta con una historia de migración diferente. Los motivos por los cuales se producen los flujos de migrantes, los costos o barreras a la migración y los destinos elegidos pueden ser muy diferentes entre países. Estas diferencias, que también se traducen al perfil de los migrantes y los hogares de origen, constituyen el argumento más fuerte detrás de las diferencias en el impacto sobre la pobreza y la desigualdad que se observa en otros trabajos. En la Tabla 3 se resumen algunas características de los migrantes de cada país, sujetas a la disponibilidad de información de cada encuesta.

Tabla 3

Perfil de los migrantes internacionales

\begin{tabular}{|c|c|c|c|c|}
\hline & $\begin{array}{l}\text { ECUADOR } \\
2006\end{array}$ & $\begin{array}{c}\text { EL SALVADOR } \\
2007\end{array}$ & $\begin{array}{c}\text { HONDURAS } \\
2004\end{array}$ & $\begin{array}{c}\text { NICARAGUA } \\
2005\end{array}$ \\
\hline \multicolumn{5}{|l|}{ Características del migrante } \\
\hline $\mathrm{N}^{\circ}$ migrantes en el hogar (1) & 1.3 & 1.8 & 1.5 & 1.6 \\
\hline $\mathrm{N}^{\circ}$ total de migrantes (miles) & $239,364.0$ & $246,791.0$ & $254,488.0$ & $222,161.0$ \\
\hline Edad promedio (actual) & 32.3 & 34.8 & 30.6 & 32.5 \\
\hline Años de escolaridad del migrante & 11.0 & 8.2 & 7.4 & 7.6 \\
\hline Porcentaje con nivel secundario & $68.7 \%$ & $32.5 \%$ & $25.4 \%$ & $28.5 \%$ \\
\hline Porcentaje hombres & $50.6 \%$ & $61.7 \%$ & $61.9 \%$ & $51.4 \%$ \\
\hline Años desde que migró & 4.0 & 6.1 & 5.1 & 7.8 \\
\hline Hogar con jefe migrante & $24 \%$ & $0 \%$ & & \\
\hline Hogar con esposa/o del jefe migrante & & $19.9 \%$ & $23.1 \%$ & \\
\hline \multicolumn{5}{|l|}{ Destino de migración } \\
\hline EEUU/Canada & $24.0 \%$ & $93.9 \%$ & $88.6 \%$ & $38.7 \%$ \\
\hline LAC & $5.4 \%$ & $6.1 \%$ & $8.9 \%$ & $59.9 \%$ \\
\hline Union Europea & $70.7 \%$ & $0.0 \%$ & $2.2 \%$ & $1.4 \%$ \\
\hline Otros & $0.0 \%$ & $0.0 \%$ & $0.3 \%$ & $0.1 \%$ \\
\hline \multicolumn{5}{|l|}{ Estructura etárea de los migrantes } \\
\hline$N^{\circ}$ de migrantes $<15$ years & $0.5 \%$ & $0.3 \%$ & $3.0 \%$ & $5.6 \%$ \\
\hline $\mathrm{N}^{\circ}$ de migrantes $[16,25]$ & $25.4 \%$ & $21.4 \%$ & $33.9 \%$ & $28.2 \%$ \\
\hline $\mathrm{N}^{\circ}$ de migrantes $[26,40]$ & $55.6 \%$ & $49.1 \%$ & $45.8 \%$ & $43.0 \%$ \\
\hline $\mathrm{N}^{\circ}$ de migrantes $[41,64]$ & $18.2 \%$ & $25.1 \%$ & $12.6 \%$ & $21.5 \%$ \\
\hline $\mathrm{N}^{\circ}$ de migrantes $\quad+65$ & $0.3 \%$ & $4.1 \%$ & $4.8 \%$ & $1.8 \%$ \\
\hline \multicolumn{5}{|l|}{ Envío de remesas (1) } \\
\hline Envío mensualizado (USD ppp) & 184.3 & 111.5 & 293.5 & 87.1 \\
\hline Participación en el ingreso familiar & $25.6 \%$ & $45.2 \%$ & $30.0 \%$ & $16.2 \%$ \\
\hline Porcentaje que envía remesas & $77.2 \%$ & $73.3 \%$ & $66.4 \%$ & $59.2 \%$ \\
\hline
\end{tabular}


Resulta interesante analizar la estructura de edad y género de los migrantes entre países. Ecuador se destaca del resto con más de 11 años de educación promedio, mientras que en el resto de los países este valor es cercano a los 8 años ${ }^{13}$. El Salvador y Honduras presentan tasas de migración de hombres mayores que en los dos países restantes y Nicaragua registra la migración con mayor antigüedad. La edad actual de los migrantes es cercana a los 30 años en todos los países y dentro de la estructura etaria se puede observar que el mayor porcentaje de migrantes se concentra en el rango de edad que va entre los 26 y los 46 años, seguido en importancia por el tramo de edad de 16 a 25 años.

El destino de los flujos migratorios es muy heterogéneo entre los países de la muestra. En Ecuador, un porcentaje mayor al 70\% de los migrantes se radica en países de la Unión Europea (en su mayoría España) y en segundo lugar en Estados Unidos. Tanto El Salvador como Honduras muestran una gran concentración de migrantes en Estados Unidos y Canadá, mientras que la migración hacia países de Latinoamérica y El Caribe ocupa el segundo lugar. En Nicaragua el patrón difiere del resto de los países, ya que aproximadamente un $60 \%$ de los migrantes se concentran en países de Latinoamérica y El Caribe, principalmente en Costa Rica. En segundo lugar, un porcentaje cercano al $40 \%$ de los migrantes nicaragüenses reportados en la EMNV se radican en Estados Unidos o Canadá. La importancia de los envíos de dinero dentro del ingreso familiar es mayor en El Salvador y menor en Nicaragua y en términos absolutos son mayores en Honduras que en el resto de los países. Un importante reflejo de la historia de migración de cada país es el porcentaje de migrantes que envían remesas en cada país, donde Nicaragua registra el menor porcentaje. Funkhouser (1995) estudia esta diferencia en el comportamiento de los migrantes de El Salvador y Nicaragua. Las posibles hipótesis que este autor evalúa tienen que ver con diferencias en las concepciones políticas de los migrantes, diferencias temporales en la migración, y finalmente, una de las hipótesis que recibe mayor apoyo empírico es la de autoselección entre los migrantes que envían remesas.

\section{Migración y remesas como estrategia del hogar}

El enfoque descriptivo de la sección anterior que vincula la pobreza y la desigualdad con las remesas ha sido ampliamente criticado en la literatura dado que supone implícitamente que las remesas son un flujo de ingreso exógeno e independiente de otras fuentes de ingresos y variables de comportamiento. Stark (1988) menciona el primer problema de identificación

${ }_{13}$ Debe tenerse en cuenta que en Ecuador sólo se registran los migrantes que dejaron el país en los 5 años anteriores a la encuesta. 
de los efectos de las remesas y tiene que ver con la omisión del ingreso que el migrante podría obtener dentro de la economía local. Si se tiene en cuenta la evidencia presentada en la sección anterior sobre el perfil de los migrantes, puede notarse que la inclusión de este tipo de efectos puede ser muy importante para muchos países debido a que una gran masa de migrantes pertenecen a rangos de edad y género que tienen altas tasas de participación laboral.

A partir de Adams (1989) se inicia una serie de trabajos que intentan comparar la distribución observada del ingreso con un escenario contrafáctico de "no migración". Las conclusiones de la metodología propuesta por Adams (1989) dependían estrictamente del supuesto de que los migrantes (o los hogares con migrantes) fueran aleatoriamente escogidos dentro de la población total. Sin embargo, una importante cantidad de trabajos (Borjas (1987), Chiquiar y Hanson (2005), McKenzie et al (2006)) documentan el proceso de migración como una decisión que depende de varios factores observables y no observables, invalidando potencialmente el supuesto de que la migración es un proceso aleatorio. Trabajos posteriores como el de Adams (2006) o Acosta et al (2008)), incluyeron el problema de selección dentro de este marco analítico.

Diversas hipótesis se han construido desde la teoría acerca del proceso de migración y remesas en relación a los motivos y características de los migrantes, lo que finalmente determina el cambio en el ingreso per cápita del hogar. Las principales propuestas han surgido desde la llamada "New Economics of Labor Migration" (NELM) que se inicia a partir de trabajos seminales como los de Stark y Levhari (1982), Stark y Bloom (1985), Stark, Taylor y Yithzaki (1986), Stark, Taylor y Yithzaki (1988) y Taylor (1992), entre otros. La NELM postula que la migración no es el resultado de estrategias individuales aisladas sino que se trata de una decisión óptima del hogar. En este sentido, la NELM constituye una crítica muy importante a los modelos tradicionales ya que sostiene que los diferenciales de ingresos laborales esperados entre dos regiones diferentes no son factores determinantes en proceso el migratorio. En el contexto de la NELM, la falta de arreglos institucionales adecuados, como el escaso desarrollo de los mercados de capitales (Lucas (1987)) son el principal argumento detrás de la migración. Dado que en estas condiciones los individuos no pueden diversificar los riesgos relacionados con su dotación de factores productivos o bien no pueden desarrollar algunas actividades que requieren cierta líquidez, algunos arreglos intrahogar pueden constituirse en una forma más eficiente de alcanzar ese objetivo. Asignar la oferta laboral entre mercados laborales domésticos y externos, que posean una 
baja correlación entre sí, puede ser una forma de diversificación de riesgos para este tipo de hogares. La menor informalidad en el mercado laboral externo también ofrece al hogar una fuente de liquidez permanente que se traduce en el envío contínuo de remesas, o bien, en el financiamiento temporal de algunas actividades productivas por parte del migrante .

Además del potencial relajamiento en las restricciones al crédito y la liquidez (Calero et al (2009), Yúnez-Naude (2001), Taylor, Edward y Wyatt (1996)), la literatura describe otros mecanismos importantes que afectan el ingreso de los hogares con remesas o migrantes a través del comportamiento del resto de los integrantes del hogar. Los miembros de hogares con remesas pueden modificar su oferta laboral ya sea reduciendo las horas trabajadas o cambiando las decisiones de participación (Hanson, (2007)).

Por otra parte, los cambios en la estructura del hogar producto de la migración pueden ser lo suficientemente importantes como para producir efectos sobre otras variables independientemente del envío de remesas. McKenzie (2006) encuentra evidencia de algunos efectos de la migración sobre variables de salud y educación que exceden a los relacionados con el envío de remesas, sin embargo, por falta de información no puede determinar empíricamente esta diferencia, argumentando que es necesario para tal fin contar con variables que expliquen por qué algunos migrantes envían dinero y otros no, es decir, considerar que pueden existir diferentes arreglos intra-hogar relacionados con la migración. Como describen Solimano (2006) y Amuedo-Dorantes (2006), existen diversas razones para remitir asociadas a diferentes arreglos entre el migrante y su familia. En primer lugar, pueden existir únicamente motivos altruistas y se espera en estos casos que las remesas decrezcan con el tiempo. En forma opuesta, el propio interés del migrante puede ser el único motivo para remitir. En este caso las remesas se envían principalmente para que la familia del migrante las invierta en su nombre a cambio de ciertos beneficios, y al mismo tiempo, el migrante recibe una tasa de retorno al capital mayor al del país donde reside. En tercer lugar, algunos autores consideran que existe un contrato de deuda implícito entre el migrante y su familia (Cox (1987)). El migrante financia generalmente los costos de migración y su inversión en capital humano con dinero del resto de los miembros del hogar y muchas veces también se financia la primera etapa en el país de destino. Bajo este esquema, las remesas constituyen el repago de esta deuda acumulada por el migrante. Por último, autores como Lucas y Stark (1985) consideran que el contrato implícito entre el migrante y su familia es similar a un seguro mutuo, donde las remesas aportan liquidez al hogar en caso de caídas temporales de otras fuentes de ingreso y a cambio el migrante 
cuenta con la posibilidad de volver al hogar de origen si no logra prosperar en el país de residencia. Notar que bajo este tipo de esquema, la migración puede tener efectos sin la necesidad de que los flujos monetarios se concreten ya que el hogar puede reducir sus riesgos no diversificables y cambiar su comportamiento.

Las formas en que las restricciones a la liquidez o crediticias pueden afectar el ingreso de los hogares son muy diversas, abarcando incluso importantes efectos intertemporales. En términos más sencillos puede utilizarse la hipótesis de autores como Taylor, et al. (1996) y Yúnez-Naude (2001) quienes consideran una economía con dos sectores de diferente productividad. El hogar puede distribuir su dotación de trabajo dentro del país en cualquiera de los sectores. Sin embargo, el sector más productivo requiere ciertos costos fijos o capital de trabajo que el hogar debe financiar. Las remesas y la migración como estrategia del hogar pueden afectar estas restricciones permitiendo que el resto de los integrantes del hogar se especialicen en la actividad más productiva ${ }^{14}$.

Otro factor que debe tenerse en cuenta el posible efecto sobre otras fuentes de ingreso a través de la acumulación de capital y ahorro. Finalmente, el número de miembros del hogar luego de migración no sólo responde a una reducción aritmética, dado que las decisiones de fertilidad pueden verse afectadas por factores como la ausencia misma del jefe del hogar. Debe tenerse en cuenta que la mayoría de las medidas de pobreza y desigualdad se calculan en base a definiciones de ingreso donde interviene el número de miembros del hogar.

\section{Simulación de los escenarios sin remesas y sin migrantes}

El procedimiento natural para determinar el efecto de las remesas sobre la pobreza y la desigualdad resulta de comparar el ingreso observado con un escenario hipotético, donde todos los individuos permanecen dentro del país y ningún hogar recibió remesas ${ }^{15}$. Las diferencias entre ambos ingresos constituyen el efecto total de la migración y las remesas.

El análisis del proceso de remesas y migración utilizando encuestas cross-section plantea una serie de desafíos que deben tenerse en cuenta. En primer lugar, existe evidencia

${ }^{14}$ Las remesas suelen asociarse a menores restricciones crediticias, mientras que la migración puede tener efectos negativos dado que el capital humano dentro del hogar se reduce. Un ejemplo típico de este último caso es cuando migra el miembro más calificado dentro del hogar.

${ }_{15}$ Notar que este escenario es diferente al que surgiría de una reducción o eliminación del flujo de remesas partiendo de la situación observada. Si bien ambos casos se basan en situaciones contrafácticas, el punto de partida es completamente diferente. Los hogares que mediante las remesas han logrado reducir sus restricciones de liquidez y crediticias por un tiempo prolongado o diversificado mejor sus riesgos, podrían enfrentar con cierta holgura una reducción temporal o permanente en el flujo de ingresos proveniente de las remesas y este nivel de ingresos puede ser completamente distinto al que el hogar hubiese obtenido en ausencia de migración y remesas. 
suficiente para no rechazar la hipótesis de selección en el proceso de migración y remesas, ya que ex ante puede esperarse que los hogares con migrantes o con remesas tengan características tanto observables como no observables diferentes a las del resto. En segundo lugar, pocos países instrumentan cuestionarios detallados sobre los migrantes que abandonan el hogar. Adicionalmente, en la sección anterior se mencionó que no todos los hogares con migrantes reciben remesas y no todos los hogares con remesas tienen un ex miembro del núcleo familiar fuera del país. Excluir del análisis algún set de estos hogares o tratarlos dentro del grupo de hogares no afectados por el proceso de migración-remesas, como es usual en la mayoría de los trabajos existentes, puede generar un potencial sesgo. Como se mencionó anteriormente, no es necesario que el flujo de remesas se materialice para tener efectos de liquidez y de riesgo, si por ejemplo los migrantes fuera del país funcionan como un seguro frente a caídas temporales de ingreso (Massey et al. (2008), Yang y Choi (2007), Amuedo-Dorantes y pozo (2002), Rosenzweig (1988)). La metodología utilizada en este trabajo intenta incluir a todos los tipos de hogar dentro del análisis, permitiendo la existencia de diferentes arreglos intra-hogar.

De acuerdo a las hipótesis planteadas por la NELM, los canales a través de los cuales las remesas afectan el bienestar de los hogares no deberían asociarse al ingreso del migrante o al tamaño del hogar sino a factores menos visibles como las restricciones crediticias, diversificación de riesgos, mejoras en la productividad y cambios en las variables de comportamiento. Sin embargo, si las hipótesis de la NELM no se cumplen deberíamos observar que las remesas aportan al hogar un flujo de ingresos muy superior al que el migrante pudiese haber obtenido dentro de la economía ${ }^{16}$. En esta sección describimos la metodología utilizada para simular diferentes escenarios contrafácticos que guardan cierta relación con ambas hipótesis.

Los objetivos de la metodología presentada en esta sección consisten en primer lugar en simular el efecto total de las remesas y la migración sobre la pobreza y la desigualdad de acuerdo a las características de cada país y en segundo lugar, distinguir cuando sea posible si los efectos más importantes corresponden a la sustitución de ingresos laborales en el mercado doméstico por remesas o bien a otros factores indirectos como los discutidos en la sección anterior.

${ }^{16}$ Descontando además el cambio en la estructura del hogar por la ausencia del migrante. 


\subsection{Simulación I: Ingreso laboral del migrante dentro del país. Efectos directos}

La primera simulación que se implementa tiene por finalidad medir la sustitución del ingreso laboral del migrante por el ingreso de remesas. En términos más sencillos, el objetivo es simular la presencia del migrante dentro del país, imputando el ingreso que el mismo hubiera obtenido en caso de no migrar. Este escenario agrega un factor adicional que es el cambio en el tamaño de los hogares cuando se incluye a los migrantes. La importancia de este último cambio no es menor si se tiene en cuenta que tanto la pobreza como la desigualdad se calculan a partir de ingresos ajustados por el tamaño del hogar. En forma ciertamente arbitraria pero conveniente podemos agrupar estos dos mecanismos dentro de lo que llamamos "efectos directos" del proceso de migración-remesas. Los efectos directos excluyen todos aquellos cambios producidos por el comportamiento de otros miembros del hogar al igual que aquellos cambios en las variables de productividad, riesgo y liquidez del hogar.

Los modelos clásicos de migración, como el propuesto por Roy (1951) y ampliamente discutido en Tunali (2000), señalan que la decisión acerca del status migratorio depende del ingreso que los individuos anticipan dentro y fuera de la economía. De esta forma, existe un mecanismo de selección por el cual sólo observamos ingresos que ex - ante fueron anticipados como superiores. En este caso, sólo observamos el ingreso laboral de los individuos ocupados que no migraron. Es conveniente por lo tanto utilizar un modelo en dos etapas tipo Heckman para corregir el sesgo por selección. Siendo $m_{i}$ la decisión de migración observada y $w_{i}$ el logaritmo del ingreso laboral observado para los individuos que residen dentro del país, la especificación que se utiliza en este caso es la siguiente:

$$
\begin{aligned}
& m_{i}^{*}=\alpha_{1}^{\prime} X_{1 i}+u_{1 i} \quad \text { [desición de migración] } \quad w_{i}=w_{i}^{*} \text { si } m_{i}^{*}>0 \\
& w_{i}^{*}=\alpha_{2}^{\prime} X_{2 i}+u_{2 i} \quad \text { [ingresos laborales] } \quad, \quad m_{i}=1 \text { si } m_{i}^{*}>0 \\
& m_{i}=0 \quad \text { si } m_{i}^{*} \leq 0
\end{aligned}
$$

Donde $\left(u_{1}, u_{2}\right)$ tienen una distribución normal bivariada con correlación $\rho$, siguiendo el modelo propuesto por Heckman (1979). $X_{1}$ es un set de variables con características del migrante como la educación, edad, sexo, entre otras. $X_{2}$ incluye, además de características del migrante, un set de características del hogar. 
Una vez realizada la imputación de $w_{i}^{*}$ para los migrantes, se puede reconstruir el ingreso familiar en este escenario, manteniendo el ingreso laboral del resto de los integrantes del hogar y otros ingresos no laborales en sus niveles observados. Las remesas son eliminadas del ingreso familiar en esta especificación.

La imputación de inobservables de los ingresos imputados se realiza a partir de la generación de diferentes muestras aleatorias de errores $\left(\hat{u}_{1 i}, \hat{u}_{2 i}\right)$ con distribución normal bivariada. Como se explica posteriormente, las distribuciones de errores $\hat{u}_{2 i}$ imputadas a la ecuación de Mincer son incidentalmente truncadas, con media potencialmente distinta de cero, dado que los errores $\hat{u}_{1 i}$ deben replicar la decisión de migración para cada individuo. Este procedimiento es similar al utilizado por Gasparini, Marchionni y Sosa Escudero (2000) para imputar errores en un modelo de selección con decisiones de oferta laboral.

Es importante resaltar que el ingreso del resto de las fuentes de ingreso del hogar que no intervienen en la simulación permanecen en sus niveles observados ${ }^{17}$ (y por lo tanto otras variables como la oferta laboral de los no migrantes o las restricciones de liquidez también se mantienen constantes) lo que introduce un sesgo dentro del ingreso familiar simulado que es corregido en las siguientes simulaciones.

Notar que para los hogares que reciben remesas pero declaran no tener migrantes el ingreso simulado coincide con el ingreso neto de remesas. Los hogares con migrantes que no reciben remesas tendrán un ingreso per cápita observado menor que el simulado si la pérdida del ingreso laboral del migrante no es compensada por la disminución en el tamaño del hogar.

\subsection{Simulación II - III: Efectos de las remesas sobre el ingreso familiar total}

El ingreso neto de remesas es una mala medida del ingreso que el hogar hubiese obtenido en un escenario sin migración ni remesas. Dejando de lado algunos efectos de equilibrio general, la única referencia con la que se cuenta para construir el ingreso sin remesas "contrafáctico" es la de los hogares que no tienen migrantes y no reciben remesas. La clave está en que para estos hogares el ingreso neto de remesas coincide exactamente con el del escenario que se intenta simular. De esta forma, el ejercicio consiste en censurar

\footnotetext{
17 Un escenario alternativo que puede plantearse es el que tiene en cuenta no solamente la decisión de migrar sino la de participación laboral tanto del migrante como las del resto de los integrantes del hogar. Barham y Boucher (1998) proponen imputar adicionalmente el status laboral, permitiendo que las decisiones de participación también cambien para los individuos pertenecientes a hogares con migrantes. De esta forma se incluye un efecto más dentro del escenario y que corresponde a los cambios en la oferta laboral del resto de los integrantes del hogar
} 
artificialmente la variable de ingreso familiar para aquellos hogares con remesas y predecir su ingreso contrafáctico en base a la muestra no seleccionada. Sin embargo, la estimación por OLS sería inconsistente si los migrantes no son aleatoriamente elegidos entre la población (McKenzie, Gibson y Stillman (2006), Lanzona, L. (1998), Chiswick, B. (2000)).

La literatura sobre determinantes de las migraciones internacionales es lo suficientemente concluyente como para rechazar a priori la hipótesis de no selectividad muestral ${ }^{18}$. Adams (2006) al igual que Acosta, et al (2008) proponen incluir en el modelo una ecuación que determina la "propensión a recibir remesas" como variable latente que es utilizada como regla de selección. De esta forma, es posible predecir consistentemente el ingreso familiar sin remesas de los hogares que reciben remesas utilizando un procedimiento en dos etapas como el propuesto por Heckman (1979). La principal ventaja de este escenario contrafáctico es que permite identificar el efecto total de las remesas sobre el ingreso familiar sin la necesidad de modelar explícitamente cambios de comportamiento, ni restricciones de liquidez o diversificación de riesgos, especialmente si las variables utilizadas como predictores son invariantes a lo largo de todo el proceso de migración (ej: educación de los adultos del hogar). Debe tenerse en cuenta que algunas variables utilizadas en la primera etapa, deben corregirse para eliminar la posible endogeneidad producida por las remesas como variable omitida ${ }^{19}$.

La metodología presentada en esta sección introduce una serie de diferencias respecto de la metodología original. En primer lugar, la regla de selección propuesta por Acosta, et al. (2008) distingue solamente si un hogar recibe o no recibe remesas ${ }^{20}$. En este sentido, se explota aquí la ventaja de contar con cierta información sobre la migración de los miembros del hogar, incluyendo dos reglas de selección muestral diferentes, una que determina si un hogar recibe o no recibe remesas y otra que determina si un hogar posee o no migrantes. Notar que a diferencia de lo planteado en Acosta, et al. (2008) la muestra también es censurada ${ }^{21}$ para aquellos hogares que tienen migrantes pero no reciben remesas. La intuición detrás de este ejercicio es que tanto las remesas como la migración pueden tener efectos sobre el ingreso no familiar aunque no se den en forma conjunta y por lo tanto el ingreso familiar sin remesas debe ser imputado en cualquiera de estos dos

\footnotetext{
18 Para una síntesis reciente sobre teorías de migración ver Massey et al. (2008)

${ }^{19} \mathrm{El}$ caso más habitual es la corrección del tamaño del hogar incluyendo al migrante, o en el caso en que se cuenta con la información, las características del jefe de hogar se corrigen con las del migrante cuando este era el jefe de hogar al momento de migrar.

20 Adams (2006) utiliza un modelo logit multinomial para distinguir entre remesas internas y externas, pero en este caso no existe ningún ordenamiento entre las opciones disponibles.

${ }^{21}$ El término más correcto para este mecanismo es el de "truncamiento incidental".
} 
casos. Como ya se mencionó, no censurar a los hogares con migrantes pero sin remesas plantea un potencial sesgo de selección. Esta característica de la simulación marca una diferencia muy importante respecto de trabajos anteriores que ignoran los efectos que la migración o las remesas pueden tener sobre el ingreso del hogar aun cuando se produzcan en forma separada.

\section{Especificación del modelo de doble selección para la imputación de ingresos familiares}

El modelo con dos ecuaciones de selección que utilizamos surge de la especificación de Tunali (1985) y Barham y Boucher (1998) quienes extienden el modelo original de Heckman (1979), aunque es necesario adaptarlo a la forma particular de selección de los datos $^{22}$. Siguiendo la idea planteada por Acosta, et.al. (2008) utilizamos el ingreso familiar sin remesas como variable de interés para construir el primer escenario contrafáctico. Definimos dos variables latentes: $M^{*}$ que refleja los beneficios netos de la migración o la propensión del hogar a tener migrantes y $R^{*}$ que puede asociarse al tipo de arreglo intrahogar en relación al envío de remesas. Las ecuaciones del modelo vienen dadas por:

$$
\begin{array}{ll}
M_{h}^{*}=\beta_{1}^{\prime} X_{1 h}+U_{1 h} & \text { [regla de selección migración] } \\
R_{h}^{*}=\beta_{1}^{\prime} X_{2 h}+U_{2 h} & \text { [regla de selección recepción de remesas] } \\
y_{\mathrm{h}}=\beta_{3}^{\prime} X_{3 h}+\sigma U_{3 h} & \text { [determinación del ingreso familiar sin remesas] }
\end{array}
$$

Donde $\sigma$ es un parámetro de escala. Se supone que los términos de error de las tres ecuaciones siguen una distribución normal trivariada:

$$
\left(U_{1 h}, U_{2 h}, U_{3 h}\right) \sim N(0, \Sigma) \quad \operatorname{con} \Sigma=\left[\begin{array}{ccc}
1 & \rho_{12} & \rho_{13} \\
\rho_{12} & 1 & \rho_{23} \\
\rho_{13} & \rho_{23} & 1
\end{array}\right]
$$

Se asume además que los errores son independientes de $X_{1}, X_{2}, X_{3}$ y entre observaciones ${ }^{23}$. Si bien $M^{*}$ y $R^{*}$ no pueden observarse directamente, puede identificarse su signo a partir de las variables binarias $M=1\left[M^{*}>0\right]$ y $R=1\left[R^{*}>0\right]$ que son iguales a cero cuando el hogar tiene migrantes o remesas respectivamente ${ }^{24}$. A diferencia del modelo estimado por

\footnotetext{
22 Barham y Boucher (1998) utilizan una ecuación de selección para la decisión de migrar y otra para la decisión de participación laboral, pero no pueden observar la participación laboral de los migrantes.

${ }^{23}$ Es posible utilizar supuestos menos restrictivos pero por razones de simplicidad se mantienen los supuestos enunciados por Barham y Boucher (1998)

${ }_{24}$ Aunque puede resultar poco intuitivo asignar 1 a la condición de "no migración" o "no remesas", es conveniente para simplificar la notación.
} 
Barham y Boucher (1998), en este caso pueden presentarse cuatro resultados posibles $(M=1, R=1),(M=1, R=0),(M=0, R=1),(M=0, R=0) . S i$ bien, el desarrollo que sigue a continuación podría simplificarse si las dos reglas de selección se asumieran independientes, no resulta razonable realizar este supuesto dado la fuerte vinculación entre la migración y las remesas.

El ingreso contrafáctico coincide con el ingreso familiar neto de remesas solamente para el subset de hogares sin remesas y sin migrantes y la variable dependiente de la última ecuación del modelo solamente se observa para el caso en que $M=1, \mathrm{R}=1$. Dada la estructura informativa del modelo la media condicional involucrada en la regresión es:

$$
E\left(y_{\mathrm{h}} \mid X_{3 h}, M, R\right)=\beta_{3}^{\prime} X_{3 h}+\sigma E\left(U_{3 h} \mid X_{3 h}, M, R\right)
$$

Para la submuestra truncada incidentalmente $(M=R=1)$ tenemos que la esperanza condicional viene dada por

$$
E\left(y_{h} \mid X_{3 h}, M=1, R=1\right)=\beta^{\prime}{ }_{3} X_{3 h}+\sigma E\left(U_{3 h} \mid U_{1 h}>-\beta^{\prime}{ }_{1} X_{1 h}, U_{2 h}>-\beta_{2}^{\prime} X_{2 h}\right)
$$

Tunali (1985), demuestra que bajo la especificación normal trivariada de los errores, el truncamiento incidental de U3 a partir de U1 y U2 modifica la media condicional de la siguiente forma:

$$
E\left(U_{3} \mid U_{1}>-\beta^{\prime}{ }_{1} X_{1}, U_{2}>-\beta^{\prime}{ }_{2} X_{2}\right)=\rho_{13} \lambda_{1}+\rho_{23} \lambda_{2}
$$

siendo $\lambda_{1}, \lambda_{2}$ análogos a la inversa de la razón de Mill del modelo clásico de Heckman y $\Phi_{b i v}$ la distribución normal bivariada estándar ${ }^{25}$.

$$
\lambda_{1}=\frac{\phi\left(\beta_{1}^{\prime} X_{1}\right) \Phi\left(\frac{\beta_{2}^{\prime} X_{2}-\rho_{12} \beta_{1}^{\prime} X_{1}}{\sqrt{1-\rho_{12}^{2}}}\right)}{\Phi_{b i v}\left(\beta_{1}^{\prime} X_{1}, \beta_{2}^{\prime} X_{2}, \rho_{12}\right)}
$$

25 Un derivación completa de los resultados del modelo de doble selección para diferentes combinaciones en la forma en que la muestra es incidentalmente truncada, puede encontrarse en de Hevia y Arrazola (2009) 


$$
\lambda_{2}=\frac{\phi\left(\beta_{2}^{\prime} X_{2}\right) \Phi\left(\frac{\beta_{1}^{\prime} X_{1}-\rho_{12} \beta_{2}^{\prime} X_{2}}{\sqrt{1-\rho_{12}^{2}}}\right)}{\Phi_{b i v}\left(\beta_{1}^{\prime} X_{1}, \beta_{2}^{\prime} X_{2}, \rho_{12}\right)}
$$

De esta forma, tenemos que:

$$
E\left(y \mid X_{3}, U_{1}>-\beta_{1}^{\prime} X_{1}, U_{2}>-\beta_{2}^{\prime} X_{2}\right)=\beta_{3}^{\prime} X_{3}+\theta_{1} \lambda_{1}+\theta_{2} \lambda_{2}, \text { con } \theta_{1}=\sigma \rho_{13} ; \theta_{2}=\sigma \rho_{23}
$$

Finalmente, la ecuación a estimar adopta la forma:

$$
y_{h} \mid X_{3}, U_{1 h}>-\beta^{\prime}{ }_{1} X_{1 h}, U_{2 h}>-\beta_{2}^{\prime} X_{2 h}=\beta_{3}^{\prime} X_{3 h}+\theta_{1} \lambda_{1 h}+\theta_{2} \lambda_{2 h}+\sigma v_{h}
$$

$\operatorname{con} E\left(v_{h} \mid X, M=1, R=1\right)=0$

Notar que la estimación de la ecuación anterior por OLS produce estimaciones inconsistentes por la omisión de $\lambda_{1}, \lambda_{2}$, resultado análogo al obtenido por Heckman (1979) para el caso de una ecuación de selección.

La estimación de los parámetros de interés puede realizarse en dos etapas en forma consistente. En una primera etapa, los parámetros de las dos ecuaciones de selección pueden ser estimadas teniendo en cuenta la siguiente función de verosimilitud que se construye a partir de las probabilidades asociadas a cada uno de los casos posibles en la muestra:

$$
\begin{aligned}
L= & \prod_{\substack{M=0 \\
R=0}} \Phi_{b i v}\left(-\beta_{1}^{\prime} X_{1},-\beta_{2}^{\prime} X_{2}, \rho_{12}\right) \times \prod_{\substack{M=0 \\
R=1}} \Phi_{b i v}\left(-\beta^{\prime}{ }_{1} X_{1}, \beta_{2}^{\prime} X_{2},-\rho_{12}\right) \\
& \times \prod_{\substack{M=1 \\
R=0}} \Phi_{b i v}\left(\beta_{1}^{\prime} X_{1},-\beta_{2}^{\prime}{ }_{2} X_{2},-\rho_{12}\right) \times \prod_{\substack{M=1 \\
R=1}} \Phi_{b i v}\left(\beta_{1}^{\prime} X_{1}, \beta_{2}^{\prime} X_{2}, \rho_{12}\right)
\end{aligned}
$$

Siendo $\Phi_{2}$ la función de distribución acumulada normal estándar bivariada. La función de verosimilitud anterior corresponde a la de un modelo probit bivariado ${ }^{26}$ para la decisión de migración y envío de remesas que puede estimarse toda la muestra de hogares. La estructura de los errores que determina que $\hat{\beta}_{1}$ y $\hat{\beta}_{2}$ puedan estimarse mediante un modelo

\footnotetext{
${ }^{26}$ Dado que $X_{1}$ y $X_{2}$ no coinciden necesariamente, el modelo corresponde al conocido en la literatura como "seemingly unrelated bivariate probit".
} 
probit bivariado resulta conveniente, dado que se contempla la posibilidad de correlación entre los errores de las dos ecuaciones de selección, situación esperable si se tiene en cuenta que el proceso de migración y recepción de remesas está altamente relacionado. Si los dos procesos no están correlacionados, es posible estimar ambas ecuaciones por separado a partir de dos modelos probit independientes aunque los resultados continúan siendo válidos. Un test de razón de verosimilitud permite testear la hipótesis nula de que $\rho_{12}=0$. A partir de los coeficientes $\hat{\beta}_{1}, \hat{\beta}_{2}, \hat{\rho}_{12}$ estimados en esta etapa por máxima verosimilitud pueden construirse $\hat{\lambda}_{1}$ y $\hat{\lambda}_{2}$.

En una segunda etapa, es posible estimar consistentemente [7] regresando por OLS el ingreso familiar sin remesas en los regresores $X_{3}, \hat{\lambda}_{1}, \hat{\lambda}_{2}$ utilizando la muestra truncada incidentalmente $(M=R=1)$. Finalmente, se puede imputar el ingreso contrafáctico sin remesas mediante la predicción lineal para los hogares con migrantes o remesas.

Los hogares sin remesas y sin migrantes mantienen en todos los escenarios el ingreso observado y no se realiza ningún tipo de imputación sobre los mismos.

\section{Imputación de factores no-observables}

Si los factores no observables no se tienen en cuenta, se reduciría artificialmente la varianza del ingreso en el escenario contrafáctico con lo cual las medidas de desigualdad se verían afectadas. Por esta razón se le imputan errores a los ingresos contrafácticos utilizando una muestra aleatoria construida a partir de la estructura supuesta para los errores dentro del modelo. Es importante tener en cuenta que si bien los errores de las tres ecuaciones siguen una distribución normal trivariada, los mecanismos de selección truncan la distribución de los errores para cada submuestra. Aquí, los errores son obtenidos para cada tipo de hogar de acuerdo a una muestra aleatoria de la distribución truncada de cada tipo de hogar.

Si $\hat{\Phi}_{3}(U, \hat{\Sigma})$ es la distribución normal trivariada estimada para los errores, las distribuciones truncadas (incidentalmente) relevantes, es decir para los hogares que se les imputa ingreso son:

$$
\varphi(U, \hat{\Sigma} \mid M=0, R=0)=\frac{\hat{\Phi}_{3}(U, \hat{\Sigma})}{\Phi_{b i v}\left(-\beta_{1}^{\prime} X_{1},-\beta_{2}^{\prime} X_{2}, \hat{\rho}_{12}\right)}
$$




$$
\begin{gathered}
\varphi(U, \hat{\Sigma} \mid M=1, R=0)=\frac{\hat{\Phi}_{3}(U, \hat{\Sigma})}{\Phi_{b i v}\left(\beta^{\prime}{ }_{1} X_{1},-\beta^{\prime}{ }_{2} X_{2}, \hat{\rho}_{12}\right)} \\
\varphi(U, \hat{\Sigma} \mid M=0, R=1)=\frac{\hat{\Phi}_{3}(U, \hat{\Sigma})}{\Phi_{b i v}\left(-\beta^{\prime}{ }_{1} X_{1}, \beta^{\prime}{ }_{2} X_{2}, \hat{\rho}_{12}\right)}
\end{gathered}
$$

La estimación del modelo permite obtener en la primer etapa un estimador consistente de $\rho_{12}$ y en la segunda etapa ${ }^{27}$ se pueden obtener las estimaciones del resto de los parámetros de la matriz de correlación $\Sigma$ al igual que el parámetro $\sigma$.

El estimador de $\sigma$ se puede derivar a partir de la muestra seleccionada teniendo en cuenta las siguientes relaciones:

$$
\begin{aligned}
& \operatorname{var}\left(v_{h} \mid X_{3}, U_{1 h}>-\beta_{1}^{\prime} X_{1 h}, U_{2 h}>-\beta^{\prime}{ }_{2} X_{2 h}\right)=\sigma-\zeta_{h} \\
& \zeta_{h}=\theta_{1}^{2}\left[\left(\beta^{\prime}{ }_{1} X_{1 h}\right) \lambda_{1 h}+\lambda_{2 h}+\rho_{12} \lambda_{3 h}\right]+\theta_{2}^{2}\left[\left(\beta^{\prime}{ }_{2} X_{2 h}\right) \lambda_{2 h}+\lambda_{1 h}+\rho_{12} \lambda_{3 h}\right]-2 \theta_{1}^{2} \theta_{2}^{2}\left(\lambda_{3 h}-\lambda_{1 h} \lambda_{2 h}\right) \\
& \lambda_{3 h}=\frac{\phi\left(\beta_{1}^{\prime} X_{1 h}, \beta^{\prime}{ }_{2} X_{2 h}, \rho_{12}\right)}{\Phi_{b i v}\left(\beta_{1}^{\prime} X_{1 h}, \beta^{\prime}{ }_{2} X_{2 h}, \rho_{12}\right)}
\end{aligned}
$$

El estimador de $\operatorname{var}\left(v_{h} \mid X_{3}, U_{1 h}>-\beta^{\prime}{ }_{1} X_{1 h}, U_{2 h}>-\beta^{\prime}{ }_{2} X_{2 h}\right)$ se obtiene como la varianza muestral de los errores estimados en la segunda etapa para la muestra seleccionada, $\zeta_{h}$ se reemplaza por su media muestral y en forma residual se obtiene el estimador de $\sigma$.

Para cada hogar de la muestra censurada se genera una muestra aleatoria a partir de las distribuciones truncadas correspondientes a cada tipo de hogar ${ }^{28}$. Las distribuciones truncadas surgen de restringir para cada hogar aquellas realizaciones de los errores $\left(\mathrm{U}_{1}, \mathrm{U}_{2}\right.$, $\mathrm{U}_{3}$ ) de tal forma que $\mathrm{U}_{1}$ y $\mathrm{U}_{2}$ sean consistentes con las decisiones de migración y remesas observadas. Este procedimiento genera una distribución truncada de $\mathrm{U}_{3}$ que potencialmente tiene media distinta de cero. El procedimiento de imputación de errores se repite 200 veces para construir intervalos de confianza de las estimaciones de los indicadores de pobreza y

27 Es importante destacar que la estructura de errores es heterocedástica y la estimación de los errores estándar es inconsistente. Tunali (1986) propone una expresión que corrige la matriz de covarianzas (asintótica).

${ }_{28}$ Notar que cada hogar tiene un punto de truncamiento diferente porque depende de $\beta_{1}^{\prime} X_{1}$ y de $\beta_{2}^{\prime} X_{2}$. Por esta razón, cada paso del procedimiento consiste en generar para cada hogar una muestra truncada de errores y asignar aleatoriamente una de las realizaciones. 
desigualdad. El supuesto detrás del ejercicio de imputación, es que la distribución de los inobservables mantiene las mismas características aun cuando cambie el status de migración y remesas, es decir, que en el escenario contrafáctico la distribución de los errores es similar a la que supone el modelo originalmente. En otras palabras, cada realización de los errores que se asigna a un hogar determinado es un vector de tres componentes $\left(\hat{U}_{1 h}, \hat{U}_{2 h}, \hat{U}_{3 h}\right)$ donde los dos primeros elementos cumplen con la restricción de replicar la el signo de la variable latente que determina si un hogar tiene migrantes o tiene remesas. Si por ejemplo un hogar es censurado dentro de la muestra por tener migrantes, entonces cualquiera de las 200 realizaciones del error que se simulan cumple con la restricción de que $\hat{\beta}^{\prime}{ }_{1} X_{1 h}+\hat{U}_{1 h}<0$ El resultado de este ejercicio de truncamiento incidental determina el signo de la media de $\hat{U}_{3 h}$ que forma parte del ingreso imputado a los hogares censurados.

Para medir este último efecto determinado por la selección en los inobservables, se simula también un escenario donde la imputación de errores es independiente del status observado de migración y remesas ${ }^{29}$, los cambios en la pobreza y la desigualdad que se deducen de esa especificación pueden explicarse principalmente por diferencias en las características observables que intervienen en la ecuación de ingresos y al compararlos con el escenario con errores incidentalmente truncados se obtiene una medida del efecto de la selección en los inobservables.

\subsection{Escenarios simulados}

En la Tabla 4 se resumen los escenarios simulados al igual que los modelos y correcciones que suponen cada uno de ellos. La primera simulación corresponde al escenario donde sólo se imputan los ingresos que el migrante hubiese obtenido dentro de la economía, actualizando también el tamaño del hogar a partir del número de migrantes.

La segunda y tercera simulación corrigen los ingresos familiares totales para los hogares con remesas o con migrantes utilizando el modelo de selectividad doble. La diferencia entre ambas simulaciones es que en el primer caso los inobservables se imputan independientemente del status de migración y remesas observado mientras que en la última simulación los errores imputados tienen en cuenta la selección en los inobservables.

\footnotetext{
${ }^{29}$ Este ejercicio se puede realizar generando distintas realizaciones de una distribución de errores normales trivariados con medias cero y matriz de covarianza de los errores $\hat{\Sigma}$. Notar que esta distribución tiene las mismas propiedades que la distribución que genera los errores del modelo en 0
} 
Tabla 4

Ingresos observados y simulaciones realizadas

\begin{tabular}{|c|c|c|c|c|}
\hline \multicolumn{2}{|r|}{ Escenario } & Corrección de ingresos & Modelo utilizado & Estructura del hogar \\
\hline \multirow{2}{*}{ 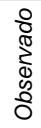 } & Ingreso observado & Observado & Observado & Observada \\
\hline & Ingreso neto de remesas & Diferencia aritmética & Diferencia aritmética & Observada \\
\hline \multirow{3}{*}{$\frac{\frac{8}{8}}{\frac{\pi}{\lessgtr}}$} & Simulación 1 & $\begin{array}{l}\text { Ingreso familiar neto de remesas con } \\
\text { imputación del ingreso laboral del migrante }\end{array}$ & Modelo de selección (Heckman) & $\begin{array}{l}\text { Corrección con número } \\
\text { de migrantes del hogar }\end{array}$ \\
\hline & Simulación 2 & $\begin{array}{l}\text { Imputación ingresos familiares para hogares } \\
\text { con remesas y hogares con migrantes }\end{array}$ & $\begin{array}{l}\text { Modelo de doble selección. } \\
\text { Ecuaciones de migración y de } \\
\text { recepción de remesas }\end{array}$ & $\begin{array}{l}\text { Corrección con número } \\
\text { de migrantes del hogar }\end{array}$ \\
\hline & Simulación 3 & $\begin{array}{l}\text { Corrección de inobservables. Distribución } \\
\text { conjunta de errores truncada y consistente con } \\
\text { las ecuaciones de selección para cada hogar }\end{array}$ & $\begin{array}{l}\text { Modelo de doble selección. } \\
\text { Ecuaciones de migración y de } \\
\text { recepción de remesas }\end{array}$ & $\begin{array}{l}\text { Corrección con número } \\
\text { de migrantes del hogar }\end{array}$ \\
\hline
\end{tabular}

Como se mencionó anteriormente, el último escenario tiene en cuenta una serie de factores indirectos que el primer escenario no corrige. Por esta razón es interesante no solamente la comparación de los diferentes escenarios respecto de la situación observada, sino también la comparación entre sí. La magnitud de esta última diferencia puede ser una medida de los efectos indirectos de las remesas, es decir de aquellos efectos que las mismas tienen sobre el ingreso del resto de los integrantes del hogar, producidas por cambios en las decisiones laborales o cambios en la productividad debido al relajamiento de restricciones de liquidez entre otros. Por otro lado, la diferencia entre el ingreso per cápita observado y el estimado en el primer escenario contrafáctico es una medida del efecto directo de las remesas, es decir aquel que surge de la sustitución del ingreso laboral del migrante por remesas conjuntamente con un cambio en el tamaño del hogar. Es importante destacar que algunos efectos indirectos como es el caso de las decisiones de fertilidad no han sido corregidos en el segundo escenario, pero son motivo de futuras investigaciones que exceden los objetivos iniciales del trabajo.

\subsection{Variables utilizadas}

La decisión sobre el set de variables a utilizar en cada una de las ecuaciones de los modelos, se realizó en base a otros estudios de migraciones o remesas, teniendo en cuenta que existe una amplia literatura al respecto. La primera columna de la Tabla A2.1 en el Apéndice 2 presenta una descripción de las variables utilizadas en el modelo de selección a nivel hogar.

Siguiendo a Acosta et al. (2008), dentro de los regresores de la ecuación de migración se incluyeron como "restricciones de exclusión" un set de variables potencialmente relacionadas con la decisión de migrar pero no relacionados con la ecuación de ingresos. La primer variable que se incluyó dentro de este set, es el número de migrantes fuera del país 
en la ciudad/villa/localidad del hogar (excluyendo los migrantes del hogar), lo cual es una proxy de las redes de migrantes fuera del país (Munshi (2003)), que reducen los costos de la migración presentes y futuros ${ }^{30}$. También se incluyó dentro de las ecuaciones de selección un índice de características de la vivienda construido mediante análisis de componentes principales (PCA). Es importante destacar que las variables utilizadas en cualquiera de las etapas deben cumplir con la restricción de ser invariantes frente a la recepción de remesas o la migración. Por esta razón dentro del índice se incluyeron sólo aquellas características que son presumiblemente invariantes frente a la recepción de remesas o la migración, como la propiedad del terreno y la vivienda, la cantidad de habitaciones dentro del hogar y la disponibilidad de cloacas ${ }^{31}$ y se excluyeron activos de menor valor como electrodomésticos.

Como analizan Bebzuck y Battistón (2010), el envío de remesas puede ser un sustituto del sistema de jubilaciones y pensiones en aquellos países donde el mismo no tiene un grado de desarrollo amplio o cobertura universal. Para tener en cuenta este efecto, se incluye la presencia de jubilados o pensionados dentro del hogar dentro de la ecuación de recepción de remesas. En varios trabajos que analizan los motivos que generan el envío de remesas (de la Briere et al (2001), Massey et al (1993), Rosenzweig (1988)), es común la referencia de algunos arreglos intra-hogar como por ejemplo la compensación monetaria por el cuidado y educación de los hijos del migrante por parte de otros miembros del hogar. Por esta razón también se incluye la cantidad de miembros de 7 a 17 años dentro del hogar ${ }^{32}$ dentro de la ecuación de recepción de remesas. Notar que el problema de endogeneidad de algunas variables no es relevante cuando el interés del modelo es la predicción, dado que no estamos interesados en la identificación de los efectos, pero si es importante cuando la variable puede cambiar producto de la migración, dado que nuestro interés es recrear el escenario sin migrantes y por lo tanto estas variables deberían ser evaluadas en los valores asociados a este escenario. En este sentido, algunas variables utilizadas como el tamaño del hogar son actualizadas al momento pre-migración, para capturar las características del hogar al momento de la decisión sobre migración-remesas. Para evitar el sesgo producido por cambios en las decisiones de fertilidad producto de la ausencia de algunos miembros del hogar, especialmente cuando el migrante es el jefe, el tamaño del hogar es construido

\footnotetext{
30 Los argumentos más utilizados son las ventajas informativas del migrante antes de partir y la mayor probabilidad de conseguir trabajo y lugar de hospedaje al momento de llegar al país receptor.

31 Cortina y de la Garza (2004) encuentran que en el caso de El Salvador, menos del 1.5\% de las remesas son usadas para mejoras o construcción de la vivienda, lo cual permite inferir que variables como la propiedad de la vivienda, cloacas o número de habitaciones son relativamente invariantes en el tiempo. Amuedo Dorantes (2006) también encuentra que más del $85 \%$ de las remesas en Nicaragua son usadas para consumo directo.

32 Dado que la ausencia del jefe de hogar puede cambiar las decisiones de fertilidad, excluimos los niños menores de 7 años.
} 
teniendo en cuenta solamente los miembros mayores a 15 años. Otras variables como las educativas son corregidas también teniendo en cuenta las características educativas del migrante y si la encuesta permite identificar al jefe de hogar dentro de los migrantes, las características que hacen referencia al jefe también son corregidas con este dato.

Para el modelo estimado a nivel individual en la primera simulación se utilizaron algunas variables del set anterior, junto con algunas características del migrante. La ecuación de selección es similar a la ecuación de migración del escenario anterior pero se incluyen además algunas características que pueden observarse también para el migrante. La ecuación de salarios incluye además de las variables educativas, de edad y género, las variables regionales, dado que suponemos que el migrante permanece o retorna al estado o provincia de origen. En la segunda columna de la Tabla A2.1 se describen las variables a nivel individual incluidas en las regresiones de este escenario.

\section{Resultados}

En la Tabla A2.2 y la Tabla A2.3 del Apéndice 2 se presentan las estimaciones econométricas de los modelos utilizados para las simulaciones. Las estimaciones del modelo a nivel individual (simulación 1) revelan que en El Salvador el signo del coeficiente que acompaña la variable $\lambda$ es positivo, indicando que los migrantes son en promedio seleccionados negativamente en relación a la distribución de inobservables del ingreso salarial, o en otras palabras que un migrante con las características promedio de la población es remunerado por debajo del promedio del ingreso laboral que se espera para un individuo seleccionado aleatoriamente de toda la población. En Ecuador y Nicaragua el coeficiente de $\lambda$ es no significativo y en el caso de Honduras es negativo y por lo tanto, los migrantes son en promedio positivamente seleccionados en relación a la distribución de inobservables del ingreso laboral. No existe consenso en la literatura acerca del signo esperado de estos coeficientes para los países Latinoamericanos. Borjas (1987) por ejemplo sostiene que los países con altos retornos a la educación y gran dispersión de ingresos laborales como es el caso de los países latinoamericanos, son quienes tienen mayor probabilidad de que los migrantes sean negativamente seleccionados. Otros autores sin embargo encuentran evidencia a favor de la selección positiva producto de la "fuga de cerebros" (Carrington y Detragiache (1998), Beine et. al. (2001)). Por otra parte, Chiquiar y Hanson (2005) muestran que a pesar de los resultados mencionados por Borjas, los migrante mexicanos en Estados Unidos no son seleccionados negativamente. 
A nivel de hogares, las estimaciones indican que en todos los países existe algún tipo de mecanismo selección con efectos significativos. En Ecuador y El Salvador, los coeficientes que acompañan $\lambda_{1}$ y $\lambda_{2}$ son positivos indicando que tanto los hogares que reciben remesas como aquellos que tienen migrantes están en promedio negativamente seleccionados en cuanto a los inobservables. En Honduras, si bien la migración a nivel de hogares no presenta evidencia de selección ni positiva ni negativa, los hogares que reciben remesas son seleccionados en promedio en forma negativa. En Nicaragua los resultados son opuestos al del resto de los países indicando que los hogares pertenecientes a la muestra censurada son positivamente seleccionados en promedio, aunque sólo el coeficiente de $\lambda_{2}$ es significativo. Este hallazgo es consistente con la historia de migración de Nicaragua. La evidencia de otros trabajos que tratan la selección de la muestra de hogares con remesas no es concluyente. Adams (2006) encuentra que no hay evidencia de selección mientras que Acosta et.al (2008) obtienen resultados que apoyan la hipótesis de selección negativa.

En el Apéndice 3, se presentan una serie de gráficos que comparan las distribuciones del logaritmo del ingreso per cápita familiar estimado para los escenarios 1 y 3 con el observado en cada encuesta. Cada distribución simulada de ingresos ${ }^{33}$ se presenta junto con el intervalo de confianza del 95\% construido a partir de las diferentes realizaciones de las distribuciones de inobservables tal como se mencionó anteriormente. Para la simulación 3, también se compara la distribución simulada y observada para la submuestra de hogares con remesas o con migrantes. La transición entre las distribuciones simuladas y observadas que se muestran en los gráficos, resumen parte de los resultados que se comentan en esta sección. A continuación se exploran los factores que explican la dirección de estos cambios.

\subsection{Cambios simulados en la pobreza}

Los principales resultados de las simulaciones para cada escenario se resumen en la Tabla 5. La evidencia muestra que en todos los escenarios y para cualquier línea de referencia la pobreza es significativamente mayor que la observada, excepto para Nicaragua donde las simulaciones 1 y 3 reflejan cambios no significativos para la mayoría de las tasas, aunque se obtienen reducciones de dos o tres puntos cuando se excluye el efecto de selección en los inobservables (simulación 2). La dirección de los cambios concuerda con los obtenidos por Acosta et al. (2008) quienes estiman que las remesas producen reducciones significativas de

\footnotetext{
33 Dado que el modelo imputa distribuciones de inobservables con medias potencialmente distintas de cero, se toma para cada individuo la media de las realizaciones simuladas del ingreso contrafáctico. Esta distribución es la que se representa en los gráficos de esta sección.
} 
la pobreza en El Salvador, Ecuador y Honduras pero no significativas en Nicaragua. Para los tres primeros países, sin embargo, la magnitud de los cambios en las tasas difiere en varios casos, aunque debe tenerse en cuenta que la cantidad de hogares involucrados en las simulaciones se incrementa notablemente en este trabajo al considerar no sólo la recepción de remesas sino la presencia de migrantes en el hogar ${ }^{34}$.

Tabla 5

Medidas de pobreza observadas y simuladas

\begin{tabular}{|c|c|c|c|c|c|c|c|c|}
\hline & \multicolumn{2}{|c|}{ Pobreza Moderada } & \multicolumn{2}{|c|}{ Pobreza Extrema } & \multicolumn{2}{|c|}{ Pobreza 2 usd } & \multicolumn{2}{|c|}{ Pobreza 1 usd } \\
\hline & valor & conf $95 \%$ & valor & conf $95 \%$ & valor & conf $95 \%$ & valor & conf $95 \%$ \\
\hline \multicolumn{9}{|l|}{ ECUADOR 2006} \\
\hline Ingreso observado & 31.60 & & 16.23 & & 22.15 & & 9.58 & \\
\hline Ingreso neto de remesas & 33.03 & & 17.39 & & 23.45 & & 10.42 & \\
\hline Simulación 1 & 33.11 * & ( 32.9233 .29 ) & 17.49 * & ( 17.3517 .61$)$ & 23.58 * & ( 23.4423 .74$)$ & 10.55 * & $\left(\begin{array}{ll}10.44 & 10.65\end{array}\right)$ \\
\hline Simulación 2 & $33.87^{*}$ & ( $33.43 \quad 34.26$ ) & 17.66 * & $\left(\begin{array}{ll}17.31 & 18.06\end{array}\right)$ & $23.87^{*}$ & ( $\left.\begin{array}{ll}23.43 & 24.28\end{array}\right)$ & 10.26 * & $\left(\begin{array}{ll}9.98 & 10.49\end{array}\right)$ \\
\hline Simulación 3 & 36.30 * & $\left(\begin{array}{ll}35.86 & 36.85\end{array}\right)$ & 19.34 * & $\left(\begin{array}{ll}18.93 & 19.69\end{array}\right)$ & 25.94 * & ( $\left.\begin{array}{ll}25.53 & 26.37\end{array}\right)$ & 11.27 * & (10.99 11.53 ) \\
\hline \multicolumn{9}{|l|}{ EL SALVADOR 2007} \\
\hline Ingreso observado & 32.37 & & 9.81 & & 27.49 & & 9.49 & \\
\hline Ingreso neto de remesas & 40.27 & & 15.81 & & 34.59 & & 15.13 & \\
\hline Simulación 1 & 36.77 * & ( 36.4937 .08 ) & 12.99 * & ( 12.8213 .20$)$ & 31.76 * & ( 31.4932 .06 ) & 12.66 * & $\left(\begin{array}{ll}12.50 & 12.83\end{array}\right)$ \\
\hline Simulación 2 & 35.99 * & ( 35.4936 .52 ) & 11.54 * & ( 11.1811 .97$)$ & 31.20 * & $\left(\begin{array}{ll}30.68 & 31.68\end{array}\right)$ & 11.25 * & $\left(\begin{array}{ll}10.88 & 11.67\end{array}\right)$ \\
\hline Simulación 3 & $38.47^{*}$ & ( 37.8638 .99 ) & 13.09 * & $\left(\begin{array}{ll}12.61 & 13.57\end{array}\right)$ & 33.49 * & ( 32.9534 .02$)$ & 12.60 * & $\left(\begin{array}{ll}12.15 & 12.99\end{array}\right)$ \\
\hline \multicolumn{9}{|l|}{ HONDURAS 2004} \\
\hline Ingreso observado & 63.37 & & 43.53 & & 39.40 & & 20.25 & \\
\hline Ingreso neto de remesas & 66.33 & & 46.82 & & 42.51 & & 22.37 & \\
\hline Simulación 1 & 61.98 * & (61.62 62.28) & 42.91 * & ( $\left.\begin{array}{ll}42.57 & 43.21\end{array}\right)$ & 40.31 * & ( 39.9440 .69 ) & 20.76 * & ( 20.4921 .09$)$ \\
\hline Simulación 2 & 64.44 * & (63.75 64.98) & 45.39 * & $\left(\begin{array}{ll}44.78 & 46.02\end{array}\right)$ & 42.03 * & $\left(\begin{array}{ll}41.34 & 42.64\end{array}\right)$ & 21.33 * & ( $\left.\begin{array}{ll}20.79 & 21.85\end{array}\right)$ \\
\hline Simulación 3 & $66.06^{*}$ & $(65.5266 .69)$ & 47.11 * & $\left(\begin{array}{ll}46.43 & 47.72)\end{array}\right.$ & 43.68 * & $\left(\begin{array}{ll}43.06 & 44.32\end{array}\right)$ & 22.46 * & $\left(\begin{array}{ll}21.87 & 22.99\end{array}\right)$ \\
\hline \multicolumn{9}{|l|}{ NICARAGUA 2005} \\
\hline Ingreso observado & 40.65 & & 16.67 & & 38.58 & & 13.21 & \\
\hline Ingreso neto de remesas & 42.66 & & 17.32 & & 40.39 & & 13.71 & \\
\hline Simulación 1 & 40.83 & ( 40.5141 .17 ) & 16.71 & ( 16.57 16.81 $)$ & 39.03 * & ( 38.6939 .50$)$ & 13.67 * & $\left(\begin{array}{ll}13.50 & 13.84\end{array}\right)$ \\
\hline Simulación 2 & 43.36 * & $\left(\begin{array}{ll}42.60 & 44.30\end{array}\right)$ & 18.54 * & $\left(\begin{array}{ll}18.01 & 19.38\end{array}\right)$ & $40.47^{*}$ & $\left(\begin{array}{ll}39.61 & 41.43\end{array}\right)$ & 14.53 * & $\left(\begin{array}{ll}14.03 & 15.28\end{array}\right)$ \\
\hline Simulación 3 & 40.44 & ( 39.5741 .17 ) & 16.73 & ( $\left.\begin{array}{ll}16.27 & 17.22\end{array}\right)$ & 37.64 * & ( 36.7238 .32 ) & 12.98 & $\left(\begin{array}{ll}12.57 & 13.46\end{array}\right)$ \\
\hline
\end{tabular}

Fuente: Elaboración propia en base a SEDLAC (CEDLAS-Banco Mundial)

Si se tienen en cuenta los efectos totales sobre la pobreza (simulación 3), el impacto más fuerte se da en El Salvador con reducciones cercanas a los 6 puntos porcentuales en las tasas de pobreza moderada y de 2 dólares diarios y reducciones cercanas a los 3 puntos porcentuales en las tasas de pobreza extrema y de 1 dólar diario. En segundo lugar de importancia se encuentran Ecuador y Honduras donde las reducciones en las tasas de pobreza se encuentran en el rango de los 2 a 5 puntos porcentuales dependiendo de la línea de pobreza. La comparación entre estos dos países indica que la reducción en las tasas de pobreza moderada y de 2 dólares diarios es más importante en Ecuador mientras que la de

\footnotetext{
${ }^{34}$ Los resultados también coinciden con los obtenidos por Acosta et al. (2007) en que el mayor impacto sobre la pobreza se da en El Salvador.
} 
pobreza extrema y 1 dólar diario es más importante en Honduras. Como se mencionó anteriormente en Nicaragua las tasas observadas y simuladas no presentan diferencias significativas excepto un pequeño aumento en la tasa de pobreza de 2 dólares diarios.

Cuando se analizan los efectos sobre la pobreza producidos solamente por la inclusión del migrante dentro del hogar, los cambios son menores en todos los países revirtiéndose incluso la dirección en Honduras para las líneas moderada y de 2 dólares diarios. Las reducciones en las tasas de pobreza de El Salvador son 2 puntos porcentuales menores en comparación con el cambio que se verificaba en la simulación 3 mientras que en Ecuador todas las tasas se reducen en aproximadamente 1 punto porcentual. Para esta misma simulación, Honduras registra una leve reducción de las tasas de pobreza extrema y de 1 dólar diario y un pequeño aumento en la pobreza moderada y de 2 dólares diarios. Al igual que en la simulación 3, los efectos en Nicaragua son muy pequeños y solamente significativos en el caso de la pobreza extrema y de 1 dólar diario.

En Ecuador, El Salvador y Honduras la tasa de pobreza de la simulación 3 es siempre superior que la de la simulación 2 lo cual es consistente con la hipótesis de que los hogares con remesas o migrantes son negativamente seleccionados en estos países. En Nicaragua en cambio donde la evidencia indica que los migrantes son positivamente seleccionados, las tasas de pobreza son mayores en la simulación 2 que en la tercera simulación, indicando que la distribución de inobservables imputada tiene media positiva para estos hogares.

Una serie de factores pueden explicar los cambios simulados en las tasas de pobreza entre los distintos escenarios. En primer lugar, la posición que ocupan los hogares con migrantes o con remesas dentro del ingreso pre-migración y pre-remesas es relevante. El Gráfico 2 muestra que la presencia de hogares con migrantes y hogares perceptores de remesas se concentran en los deciles más pobres en el caso del El Salvador y el los deciles más ricos en Nicaragua, sobre todo cuando se utiliza el escenario pre-remesas y pre-migración de la simulación 3. Este patrón coincide con los hallazgos de otros trabajos y es coherente con las diferencias históricas en el proceso migratorio de ambos países ${ }^{35}$. Teniendo en cuenta estos patrones, varias razones contribuyen al bajo impacto sobre la pobreza en Nicaragua,

\footnotetext{
35 Baumeister (2006) resalta que más del 70\% de los migrantes Nicaragüenses abandonó el país antes de la década del 90 y describe que el proceso de migración impulsado por el exilio político y el aumento de la violencia interna, comenzó por las clases más altas seguida de trabajadores muy calificados aunque en los últimos años se ha incrementado el flujo de migrantes de menores recursos. Este autor también resalta la mayor educación promedio de los migrantes en Estados Unidos en relación a los migrantes en Costa Rica, donde las razones económicas para la migración cobran mayor importancia que las políticas. Funkhouser (1995) por su parte menciona que en ambos países los procesos políticos que impulsan la salida de exiliados es completamente opuesta.
} 
en primer lugar los motivos de migración contienen un fuerte componente político debilitando el argumento de que la migración corresponde a una estrategia para aumentar el bienestar económico de todo el hogar. En segundo lugar, los hogares involucrados en el proceso se concentran en la parte alta de la distribución y finalmente el modelo estimado sugiere que estos hogares están positivamente seleccionados con lo cual existe un componente inobservable de los ingresos que en el escenario simulado contribuirían a aumentar los ingresos contrafácticos y de esta forma se reduciría la brecha respecto del ingreso observado. En el caso de El Salvador en cambio, la mayoría de las fuerzas operan en sentido inverso, además de que los hogares con migrantes o remesas parecen ubicarse en la parte más pobre de la distribución de ingresos al momento de migrar, los inobservables imputados tienen un efecto negativo sobre el ingreso contrafáctico aumentando aún más la brecha con el ingreso observado. Además de las diferencias en los procesos políticos y bélicos que impulsaron la migración en estos dos países, las políticas de los países de destino pueden haber influido en profundizar el proceso de selección. Si las políticas de visado e inmigración respecto de Nicaragua fueron más estrictas sólo aquellos hogares con liquidez suficiente, mayores redes de contacto, etc. pudieron haber sorteado los costos y barreras de emigración.

\section{Gráfico 2}

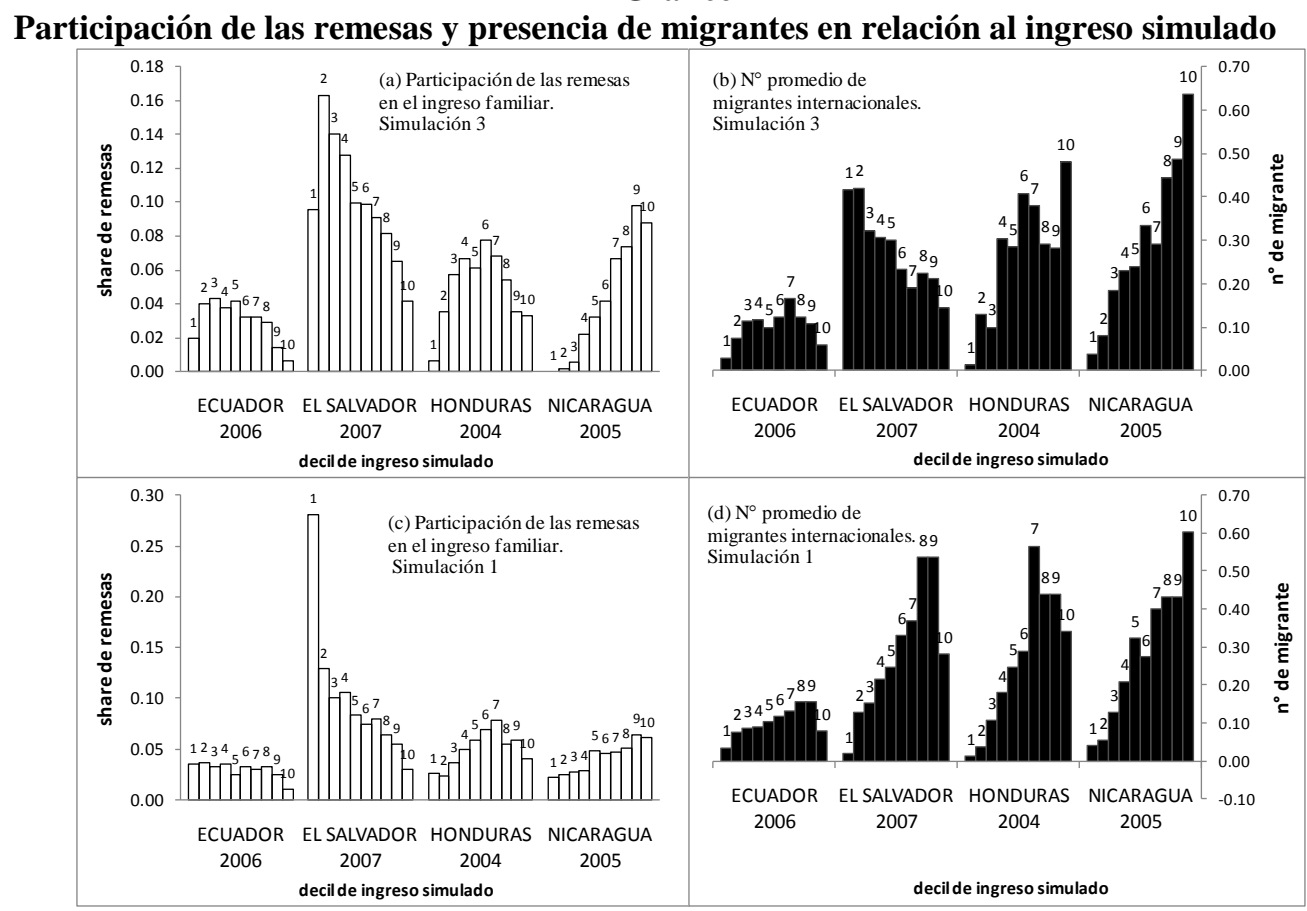

Fuente: Elaboración propia en base a SEDLAC (CEDLAS-Banco Mundial) 
Debe tenerse en cuenta también que la medición de la pobreza en los escenarios simulados incluye a los migrantes, y manteniendo el resto de los factores constantes, esto refuerza la magnitud de algunos cambios, porque incrementa las tasas simuladas en los países donde los migrantes provienen de hogares pobres como El Salvador y reduce la de los países como Nicaragua donde la mayoría de los migrantes provienen de hogares no pobres.

En Honduras y Ecuador se observa que la participación de las remesas es más alta en el centro de la distribución disminuyendo su importancia en ambos extremos. Los dos países sirven para ilustrar la importancia de utilizar el ingreso simulado como herramienta para evaluar el verdadero impacto de las remesas ya que este patrón no se verifica cuando se utiliza el ingreso neto de remesas en lugar del ingreso simulado. En el caso de los migrantes, mientras que en Ecuador también existe una mayor concentración en los deciles centrales, en Honduras este patrón se interrumpe por una fuerte concentración de migrantes en el decil superior, lo cual puede explicarse por cierta presencia de migrantes que abandonan el país con fines educativos, generalmente concentrados en el decil superior $^{36}$.

Es importante destacar la diferencia que se observa en el patrón de los migrantes y las remesas cuando se consideran diferentes simulaciones. Tal como mencionamos en secciones anteriores, la incorporación de todos los efectos de las remesas y la migración puede cambiar completamente las conclusiones acerca de la posición inicial de los hogares involucrados en el proceso. El caso más notable es el de los migrantes en El Salvador, donde la simulación 1 indica que los migrantes se distribuyen en forma creciente respecto del ingreso mientras que si tomamos la simulación 3 los migrantes tienden a distribuirse en forma decreciente respecto del ingreso.

\section{Ganadores y perdedores del proceso de migración y remesas}

A pesar de las reducciones en las tasas de pobreza, es claro tanto desde el punto de vista teórico como empírico que sobre el ingreso familiar operan efectos positivos y negativos y por lo tanto existen ganadores y perdedores en el proceso. Si el proceso de selección de migrantes se basa en una decisión racional del hogar para aumentar su bienestar, la cantidad de hogares con efectos negativos debería ser baja. Sin embargo esta afirmación es válida solamente en términos esperados y previamente a la decisión de migrar. Por otra parte,

\footnotetext{
36 Las estimaciones revelan que más del $55 \%$ de los migrantes que abandonaron el país por motivos educativos pertenecen al decil superior de ingreso contrafáctico (simulación 3). Este fenómeno es conocido usualmente con el nombre de "fuga de cerebros" (Mattoo, Neagu y Özden (2005)).
} 
pueden existir motivos menos altruistas en la decisión de migrar o causas más exógenas al cambio en el bienestar como la salida de exiliados políticos o refugiados por guerras como sucedió en El Salvador y Nicaragua. Es esperable además que la transición entre el escenario simulado y el observado sea diferente para hogares con distinto status de migración o diferentes arreglos intra-hogar.

El caso más sencillo de analizar es el que se presenta en el Gráfico 3, donde se analiza la transición de pobreza moderada entre la simulación 1 y el escenario observado para diferentes tipos de hogares según el status de migración y de remesas. Los hogares con remesas que no registran migrantes resultan un caso trivial dentro de la simulación 1 dado que la diferencia entre el ingreso simulado y el observado es el monto de las remesas y los únicos cambios que pueden darse son positivos. El Salvador y Honduras son los países donde un mayor porcentaje de hogares salen de la pobreza por este efecto. Como resalta Rivera Funes (2005) en El Salvador luego de un proceso de desmembramiento familiar y aislamiento de los hogares con exiliados durante la guerra de los años 80 , se restablece a partir de la década del 90 muchos de los vínculos familiares a través del envío de remesas. Para estos hogares es más probable que el migrante no sea incluido dentro de los miembros del hogar en las encuestas o bien porque se trata de familiares más lejanos o bien por la distancia temporal de la migración. En el caso de Ecuador se debe tener en cuenta que el registro de migrantes sólo está disponible para los últimos 5 años dentro de la encuesta, por esta razón dentro de este grupo pueden existir hogares con migrantes de mucha antigüedad. Como menciona Solimano (2003), los motivos altruistas para remitir pueden disminuir con el tiempo, lo que puede explicar que las remesas registradas para estos hogares sean bajas en comparación al resto de los hogares receptores lo cual se refleja en un bajo impacto directo sobre la pobreza. Por otra parte, los hogares que tienen migrantes pero no reciben remesas muestran sólo efectos negativos, porque la pérdida de ingresos laborales del hogar (que no es compensada por remesas) supera el efecto de un menor número de integrantes entre los cuales se divide el resto del ingreso familiar. Si bien esta conclusión no es necesariamente cierta en todos los casos, es altamente probable cuando la mayoría de los migrantes son individuos en edades de alta participación laboral, como sucede en los cuatro países. 
Gráfico 3

Status de pobreza entre escenarios (Simulación 1)

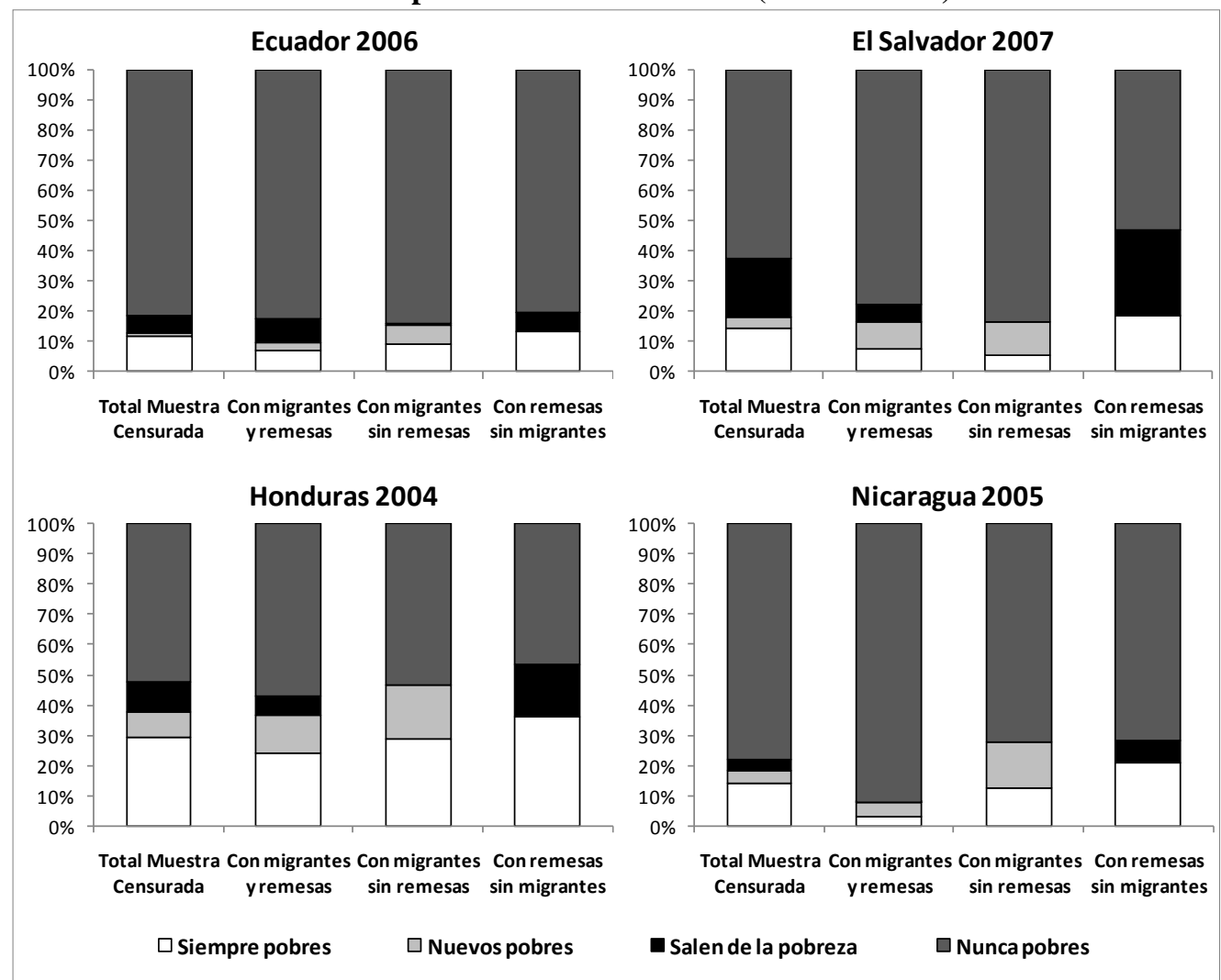

Fuente: Elaboración propia en base a SEDLAC (CEDLAS-Banco Mundial)

Nicaragua y Honduras son los países donde la presencia de nuevos pobres es más fuerte para esta simulación. El resultado para Nicaragua es bastante directo si se tiene en cuenta que los migrantes en términos de observables poseen características más remuneradas como mayor educación, u origen en zonas urbanas y que no existe evidencia de selección negativa en los inobservables, por lo que los ingresos laborales imputados dentro del país podrían ser altos en relación a las remesas enviadas. Además debe tenerse en cuenta que los motivos altruistas para remitir pueden ser menores si el hogar de origen tiene ingresos altos provenientes de otras fuentes como evidencian muchos trabajos (Germenji, Beka y Sarris (2001), Holst y Schrooten (2006)). En el caso de Honduras, el resultado está relacionado con la fuerte presencia de migrantes en el decil más rico que se observaba en el Gráfico 2 quienes tienen una probabilidad menor de enviar remesas por las mismas razones mencionadas anteriormente.

En el caso de los hogares que perciben remesas y además declaran tener migrantes, el porcentaje de hogares que salen de la pobreza se compensa con el porcentaje de hogares que pasan a ser pobres en El Salvador y Honduras arrojando en neto un leve aumento de la pobreza para este grupo. En Nicaragua la mayoría de estos hogares permanece invariante 
en cuanto al status de pobreza y en Ecuador hay una leve presencia de hogares que salen de la pobreza junto con un porcentaje aún menor de hogares que terminan debajo de la línea de pobreza moderada. Los hogares de este grupo están sujetos a dos efectos diferentes, por un lado los ingreso laborales aumentan dentro del escenario simulado por la presencia del migrante pero por otro lado el ingreso total se divide por un número mayor de individuos.

Finalmente si se tiene en cuenta el total de la muestra censurada, es decir todos los hogares que tienen migrantes o remesas independientemente de su combinación, se verifica que en El Salvador y Ecuador predominan los hogares que salen de la pobreza mientras que en Honduras este efecto es compensado en parte por los "nuevos pobres". En Nicaragua en cambio no hay movimientos significativos en el status de pobreza entre el escenario 1 y el observado, reflejando la baja concentración de hogares pobres que tienen migrantes o reciben remesas.

El Gráfico 4 presenta un análisis similar al anterior pero a partir de la simulación 3 donde intervienen la totalidad de los efectos positivos y negativos del proceso de migraciones y remesas. En este caso no es obvia la dirección de los cambios para ningún tipo de hogar, sin embargo se mantienen alguna de las conclusiones anteriores aun cuando la simulación imputa el ingreso familiar en su conjunto.

La primera conclusión que puede obtenerse es que para el total de la muestra censurada el porcentaje de hogares que sale de la pobreza representa un porcentaje mucho mayor que los "nuevos pobres" en todos los países excepto Nicaragua donde esta conclusión se revierte. Resulta notable que Honduras refleja un porcentaje de hogares que cambian de status más alto que el resto de los países, pero debe tenerse en cuenta que las tasas de pobreza en este país son superiores al 50\% y que los hogares sujetos a cambios de ingresos se encuentran precisamente concentrados en los deciles centrales de la distribución de ingreso pre migración y pre remesas. Los hogares que tienen tanto migrantes como remesas poseen una composición similar a la del total de la muestra censurada donde resalta el hecho de que en Nicaragua más del 90\% de estos hogares tienen ingresos mayores a la línea de pobreza moderada, mientras que en El Salvador, que posee tasas de pobreza menores, el porcentaje no supera el 50\% indicando claramente la ubicación de estos hogares dentro de la distribución de ingresos pre-migración y pre-remesas. 


\section{Gráfico 4}

Status de pobreza entre escenarios. (Simulación 3)

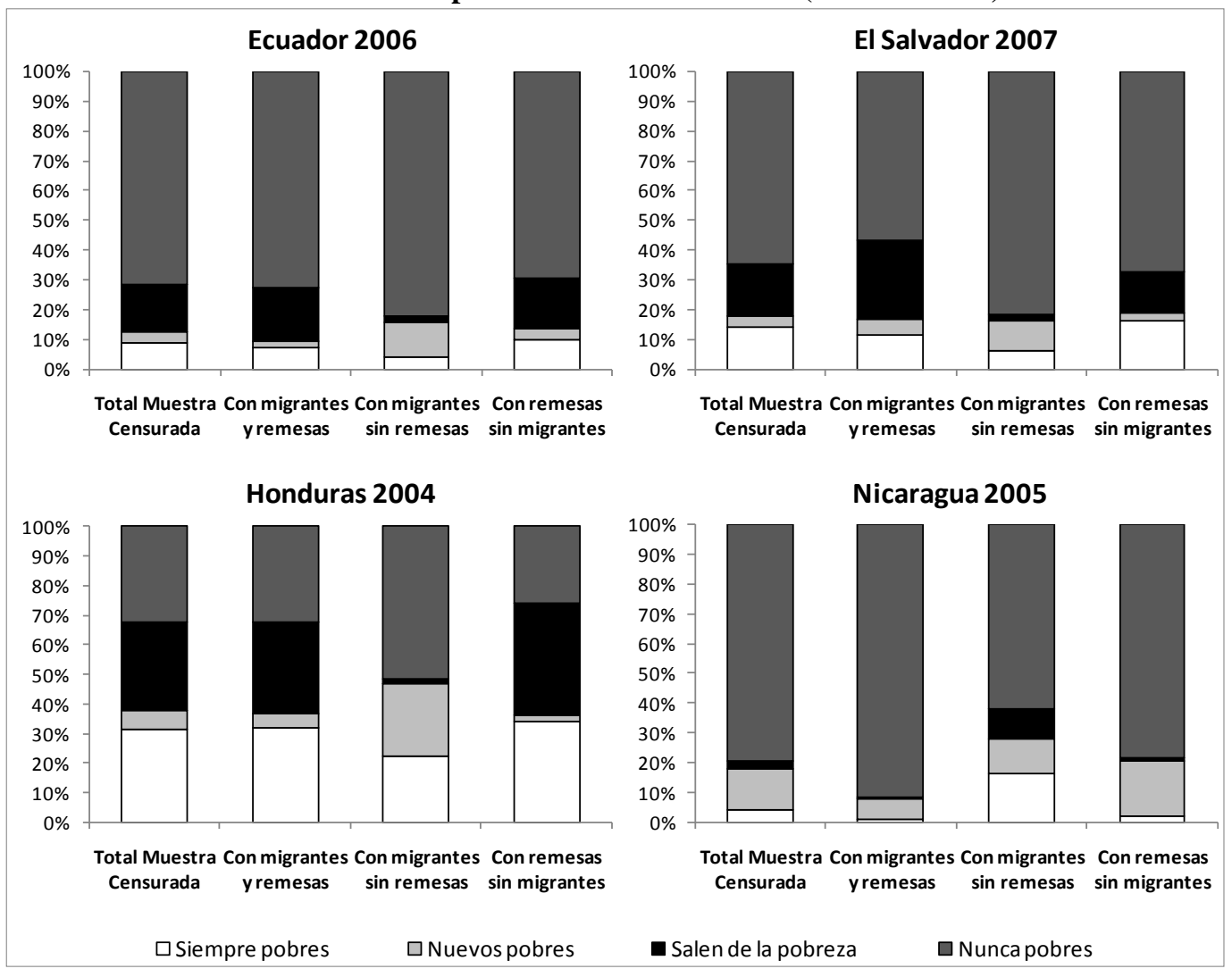

Fuente: Elaboración propia en base a SEDLAC (CEDLAS-Banco Mundial)

Los hogares perceptores de remesas que no declaran migrantes tienen en todos los países, excepto en Nicaragua, una fuerte presencia de hogares que salen de la pobreza, mientras que los hogares con migrantes que no remiten dinero tienen a tener mayor porcentaje de "nuevos pobres". Para aquellos que tienen migrantes pero no reciben remesas las conclusiones se asemejan a las de la simulación 1, donde existe una presencia mayor de hogares que pasan a ser pobres en el escenario observado, especialmente en Honduras. Estos resultados indicarían que la migración en forma aislada tiende a tener efectos totales negativos sobre el ingreso de los hogares mientras que el flujo de remesas en forma aislada tiene para tres de los cuatro países efectos claramente positivos.

En Nicaragua en cambio, la baja presencia de hogares que salen de la pobreza se debe a la baja cantidad de hogares inicialmente pobres en el escenario simulado y por otro lado a que los inobservables imputados tienden a reducir la brecha entre el ingreso simulado y el observado. Existen además muchas razones que pueden explicar desde el punto de vista teórico que las remesas tengan un impacto negativo sobre el ingreso de los hogares aún cuando el migrante no sea cercano al hogar como se observa en Nicaragua. La disminución 
de la oferta laboral de los individuos dentro del país por un aumento en el salario de reserva es una de las posibles explicaciones (Amuedo-Dorantes y Pozo (2006), Yang (2008)). En segundo lugar puede ocurrir que los migrantes con mucho tiempo de residencia en el exterior no sean declarados por el hogar como miembros antiguos y en este caso se sobreestimaría el ingreso del escenario simulado reduciendo los efectos positivos de las remesas por una subestimación del tamaño simulado del hogar y porque además las remesas pueden disminuir a lo largo del tiempo. Las causas políticas o bélicas en el proceso de migración también son importantes dado que se debilitaría la teoría de que los hogares que tienen migrantes son aquellos que en términos esperados proyectan aumentar sus ingresos luego de la migración. La evidencia de selección negativa encontrada en este trabajo también es consistente con esta idea.

\section{Efectos directos e indirectos sobre la pobreza}

Los cambios totales en que surgen de comparar la pobreza de la simulación 3 con las tasas de pobreza observadas, se pueden descomponer en efectos directos (retorno del migrante al hogar) y efectos indirectos utilizando la simulación 1. Esto se puede realizar teniendo en cuenta que las diferencias entre el escenario observado y el de la simulación 1 se deben solamente a la incorporación del migrante dentro de la economía doméstica manteniendo constante el resto de las fuentes de ingreso excepto las remesas y de esta forma el comportamiento de los integrantes del hogar que no migraron como cualquier otra variable inobservada permanecen constantes. Una vez que se descuenta el efecto directo de la sustitución de las remesas por ingreso laboral del migrante, las diferencias respecto de la tercera simulación se pueden atribuir al resto de los efectos indirectos que no son modelados explícitamente como cambios en la oferta laboral, restricciones de liquidez, riesgo, etc.

El Gráfico 5 muestra esta descomposición para los cambios en todas las tasas de pobreza. Los resultados muestran que en Ecuador y Honduras, los efectos indirectos explican con mayor fuerza la reducción en las tasas totales de pobreza, mientras que en El Salvador la reducción se debe principalmente al flujo monetario de remesas que reemplaza el ingreso del migrante teniendo mucha menor importancia los efectos producidos por otros canales indirectos. Nicaragua, donde la mayoría de los cambios en las tasas de pobreza son no significativos, se observa para algunas tasas que la dirección de los efectos indirectos es negativa y opuesta a la de los efectos directos, es decir que aun cuando las remesas compensen la caída en el ingreso laboral del hogar por la salida del migrante, existen 
efectos indirectos que tienden a aumentar la pobreza. En Honduras en cambio, los efectos directos tienen un efecto negativo sobre los hogares indicando que el envío de remesas no compensa la caída en el ingreso laboral del migrante, pero que los efectos indirectos sobre el ingreso son suficientemente importantes para revertir el primer cambio.

\section{Gráfico 5}

Efectos directos e indirectos sobre la pobreza

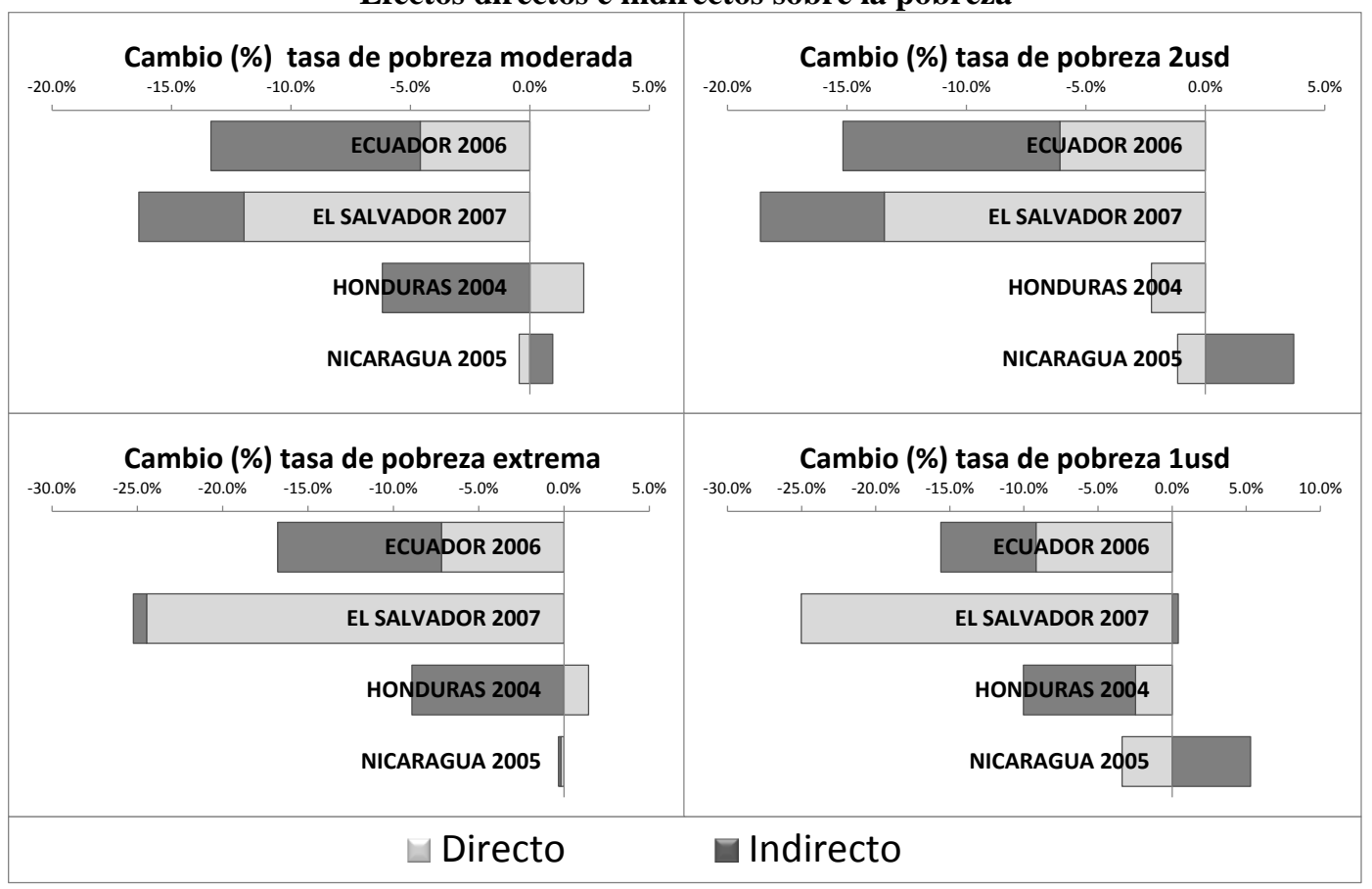

Fuente: Elaboración propia en base a SEDLAC (CEDLAS-Banco Mundial)

La gran importancia de los efectos indirectos en Ecuador y Honduras es un resultado esperable y consistente con los argumentos teóricos analizados en secciones anteriores. Los efectos de la migración y las remesas son más fuertes en el centro de la distribución para estos dos países y son precisamente estos hogares los más sensibles a cambios indirectos como los producidos sobre restricciones de liquidez o crediticias que permiten mejorar la productividad del resto de los miembros del hogar que no migraron. Si en cambio los hogares involucrados en el proceso se concentran en los deciles más pobres, es posible que las remesas deban cubrir algunas necesidades básicas mejorando la situación de pobreza pero restando importancia a las remesas como elemento de liquidez para mejorar la productividad del hogar. Este argumento es consistente con lo que menciona Rivera Funes (2005) quien analiza una encuesta realizada a hogares Salvadoreños con migrantes, donde más del $60 \%$ de las familias encuestadas consideran que la mejora alimentaria ha sido el principal efecto de las remesas sobre su bienestar. Un argumento más a favor de esta interpretación es la que se observa cuando se toman líneas de pobreza cada vez menores. 
Puede observarse que la importancia de los efectos directos aumenta y la de los indirectos se reduce cuando la línea de pobreza es más baja.

En forma más precisa, Gráfico 6 estima la diferencia porcentual entre el ingreso observado y el simulado en los escenarios 1 y 3 para cada percentil de ingreso simulado. La diferencia entre ambas curvas de incidencia representan los efectos indirectos mientras que la línea punteada estima los cambios directos.

Gráfico 6

Curvas de incidencia del proceso migración-remesas (Simulaciones 1 y 3)

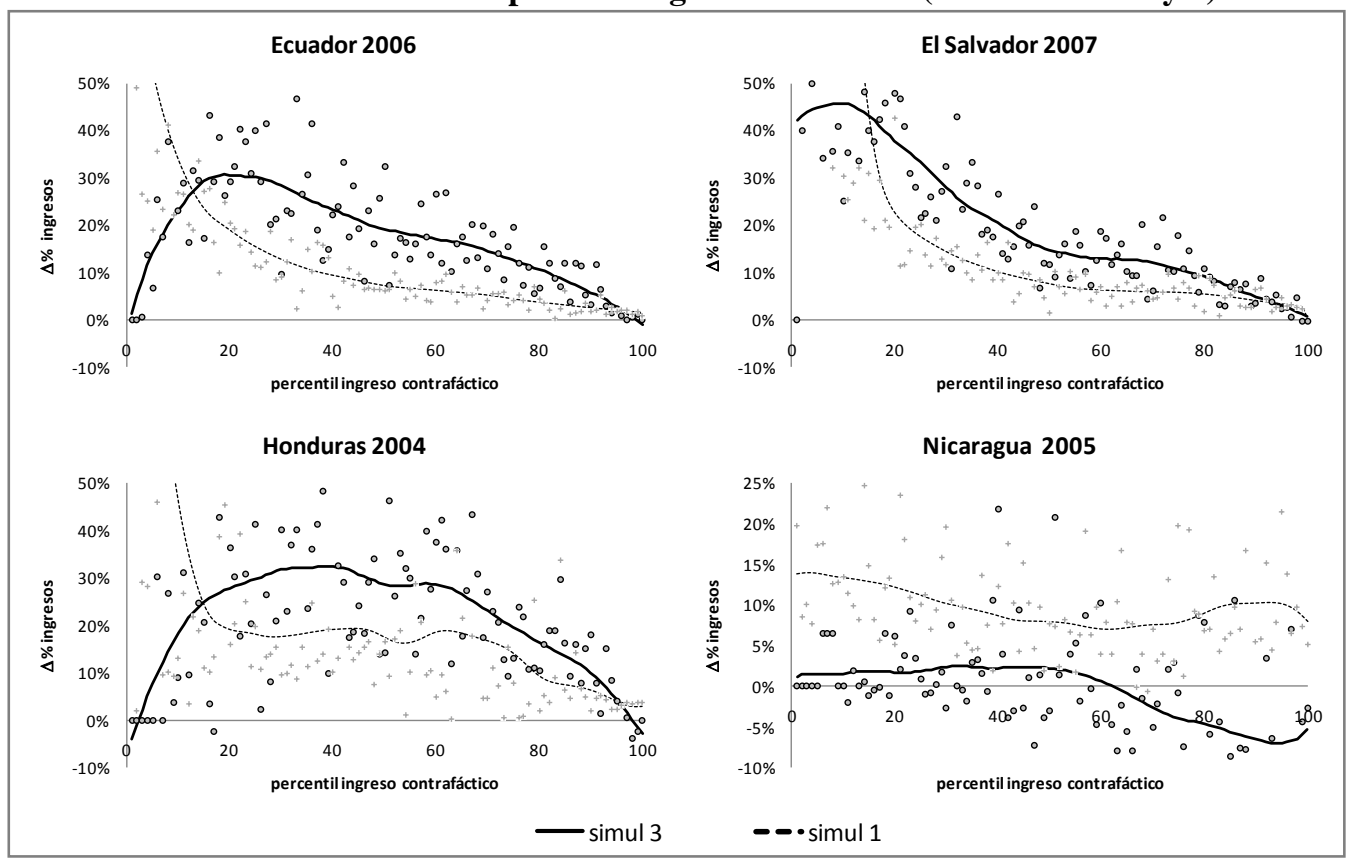

Fuente: Elaboración propia en base a SEDLAC (CEDLAS-Banco Mundial)

Puede observarse en primer lugar que tanto en Ecuador como Honduras la curva de incidencia total tiene forma de $\mathrm{U}$ invertida mostrando un mayor efecto en el centro de la distribución. El Salvador en cambio muestra una incidencia total decreciente y en Nicaragua prácticamente no hay cambios totales aunque los percentiles más altos tienen una caída en el nivel de ingresos. La curva que describe los cambios entre el ingreso observado y el de la primera simulación es decreciente en Ecuador, El Salvador y Honduras con un tramo fuertemente decreciente en los 20 percentiles más pobres. La forma de esta curva se produce por la presencia de muchos hogares pobres con remesas y que no declaran migrantes, los cuales sólo tienen efectos directos positivos tal como se explicó anteriormente. En los tres primeros países se observa que la diferencia entre las dos curvas es menor en los extremos de la distribución, indicando que para los hogares más pobres los 
beneficios del proceso están más ligados al valor recibido de las remesas pero no tanto a los cambios indirectos que podrían provocar tanto las remesas como la migración.

La incidencia en el caso de Nicaragua es diferente al resto de los países, además de que los cambios son menores las dos curvas son más horizontales y con tendencia opuesta en los percentiles más ricos, lo que determina que los efectos indirectos sean negativos para estos hogares. A diferencia del resto de los países, en Nicaragua los efectos indirectos son menores en el centro de la distribución.

\subsection{Cambios simulados en la desigualdad}

La Tabla 6 resume los indicadores de desigualdad obtenidos para cada simulación junto con el intervalo de confianza derivado de las distintas realizaciones de los errores que se utilizaron para construir los ingresos simulados. En todos los países cuando se tienen en cuenta todos los efectos (simulación 3), el índice de Gini se reduce en aproximadamente 2 puntos entre el escenario simulado y el observado, indicando un efecto igualador del proceso de migraciones y remesas ${ }^{37}$. En el caso de la simulación 3, como se puede observar en el Gráfico 6, en todos los países la incidencia promedio del proceso es positiva y se concentra en percentiles bajos y medios como Ecuador, El Salvador y Honduras o bien existe un impacto negativo en los percentiles más ricos como es el caso de Nicaragua. Cualquiera de estos movimientos reduce la desigualdad global como demuestra la Tabla 6.

Tabla 6

Medidas de desigualdad observadas y simuladas

\begin{tabular}{|c|c|c|c|c|c|c|c|c|}
\hline \multirow[b]{2}{*}{ Escenario } & \multicolumn{2}{|c|}{ ECUADOR 2006} & \multicolumn{2}{|c|}{ EL SALVADOR 2007} & \multicolumn{2}{|c|}{ HONDURAS 2004} & \multicolumn{2}{|c|}{ NICARAGUA 2005} \\
\hline & gini & conf $95 \%$ & gini & conf $95 \%$ & gini & conf $95 \%$ & gini & conf $95 \%$ \\
\hline Ingreso observado & 0.539 & & 0.468 & & 0.625 & & 0.522 & \\
\hline Ingreso neto de remesas & 0.544 & & 0.496 & & 0.623 & & 0.518 & \\
\hline Simulación 1 & 0.543 * & $\left(\begin{array}{ll}0.542 & 0.546\end{array}\right)$ & 0.479 * & $\left(\begin{array}{ll}0.477 & 0.481\end{array}\right)$ & 0.612 * & $\left(\begin{array}{ll}0.610 & 0.615\end{array}\right)$ & 0.508 * & $(0.506) 0.510$ \\
\hline Simulación 2 & 0.552 * & $\left(\begin{array}{ll}0.548 & 0.558\end{array}\right)$ & 0.479 * & $\left(\begin{array}{ll}0.475 & 0.483\end{array}\right)$ & 0.642 * & $\left(\begin{array}{ll}0.639 & 0.646\end{array}\right)$ & $0.533^{*}$ & $(0.525) 0.543$ \\
\hline Simulación 3 & $0.554^{*}$ & $\left(\begin{array}{ll}0.551 & 0.558\end{array}\right)$ & 0.482 * & $\left(\begin{array}{ll}0.479 & 0.487\end{array}\right)$ & 0.646 * & $\left(\begin{array}{ll}0.644 & 0.650\end{array}\right)$ & $0.537^{*}$ & $(0.528) 0.545$ \\
\hline
\end{tabular}

En todos los casos el índice de Gini estimado en la simulación 3 es superior al estimado en la simulación 2 reflejando que la selección en los inobservables aumenta la desigualdad. La simulación 1 no presenta un patrón uniforme entre países, mientras que en Ecuador y El

\footnotetext{
${ }^{37}$ La dirección de los cambios es similar a la obtenida para estos cuatro países por Acosta, et al (2008) aunque la magnitud de los cambios difiere en algunos casos.
} 
Salvador la desigualdad se reduce al sustituir el ingreso laboral de migrante por remesas, en Honduras y Nicaragua este movimiento produce un aumento de la desigualdad.

El Gráfico 7 muestra el porcentaje de hogares que aumentan, reducen o mantienen constante su ingreso cuando pasan de un escenario simulado al escenario observado.

\section{Gráfico 7}

Transición entre escenarios simulado y observado (porcentaje de hogares sobre total)

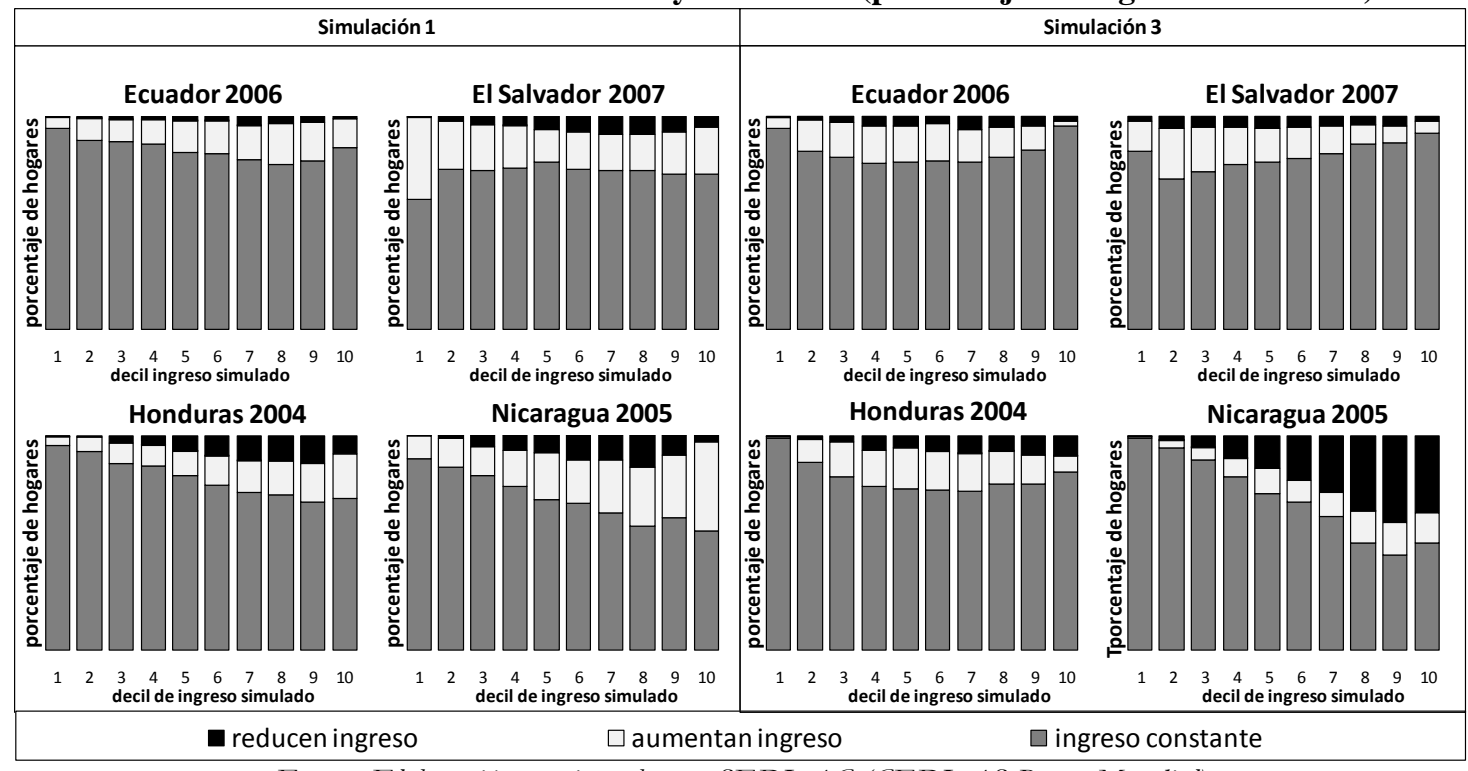

Fuente: Elaboración propia en base a SEDLAC (CEDLAS-Banco Mundial)

El aumento en la desigualdad que se observa en la simulación 1 para Honduras y Nicaragua se puede explicar a partir de este gráfico. En ambos países, aunque con mayor fuerza en Nicaragua, existe un porcentaje relativamente alto de hogares pertenecientes a los deciles superiores que aumentan su ingreso lo que produce un aumento en la desigualdad. Si bien Ecuador también hay un porcentaje alto de hogares que aumentan su ingreso en los deciles más altos, existen movimientos ascendentes importantes en deciles intermedios y bajos que compensan este efecto, mientras que en Honduras los movimientos ascendentes se compensan con los descendentes en los deciles medios y bajos.

La gran cantidad de movimientos descendentes en los deciles superiores en Honduras y Nicaragua para la primera simulación, puede explicarse a partir del tipo de selección de los migrantes y la presencia de migrantes de deciles altos que no envían remesas. Si los migrantes son seleccionados positivamente tanto en inobservables como sugieren las estimaciones de la simulación 1 para Honduras como en términos observables como sugiere la posición de los migrantes en la distribución simulada, el ingreso imputado a los migrantes tenderá a ser alto y difícil de compensar por el envío de remesas, lo que 
producirá que el ingreso simulado sea mayor que el observado para estos hogares. En ambos países sin embargo, estos movimientos se compensan con los efectos positivos que registran los hogares con remesas que no declaran migrantes que se ubican con mayor importancia en deciles altos ${ }^{38}$, los cuales sólo obtienen incrementos de ingresos al pasar del escenario simulado 1 al escenario observado. La fuerte presencia de movimientos ascendentes en El Salvador en cambio se explica en forma opuesta, los migrantes son retribuidos con bajos ingresos dentro de la economía doméstica y la incorporación de las remesas produce un fuerte efecto directo en el ingreso familiar.

En el Gráfico 7, la simulación 3 muestra que los movimientos ascendentes se dan con mayor fuerza en el centro de la distribución para Ecuador y Honduras, en los deciles bajos para El Salvador mientras que en Nicaragua predominan los movimientos descendentes de los deciles superiores.

Es importante destacar que al igual que sucedía con las tasas de pobreza, existe un efecto producido por el aumento del número de individuos que son incluidos en la medición del índice de Gini en los escenarios simulados. El Gráfico 8 presenta el cambio en el índice de Gini de la simulación 3 producido únicamente por la incorporación de los migrantes en la medición.

\section{Gráfico 8}

Efecto de la inclusión de los migrantes sobre la desigualdad (Simulación 3)

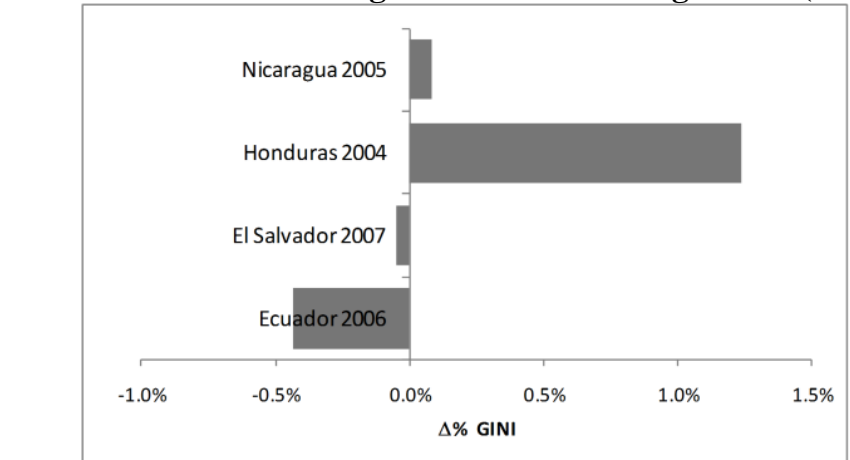

Fuente: Elaboración propia en base a SEDLAC (CEDLAS-Banco Mundial)

Varios efectos determinan si la inclusión de los migrantes dentro de la medición aumenta o reduce la desigualdad. Por un lado es relevante la posición de los hogares con migrantes dentro de la distribución de ingresos, es decir si se encuentran en percentiles altos o bajos, por otro lado también afectan el grado y la forma de dispersión de estos hogares dentro de la distribución al igual que el número de migrantes por hogar.

${ }^{38}$ En el Tabla A2.3 del Apéndice 3 se presenta la distribución de todos los tipos de hogares de acuerdo a los deciles de ingreso simulados. 
Los resultados indican que El Salvador y Nicaragua tienen cambios muy pequeños en el índice de Gini cuando se incorporan los migrantes, mientras que en Honduras hay un cambio desigualador. En Ecuador la inclusión de los migrantes en la medición reduce la desigualdad en la simulación 3.

\section{Efectos directos e indirectos sobre la desigualdad}

$\mathrm{Al}$ igual que con las tasas simuladas de pobreza, es posible determinar la importancia de los efectos directos e indirectos dentro de los cambios totales en la desigualdad como se observa en el Gráfico 9.

Gráfico 9

Efectos directos e indirectos sobre la desigualdad

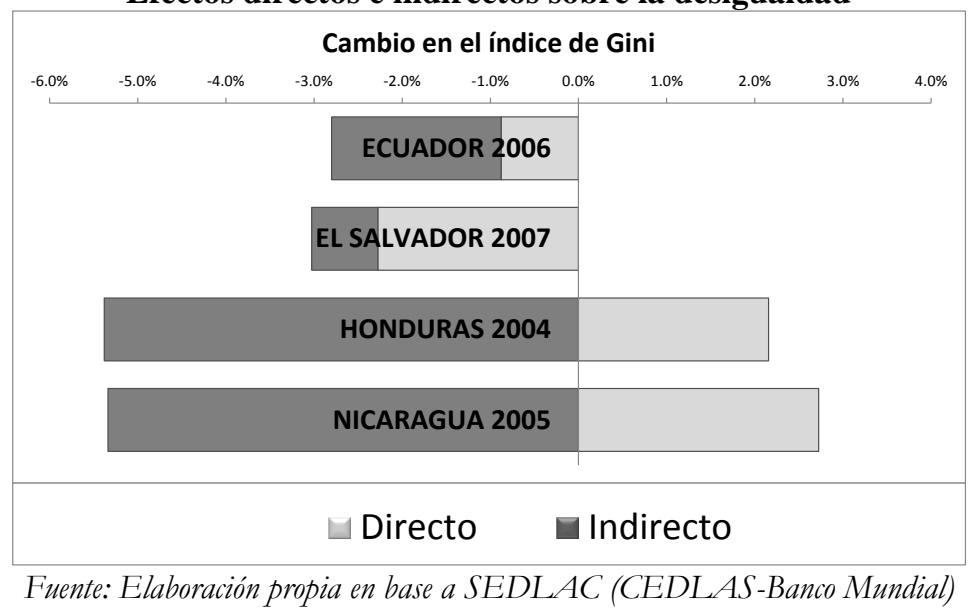

Puede observarse que Ecuador sigue teniendo una fuerte presencia de efectos indirectos como sucedía en los cambios de pobreza y El Salvador una fuerte presencia de efectos directos. En este último país, la caída en la desigualdad se produce principalmente por un fuerte aumento en el ingreso de los percentiles más bajos por lo tanto es esperable que los efectos directos sean más importantes. En el resto de los países la caída en la desigualdad está menos asociada a los percentiles más pobres y por lo tanto es esperable que la importancia de los efectos directos disminuya. Como se mencionó anteriormente, la distribución de los hogares con remesas y sin migrantes al igual que la distribución de los hogares con migrantes y sin remesas también explican en gran parte el efecto directo negativo en Honduras y Nicaragua y el efecto positivo en Ecuador y El Salvador.

Ajuste por adulto equivalente y economías de escala 
Si bien la utilización del ingreso per-cápita familiar para estimar la pobreza es ampliamente difundida, la misma ha recibido diversas críticas en la literatura ${ }^{39}$ (Deaton y Paxon (1997)). Dado que en este trabajo el cambio en la estructura del hogar producto de la salida del migrante es un factor importante, se recalculan las tasas de pobreza y los cambios para diferentes definiciones de ingreso equivalente ${ }^{40}$. El ajuste por adulto equivalente tiende a amplificar el efecto positivo que tiene un menor tamaño de hogar ${ }^{41}$ dado que los migrantes tienden a ser adultos mayores de 18 años. Por otra parte, el ajuste por economías de escala tiende a reducir este efecto positivo porque el cambio en el tamaño del hogar tiene bajo impacto sobre el factor de ajuste. A pesar de estos efectos, dado que los ajustes también modifican las tasas iniciales de pobreza, el impacto final sobre la pobreza no es evidente. El Gráfico 10 muestra el cambio porcentual en las tasas de pobreza para diferentes definiciones de ingreso equivalente.

\section{Gráfico 10}

Cambio porcentual en las tasas de pobreza utilizando ingreso equivalente (simulación 3)

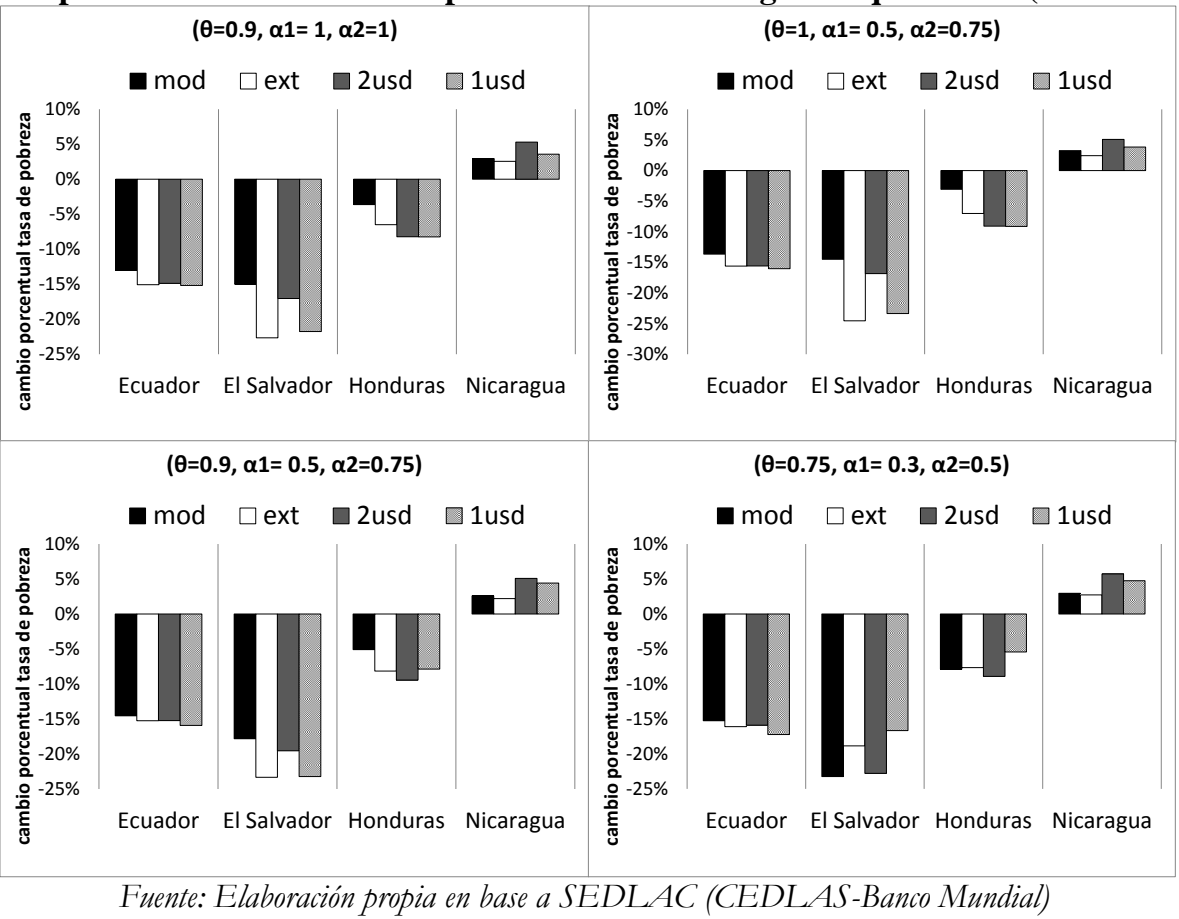

A pesar de que las tasas iniciales de pobreza son diferentes cuando se utilizan distintas definiciones de ingreso equivalente, los resultados indican que la dirección de los cambios obtenidos anteriormente se mantiene para los diferentes ajustes.

\footnotetext{
39 Si bien algunas críticas abarcan también al ingreso como medida de bienestar, el impacto sobre otras variables como el consumo está fuera del alcance de este trabajo.

${ }^{40}$ Se define el ingreso equivalente como $Y_{h} /\left(\alpha_{1} C_{1}+\alpha_{2} C_{2}+A\right)^{\theta}$, donde $Y h$ es el ingreso total del hogar, A es el número de adultos, $\mathrm{C} 1$ el número de niños menores a 5 años y $\mathrm{C} 2$ el número de niños entre 6 y 14 . Los parámetros $\alpha 1$ y $\alpha 2$ permiten ajustar diferentes pesos para adultos y niños en el hogar y el parámetro $\theta$ permite ajustar la medida de consumo e ingreso por economías de escala relacionadas con el tamaño del hogar

${ }^{41}$ Dado un nivel de ingreso total, es decir sin tener en cuenta la pérdida de ingresos laborales del migrante.
} 


\section{Comentarios finales}

Los resultados del trabajo aportan evidencia sobre la importancia de las remesas y la migración internacional en relación a la pobreza y la desigualdad. A partir de diferentes simulaciones se estimaron los cambios producidos en ambas medidas. Los cambios totales se pueden descomponer en efectos directos e indirectos. Los cambios directos están relacionados con la salida del migrante del hogar y la sustitución de ingresos laborales por remesas. Los efectos indirectos (no observables) operan sobre el resto de los miembros del hogar y entre ellos se incluyen restricciones a la liquidez o cambios en las decisiones laborales.

La evidencia muestra que en todos los escenarios simulados y para cualquier definición de utilizada, la pobreza es significativamente mayor que la observada, excepto para Nicaragua donde el efecto total es no significativo para la mayoría de las definiciones de pobreza cuando se incluye la selección en inobservables.

El Salvador es el país donde se estimó el mayor impacto del proceso de migraciones y remesas sobre la pobreza y en segundo lugar de importancia se encuentran Ecuador y Honduras. En Nicaragua los cambios son menores que en el resto de los países.

Varios son los factores que pueden explicar la dirección de los cambios estimados. La posición que ocupan los hogares con migrantes o con remesas dentro del ingreso premigración y pre-remesas es uno de los factores más relevantes y se relaciona estrechamente con las diferencias históricas y las causas de migración de cada país que fueron analizadas en el trabajo. El nivel de calificación de los migrantes y el tipo de selección de los hogares (positiva o negativa) aparecen también como determinantes importantes de los efectos obtenidos.

Es importante destacar que la estimación de un ingreso contrafáctico que tenga en cuenta el problema de selección muestral es fundamental para obtener conclusiones válidas. En este sentido, los resultados del trabajo son diferentes a los que se obtienen cuando se estima la pobreza a partir del ingreso neto de remesas.

Para comprender la dinámica interna de la pobreza en cada país cuando se tiene en cuenta la migración y las remesas, se dividió la muestra en diferentes grupos de hogares de acuerdo al cambio de status en la pobreza entre el escenario contrafáctico y el observado. Los resultados muestran que la pobreza se reduce fuertemente para aquellos hogares que 
reciben remesas pero no declaran tener migrantes. En forma opuesta, entre el grupo de hogares que sufren la partida de un miembro del hogar pero no reciben remesas en compensación, se concentra un porcentaje mayor de hogares que pasan a ser pobres debido a la migración. Para los hogares con migrantes y con remesas los resultados son más ambiguos pero se encuentra que en todos los países, con excepción de Nicaragua, hay un mayor porcentaje de hogares que salen de la pobreza gracias a las remesas y la migración. Si bien no es posible identificar en forma separada, los resultados aportan a la intuición de que la migración en forma aislada y sin remesas que la compensen reporta, en términos generales, una mayor cantidad de costos que beneficios para el hogar.

Cuando se descomponen los cambios totales en la pobreza, los resultados muestran que en Ecuador y Honduras los efectos indirectos explican con mayor fuerza la reducción en las tasas totales de pobreza, mientras que en El Salvador la reducción se debe principalmente al flujo monetario de remesas que reemplaza el ingreso del migrante. En Nicaragua, se observa que aun cuando las remesas puedan compensar la pérdida del ingreso laboral del migrante, existen efectos indirectos que tienden a aumentar la pobreza. Estos resultados también se registran dentro de cada país. La conclusión más importante que arroja este trabajo es que los efectos indirectos son más importantes para los hogares ubicados en el centro de la distribución, mientras que para los hogares más pobres el efecto directo de la sustitución de ingresos laborales por remesas es la principal causa de la reducción en la pobreza. En los hogares de mayor ingreso los efectos indirectos tienden a ser negativos o nulos. Este resultado es coherente con la intuición de que son los hogares del centro de la distribución quienes pueden aprovechar mejor el aumento de la liquidez y la posibilidad de diversificar riesgos mientras que los hogares de ingresos bajos tienden a cubrir necesidades más básicas, reduciendo la importancia de la migración como estrategia de liquidez o diversificación de riesgos. Existen también argumentos teóricos que asocien los efectos negativos de la migración y las remesas en los hogares de mayor ingreso, pero en el caso de Nicaragua también se debe tener en cuenta el fuerte componente político del proceso migratorio.

En los cuatro países, el índice de Gini se reduce en aproximadamente 2 puntos entre el escenario simulado y el observado, indicando un efecto igualador del proceso de migraciones y remesas. Las matrices de transición entre los escenarios simulados y el escenario observado indica que la reducción de la desigualdad se produce por una mejora relativa de los hogares de ingresos bajos (El Salvador) e intermedios (Honduras y Ecuador) 
o bien por un deterioro relativo de los ingresos de los hogares de los percentiles altos (Nicaragua), aunque en todos los deciles existen movimientos ascendentes y descendentes en relación a la posición de los hogares en la distribución contrafáctica. La descomposición de los cambios en la desigualdad muestra que al igual que sucedía con la pobreza, en El Salvador los efectos directos son más importantes principalmente debido al incremento en el ingreso de los hogares en los deciles muy bajos. En ecuador los efectos indirectos son mayores y refuerzan el impacto igualador de los cambios directos. Honduras y Nicaragua en cambio muestran un impacto directo desigualador de las remesas y la migración mientras que los efectos directos son fuertemente igualadores.

Si bien los resultados del trabajo son coherentes con los hallazgos de otros autores y los principales modelos teóricos, existen una serie de limitaciones obvias que se derivan de la falta de disponibilidad de encuestas de panel en estos países y otras limitaciones propias de la metodología. La posibilidad de contar con encuestas de panel permitiría una mejor estimación y discriminación de los efectos indirectos de las remesas y al mismo tiempo la implementación de técnicas más robustas. Por otra parte, es posible extender los escenarios simulados incorporando elementos más complejos que fueron dejados de lado en este trabajo. La simulación de los cambios en las decisiones de fertilidad y del status laboral del migrante y los otros miembros del hogar, son también extensiones naturales de este trabajo. La incorporación de efectos de equilibrio general constituye también una tarea pendiente si se tienen en cuenta las magnitudes macroeconómicas involucradas en el proceso.

\section{Referencias}

Acosta P., Calderon, C., Fajnzylber, P. O. y Lopez, H. (2008), "What is the Impact of International Remittances on Poverty and Inequality in Latin America?", World Development Vol. 36, No. 1, pp. 89-114

Acosta P., Fajnzylber, P. and H. Lopez (2007), "Remittances and Household Behavior: Evidence for Latin America", in Fajnzylber P. and H. Lopez (eds.), Remittances and Development: Lessons from Latin America, World Bank.

Acosta P., Calderón, C., Fajnzylber, P. O. y Lopez, H. (2007), "How Important are Remittances in Latin America?", in Fajnzylber P. and H. Lopez (eds.), Remittances and Development: Lessons from Latin America, World Bank.

Acosta P., Fajnzylber, O. and Lopez, H. (2007), "The Impact of Remittances on Poverty and Human Capital: Evidence from Latin American Household Surveys”, in Özden Ç. and M. Schiff (eds.), International Migration, Economic Development and Policy, World Bank-Palgrave Macmillan.

Acosta P. (2006), "Labor Supply, School Attendance, and Remittances from International Migration: The Case of El Salvador”, Policy Research Working Paper No. 3903, World Bank, April.

Adams, R.. (2006) 'Remittances, Poverty, and Investment in Guatemala'. In C. Ozden and M. Schiff (eds) 2006. 
Adams R. (2005), "Remittances, Household Expenditures and Investment in Guatemala", Policy Research Working Paper No. 3532, World Bank.

Adams, R, y Page, J. (2003). "International migration, remittances, and poverty in developing countries," Policy Research Working Paper Series 3179, The World Bank.

Adams, R.. (1998) "Remittances, Investment and Rural Asset Accumulation in Pakistan" Economic Development and Cultural Change, 47: 155-173.

Adams, R.. (1991) "The effects of international remittances on poverty, inequality, and development in rural Egypt:"Research reports 86, International Food Policy Research Institute (IFPRI).

Amuedo-Dorantes C., Georges, A. y Pozo, S. Amuedo (2008). "Migration, Remittances and Children's Schooling in Haiti," IZA Discussion Papers 3657, Institute for the Study of Labor (IZA)

Amuedo-Dorantes C. y Pozo S. (2006), "Migration, Remittances, and Male and Female Employment Patterns", American Economic Review, Vol. 96, No. 2.

Amuedo-Dorantes C. (2006) "Remittances and Their Microeconomic Impacts: Evidence from Latin America" Migration, Trade and Development". Proceedings of the 2006 Conference on Migration, Trade, and Development

Amuedo-Dorantes, C. y Pozo, S. (2002), "Remittances as insurance: evidence from Mexican immigrants" Journal of Population Economics, Springer, vol. 19(2), pages 227-254

Barham, B., Boucher, S. (1998) "Migration, Remittances and Inequality: Estimating the Net Effects of Migration on Income Distribution", Journal of Development Economics 55, pp. 307-331.

Baumeister, E. (2006) "Migración internacional y desarrollo en Nicaragua". Serie Población y Desarrollo, \# 67, UN-ECLAC

Beine, M., Docquier, F. and Rapoport, H. (2001). "Brain Drain and Economic Growth: Theory and Evidence.” J. Development Econ. 64 (February). 275-89.

Borjas, G. J. (1987). "Self-Selection and the Earnings of Immigrants.” American Economic Review .77: 531-53.

Calero, C., Bedi, A. S. y Sparrow, R. (2009). "Remittances, Liquidity Constraints and Human Capital Investments in Ecuador," World Development, Elsevier, vol. 37(6), pages 1143-1154

Cortina, J. y de la Garza, R. (2004) "Immigrant Remitting Behavior and its Developmental Consequences for Mexico and El Salvador", The Tomás Rivera Policy Institute.

Cox, D. y Jimenez, E., (1998) "Risk Sharing and Private Transfers: What about Urban Households?," Economic Development and Cultural Change, University of Chicago Press, vol. 46(3), pages 621-37

Cox, D., (1987), “Motives for Private Income Transfers,” Journal of Political Economy 95 (June): 508-46.

De Haan,A., (1999) "Livelihoods and Poverty: The Role of Migration: A Critical Review of the Migration Literature," Journal of Development Studies (Vol. 36, No. 2, 1999)

De la Briere, B., Sadoulet, E., de Janvry, A., y Lambert, S. (2002). "The roles of destination, gender, and household composition in explaining remittances: an analysis for the Dominican Sierra". The Journal of Development Studies, 68, 309-328.

Deaton, A. y Paxson, C. (1997). "Poverty among children and the elderly in developing countries". Working paper, Princeton University.

Edwards, C., A. y Ureta, M . (2003). "International migration, remittances, and schooling: evidence from El Salvador," Journal of Development Economics, Elsevier, vol. 72(2), pages 429-461

Ellis, F., (2003), “A Livelihoods Approach to Migration and Poverty Reduction”, Paper Commissioned by the Department for International Development (DFID) 
Germenji, E., Beka, I., y Sarris, A. (2001). "Estimating remittance functions for rural-based Albanian emigrants”. Working paper, ACE research project, P97-8158-R.

Hanson, G., (2007) "Emigration, remittances and labor force participation in Mexico," INTAL Working Papers 1456, Inter-American Development Bank, INTAL.

Hevia J. y Arrazola, M. (2009) "Marginal effects in the double selection regression model: an illustration for the wages of women in Spain", Economics Bulletin, Vol. 29 no.2 pp. 611-621.

Holst, E., y Schrooten, M. (2006). "Migration and money- What determines remittances? Evidence from Germany". Institute of Economic Research, Hitotsubashi University,Discussion Paper Series, 477.

Kandel, W. y Kao, G. (2001) “The Impact of Temporary Labor Migration on Mexican Children's Educational Aspirations and Performance" International Migration Review Vol. 35, No. 4, pp. 1205-31.

Lanzona, L.A., "Migration, Self-selection and Earnings in Philippine Rural Communities," Journal of Development Economics 56 (1998), 27-50.

Lipton, M. (1980). "Migration from rural areas of poor countries: the impact on rural productivity and income distribution". World Development, 8(1): 1-24.

Lucas, R. E. B. (1987). “Emigration to South Africa’s Mines”. American Economic Review, 77: 313-30.

Massey, D. S., Arango, J., Hugo., G., Kouaouci, A., Pellegrino, A. y Taylor, J.E. (1993). "Theories of International Migration: A Review and Appraisal”. Population and Development Review, 19(3): 431-466.

Mattoo, A., Neagu I., y Özden, C. (2005), "Brain Waste? Educated Immigrants in the US Labor Market", Policy Research Working Paper \#3581, World Bank, Washington DC

McKenzie, D. (2006) 'Beyond Remittances: The Effects of Migration on Mexican Households'. In C. Ozden and M. Schiff (eds) 2006.

McKenzie, D., Gibson, D., J., y Stillman, S. (2006) "How important is selection? Experimental vs. Nonexperimental Measures of the Income Gains from Migration?” IZA Discussion Paper No. 2087, Bonn: IZA.

Mora Rivera, J. J., (2005) "The impact of migration and Remittances on distribution and sources income: The mexican rural case". United Nations Expert Group Meeting on International Migration and Development. Population Division. Department of Economic and Social Affairs

Munshi, K. (2003) "Networks in the Modern Economy: Mexican Migrants in the US Labor Market." Quarterly Journal of Economics 118 (2): 549-599.

Nakosteen, R.A., y M. Zimmer". (1980) Migration and Income: The Question of Self-Selection," Southern Economic Journal 46, 840-51.

Neyapti, B., (2004) “Trends in Worker's Remittances: a Worldwide Overview”.Emerging Markets Finance and Trade, Vol 40, No 2, pp. 82-90.

Orozco, M. Lockwood, C. Rouse, R. (2006) "Migraciones y remesas en América Latina y el Caribe: Los flujos intrarregionales y las determinantes macroeconómicas". SELA. Sistema Económico Latinoamericano y del Caribe. Disponible en http://www.hegoa.ehu.es/dossierra/migracion/SELA=remesas2006.pdf

Ratha, D. y Xu, Z., (2008) Migration and Remittances Factbook 2008, World Bank Publications.

Rivera Funes, O.F. (2005) "Las migraciones internacionales y sus efectos económicos en El Salvador", Población y Salud en Mesoamérica. Vol 2, no.2, Centro Americano de Población.

Rodriguez E. and E. Tiongson (2001), "Temporary Migration Overseas and Household Labor Supply: Evidence from Urban Philippines", International Migration Review, Vol. 35, No. 3.

Rosenzweig, M. R., (1988). "Risk, implicit contracts, and the family in rural areas of low income countries". Economic Journal 98 (393), 1148-1170 
Roy, A. D. (1951). "Some Thoughts on the Distribution of Earnings." Oxford Econ. Papers 3 (June): 135-46.

Rozelle, S., J.E. Taylor, and A. De Brauw (1999). "Migration, remittances, and agricultural productivity in China”. The American Economic Review, 89:287-291.

Solimano, A. (2006) "Remittances by emigrants: issues and evidence". Serie Macroeconomía del Desarrollo, Series Macroeconomics of Development, \# 26, UN-ECLAC

Stark, O. and Bloom, D. E. (1985). "The New Economics of Labor Migration”. The American Economic Review, 75(2): 173-178.

Stark, O., Taylor, J.E. y Yitzhaki, S. (1986). "Remittances and Inequality". The Economic Journal, 96(383): 722740 .

Stark, O., Taylor, J.E. y Yitzhaki, S. (1988). "Migration, Remittances and Inequality. A sensitivity Analysis Using the Extended Gini Index". Journal of Development Economics, 28(3): 309-322.

Taylor, J.E. (1992). "Remittances and Inequality Reconsidered: Direct, Indirect, and Intertemporal Effects". Journal of Policy Modeling, 14(2): 187-208.

Taylor, J.E.and Wyatt T.J. (1996). "The Shadow Value of Migrant Remittances, Income and Inequality in a Household-farm Economy". The Journal of Development Studies, 32(6): 899-912.

Tunali, L. (1986) "A General Structure for Models of Double Selection and an Application to a Joint Migration/Earning Process with Remigration”, Research in Labour Economics 8, 235-82.

Tunali, L. (2000) “Rationality of Migration” International Economic Review, Vol. 41, No. 4, (Nov., 2000), pp. 893920

Wouterse, F., y Taylor, J. E., (2008) "Migration and Income Diversification: Evidence from Burkina Faso," World Development, Elsevier, vol. 36(4), pages 625-640

Yang, D. (2008) "International Migration, Remittances and Household Investment: Evidence from Philippine Migrants' Exchange Rate Shocks", The Economic Journal Royal Economic Society, vol. 118(528), pages 591-630, 04.

Yang, D. y H. Choi, H. (2007), "Are Remittances Insurance? Evidence from Rainfall Shocks in the Philippines", World Bank Economic Review, Vol. 21, No. 2.

Yúnez-Naude, A. (2001). "Las remesas y el desarrollo rural". en Seminario Internacional transferencia y el uso de las remesas: Proyectos Productivos y de Ahorro. Zacatecas, México 


\section{Apéndice 1: Perfil de los hogares receptores de remesas y hogares con migrantes}

Tabla A.1.1

Variables demográficas y regionales

\begin{tabular}{|c|c|c|c|c|c|c|c|c|c|c|c|c|c|c|c|c|c|c|c|c|c|c|c|c|}
\hline & \multirow{2}{*}{\multicolumn{6}{|c|}{ ECUADOR 2006}} & \multicolumn{6}{|c|}{ EL SALVADOR 2007} & \multicolumn{6}{|c|}{ HONDURAS 2004} & \multicolumn{6}{|c|}{ NICARAGUA 2005} \\
\hline & & & & & & & \multicolumn{3}{|c|}{ Recepción de remesas } & \multicolumn{3}{|c|}{ Presencia de migrantes } & \multicolumn{6}{|c|}{ Recepción de remesas Presencia de migrantes } & \multicolumn{6}{|c|}{ Recepción de remesas Presencia de migrantes } \\
\hline & \multicolumn{3}{|c|}{\begin{tabular}{|c|} 
Recepción de remesas \\
No
\end{tabular}} & $\begin{array}{c}\text { Con } \\
\text { Mgrante }\end{array}$ & $\begin{array}{c}\text { Sin } \\
\text { Mgrante }\end{array}$ & Dif & Receptor & Receptor & Dif & $\begin{array}{c}\text { Con } \\
\text { Mgrante }\end{array}$ & $\begin{array}{c}\text { Sin } \\
\text { Mgrante }\end{array}$ & Dif & Recepto & $\begin{array}{c}\text { No } \\
\text { Receptor }\end{array}$ & Dif & $\begin{array}{c}\text { Con } \\
\text { Migrante }\end{array}$ & 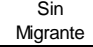 & Dif & Receptor & $\begin{array}{c}\text { No } \\
\text { Receptor }\end{array}$ & Dif & $\begin{array}{c}\text { Con } \\
\text { Migrante } \\
\text { (n) }\end{array}$ & $\begin{array}{c}\text { Sin } \\
\text { Mgrante }\end{array}$ & Dif \\
\hline & 15.9 & 84.1 & & 5.8 & 94.2 & & 26.7 & 73.3 & & 10.0 & 90.0 & & 15.2 & 84.8 & & 12.0 & 88.0 & & 22.4 & 77.6 & & 13.3 & 86.7 & \\
\hline ricti 15$]$ & & 35.2 & & 32 & $34 . \varepsilon$ & & & & 0.2 & & & $-1.5^{* *}$ & & & & & & & & 6.7 & & & & -5.3 \\
\hline & 18 & $\begin{array}{l}17.8 \\
225\end{array}$ & & 14 & & 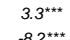 & 20.0 & & otovt & & 18.8 & $1.6^{\prime *}$ & $\begin{aligned} 24.1 \\
1.8 .\end{aligned}$ & & & & & $3.4^{4 * *}$ & & & & & & 2.". \\
\hline & & & & & & & & & & & $\begin{array}{l}22.6 \\
18.8\end{array}$ & 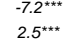 & & & & & & & & & & & & 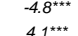 \\
\hline & $\begin{array}{r}8.3 \\
1000\end{array}$ & $\begin{array}{l}1.5 \\
5.9 \\
1.90\end{array}$ & $2.3 . \cdots$ & 6 & $\begin{array}{c}6.5 \\
6.3 \\
100\end{array}$ & 0.5 & 10.5 & 6.3 & 4.2."' & 11 & 7.0 & $4.5 \%$ & 5.2 & 4.0 & ${ }_{1.2}^{2 *}$ & 5 & 4.0 & 1.4\% & 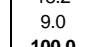 & 4.1 & $4.9 \cdots$ & & 4.7 & 3.6." \\
\hline centa & 46.7 & 50.1 & & 48.4 & 49.6 & -1.2 & 43.8 & 48.4 & 5 & 43. & 47.6 & -4 & 44.8 & 49.6 & 9 & 10 & 49.5 & $-5.4^{* * * *}$ & 46.5 & 49.8 & 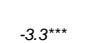 & 47.1 & 49.4 & $3^{*}$ \\
\hline & & & & & & & & & & & & & & & & & & & & & & & & \\
\hline isa af & 1.8 & $\begin{array}{l}4.0 \\
2.2\end{array}$ & $-0.4^{\cdots \cdots}$ & $\begin{array}{l}4.1 \\
1.9\end{array}$ & $\begin{array}{l}4.1 \\
2.2\end{array}$ & $\begin{array}{l}0.1 \cdots \cdots \\
0.2^{2} \cdots\end{array}$ & 2.7 & $\begin{array}{l}4.0 \\
2.6\end{array}$ & $0.1 . \cdots$ & 2.8 & $\begin{array}{l}4.0 \\
2.6\end{array}$ & $\begin{array}{l}0.0 . \cdots \\
0.0^{2} \cdots\end{array}$ & 2.2 & $\begin{array}{l}4.9 \\
2.9\end{array}$ & $\begin{array}{c}0.0 \\
0.7^{m}\end{array}$ & $\begin{array}{l}5.0 \\
2.5\end{array}$ & $\begin{array}{l}4.9 \\
2.8\end{array}$ & $\begin{array}{l}0.1 \cdots * \\
-0.4^{* \cdots *}\end{array}$ & $\begin{array}{l}4.8 \\
2.8\end{array}$ & $\begin{array}{l}5.3 \\
3.3\end{array}$ & $\begin{array}{l}-0.5 \cdots \\
0.5 \cdots\end{array}$ & $\begin{array}{l}5.0 \\
2.7\end{array}$ & $\begin{array}{l}5.2 \\
3.2\end{array}$ & $\begin{array}{l}-0.2^{2} \\
-0.5^{*}\end{array}$ \\
\hline & & & & & & & & & & & & & & & & & & & & & & & & \\
\hline $\begin{array}{l}\text { ritanoo } \\
\text { otal }\end{array}$ & $\begin{array}{l}73.3 \\
76.7 \\
100.0\end{array}$ & $\begin{array}{c}3.6 \\
64.4 \\
100.0\end{array}$ & $\begin{array}{r}-12 . \\
12 .\end{array}$ & $\begin{array}{l}\begin{array}{l}71.1 \\
100.0\end{array}\end{array}$ & $\begin{array}{l}66.1 \\
100.0\end{array}$ & on. & $\begin{array}{l}60.0 \\
100.0\end{array}$ & $\begin{array}{l}63.6 \\
100.0\end{array}$ & 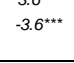 & $\begin{array}{l}58.9 \\
100.0\end{array}$ & $\begin{array}{l}63.1 \\
100.0\end{array}$ & $\begin{array}{l}-4.1, \ldots \\
-4.1\end{array}$ & $\begin{array}{l}60.6 \\
100.0\end{array}$ & $\begin{array}{l}40.1 \\
46.1 \\
1000 .\end{array}$ & $\begin{array}{l}-14.93 \\
14.5\end{array}$ & $\begin{array}{l}565.8 \\
100.0\end{array}$ & $\begin{array}{l}47.1 \\
100.0\end{array}$ & $9.77^{\prime \prime}$ & $\begin{array}{l}699.4 \\
100.0\end{array}$ & $\begin{array}{r}51.9 \\
100.0\end{array}$ & $17.5^{\prime \prime \prime}$ & $\begin{array}{l}73.6 \\
100.0\end{array}$ & $\begin{array}{l}53.1 \\
100.0\end{array}$ & $20.5^{\circ}$ \\
\hline
\end{tabular}

Tabla A.1.2

Variables de infraestructura del hogar

\begin{tabular}{|c|c|c|c|c|c|c|c|c|c|c|c|c|c|c|c|c|c|c|c|c|c|c|c|c|}
\hline & \multirow{2}{*}{\multicolumn{6}{|c|}{ ECUADOR 2006}} & \multirow{2}{*}{\multicolumn{6}{|c|}{ EL SALVADOR 2007}} & \multirow{2}{*}{\multicolumn{6}{|c|}{ HONDURAS 2004}} & \multicolumn{6}{|c|}{ NICARAGUA 2005} \\
\hline & & & & & & Presencia de migrantes & & & & & & Presencia de migrantes & & & & & & Presencia de migrantes & \multicolumn{3}{|c|}{ Recepción de remesas } & \multicolumn{3}{|c|}{ Presencia de migrantes } \\
\hline & Receptor & $\begin{array}{c}\text { No } \\
\text { Receptor }\end{array}$ & Dif & $\begin{array}{c}\text { Con } \\
\text { Migrante }\end{array}$ & $\begin{array}{c}\text { Sin } \\
\text { Migrante }\end{array}$ & Dif & Receptor & $\begin{array}{c}\text { No } \\
\text { Receptor }\end{array}$ & Dif & $\begin{array}{l}\text { Con } \\
\text { Migrante }\end{array}$ & $\begin{array}{c}\text { Sin } \\
\text { Migrante }\end{array}$ & Dif & eptor & $\begin{array}{c}\text { No } \\
\text { Receptor }\end{array}$ & Dif & $\begin{array}{c}\text { Con } \\
\text { Migrante }\end{array}$ & $\begin{array}{c}\text { Sin } \\
\text { Migrante }\end{array}$ & Dif & eptor & $\begin{array}{c}\text { No } \\
\text { Receptor }\end{array}$ & Dif & $\begin{array}{c}\text { Con } \\
\text { Migrante } \\
\end{array}$ & $\begin{array}{c}\text { Sin } \\
\text { Migrante }\end{array}$ & Dif \\
\hline Propiedad del hogar & 67.8 & 65.3 & $2.5^{* *}$ & 74.4 & 65.1 & $9.2^{* * *}$ & 68.1 & 63.5 & $4.6^{* * *}$ & 75.8 & 63.5 & $12.4^{*+*}$ & 66.9 & 63.5 & $3.3^{*+}$ & 72.2 & 62.9 & $9.3^{*+*}$ & 78.1 & 76.8 & 1.30 & 82.2 & 76.3 & $5.9^{\text {t+*t }}$ \\
\hline No de habitaciones & 5.7 & 4.7 & $0.9^{* * *}$ & 5.8 & 4.8 & $0.9^{* * *}$ & 2.9 & 2.4 & $0.5^{* * *}$ & 3.1 & 2.4 & $0.6^{* * *+}$ & 3.8 & 3.1 & $0.7^{* * *}$ & 4.2 & 3.1 & $1.0^{* * *}$ & 2.8 & 2.5 & $0.3^{* * *}$ & 3.0 & 2.5 & $0.6^{*+*}$ \\
\hline Personas por habitación & 0.9 & 1.1 & $-0.2^{2+* t}$ & 0.8 & 1.1 & $-0.2^{4+*}$ & 1.8 & 2.3 & $-0.4^{*+*+}$ & 1.7 & 2.2 & $-0.5^{* * *}$ & 1.7 & 2.1 & $-0.4^{* * *}$ & 1.6 & 2.1 & $-0.6^{*+*}$ & 2.2 & 2.8 & $-0.6^{* *+\cdots}$ & 2.1 & 2.7 & $-0.6^{+*+*}$ \\
\hline Vivienda precaria & 5.4 & 9.5 & $-4.1^{+* * t}$ & 4.5 & 9.1 & $-4.6^{\text {t+t+ }}$ & 3.0 & 7.9 & $-4.9^{\text {tat }}$ & 2.6 & 7.0 & $-4.4^{4+*}$ & 6.5 & 8.3 & $-1.9^{* * *}$ & 4.6 & 8.5 & $-3.9^{m+*}$ & 4.0 & 5.2 & $-1.2^{* * *}$ & 2.7 & 5.3 & $-2.6^{4+*}$ \\
\hline Materiales preca & 13.8 & 26.5 & $-12.7^{*+* t}$ & 15.8 & 25.1 & $-9.3^{* *+}$ & 22.1 & 27.3 & $-5.2^{*+*}$ & 21.9 & 26.4 & $-4.5^{* * *}$ & 26.6 & 45.6 & $-19.0^{* * *}$ & 29.5 & 44.5 & $-15.0^{\circ * *}$ & 10.8 & 14.6 & $-3.8^{* *+}$ & 8.9 & 14.4 & $-5.5^{*+*}$ \\
\hline Agua corri & 90.1 & 76.3 & $13.8^{* * *}$ & 92.1 & 77.6 & $14.5^{5 *+}$ & 71.5 & 67.2 & $4.4^{* * *}$ & 73.3 & 67.8 & $5.5^{\cdots * *}$ & 88.6 & 78.7 & $9 . g^{* * *}$ & 90.5 & 78.9 & $11.6^{4 * *}$ & 75.8 & 61.0 & $14.8^{* * *}$ & 3.5 & 62.4 & $16.1^{t+*+}$ \\
\hline ño hig & 92.5 & 80.4 & $12.1^{1 * * *}$ & 91.6 & 81.8 & $9.9^{* * * *}$ & 40.7 & 38.0 & $2.7^{7 * * *}$ & 39.8 & 38.6 & 1.30 & 60.3 & 41.8 & $18.5^{* * * *}$ & 58.7 & 42.8 & $16.0^{0+* t}$ & 1.1 & 25.5 & $15.7^{\mathrm{m*m}}$ & 45.6 & 26.7 & $19.0^{*+*}$ \\
\hline
\end{tabular}


Tabla A.1.3

Variables educativas

\begin{tabular}{|c|c|c|c|c|c|c|c|c|c|c|c|c|c|c|c|c|c|c|c|c|c|c|c|c|}
\hline & \multicolumn{6}{|c|}{ ECUADOR 2006} & \multicolumn{6}{|c|}{ EL SALVADOR 2007} & \multicolumn{6}{|c|}{$\begin{array}{l}\text { HONDURAS } 2004 \\
\end{array}$} & \multicolumn{6}{|c|}{$\begin{array}{l}\text { NICARAGUA } 2005 \\
\end{array}$} \\
\hline & \multicolumn{3}{|c|}{\begin{tabular}{|l|} 
Recepción de remesas \\
\end{tabular}} & \multicolumn{3}{|c|}{$\begin{array}{l}\text { Presencia de migrantes } \\
\end{array}$} & \multicolumn{3}{|c|}{ Recepción de remesas } & \multicolumn{3}{|c|}{ Presencia de migrantes } & \multicolumn{3}{|c|}{ Recepción de remesas } & \multicolumn{3}{|c|}{ Presencia de migrantes } & \multicolumn{3}{|c|}{\begin{tabular}{|l|} 
Recepción de remesas \\
\end{tabular}} & \multicolumn{3}{|c|}{ Presencia de migrantes } \\
\hline & Receptor & $\begin{array}{c}\text { No } \\
\text { Receptor }\end{array}$ & Dif & $\begin{array}{c}\text { Con } \\
\text { Migrante }\end{array}$ & $\begin{array}{c}\mathrm{Sin} \\
\text { Migrante }\end{array}$ & Dif & Receptor & $\begin{array}{c}\text { No } \\
\text { Receptor }\end{array}$ & Dif & $\begin{array}{c}\text { Con } \\
\text { Migrante }\end{array}$ & $\begin{array}{c}\mathrm{Sin} \\
\text { Migrante }\end{array}$ & Dif & Receptor & $\begin{array}{c}\text { No } \\
\text { Receptor }\end{array}$ & Dif & $\begin{array}{c}\text { Con } \\
\text { Migrante }\end{array}$ & $\begin{array}{c}\mathrm{Sin} \\
\text { Migrante }\end{array}$ & Dif & Receptor & $\begin{array}{c}\text { No } \\
\text { inceptor }\end{array}$ & Dif & $\begin{array}{c}\text { Con } \\
\text { Migrante }\end{array}$ & $\begin{array}{c}\text { Sin } \\
\text { Migrante }\end{array}$ & Dif \\
\hline \multirow{2}{*}{\multicolumn{25}{|c|}{ Años de educación }} \\
\hline & 8.1 & 7.1 & $0.9^{t+*+x}$ & 7.5 & 7.3 & $0.3^{+*+*}$ & 5.5 & 5.7 & $-0.2^{2+*+}$ & 5.5 & 5.7 & $-0.2^{2+*}$ & 5.8 & 4.7 & $1.1^{* * *+}$ & 5.5 & 4.8 & $0.7^{* * *+}$ & 5.8 & 4.9 & $0.9^{* * * *}$ & 6.0 & 5.0 & $1.0^{+2+*}$ \\
\hline$[10,20]$ & 7.6 & 6.8 & $0.8^{*+*}$ & 7.4 & 6.9 & $0.5^{* * *}$ & 6.3 & 6.0 & $0.3^{+*+*}$ & 6.2 & 6.1 & $0.1^{*}$ & 6.2 & 5.0 & $1.2^{2 * * *}$ & 5.9 & 5.0 & $0.9^{* * *}$ & 6.2 & 5.1 & $1.1^{1+*}$ & 6.3 & 5.2 & $1.2^{*+*+}$ \\
\hline$[21,30]$ & 11.2 & 9.4 & $1.8^{* * *+}$ & 11.1 & 9.6 & $1.5^{* * *}$ & 9.5 & 8.6 & $0.9^{*+*}$ & 9.9 & 8.7 & $1.2^{* * *}$ & 8.0 & 6.3 & $1.7^{* * *}$ & 7.7 & 6.4 & $1.3^{*+*}$ & 8.7 & 6.9 & $1.7^{+* *+}$ & 8.5 & 7.1 & $1.3^{*+*+}$ \\
\hline$[31$, & 10.5 & 9.2 & $1.4^{* *+*}$ & 9.8 & 9.3 & 0.50 & 8.4 & 7.7 & $0.8^{*+*}$ & 8.5 & 7.8 & $0.7^{* *+*}$ & 7.6 & 5.6 & $2.0^{* * *}$ & 6.7 & 5.8 & $0.9^{* * *}$ & 7.3 & 6.1 & $1.2^{2+*}$ & 8.1 & 6.2 & $2.0^{*+* *}$ \\
\hline$[41,50]$ & 9.7 & 8.3 & $1.4^{* * *}$ & 8.5 & 8.5 & 0.00 & 6.0 & 6.8 & $-0.8^{t+*}$ & 5.5 & 6.7 & $-1.2^{2 * *}$ & 6.3 & 5.0 & $1.2^{* * *+}$ & 5.3 & 5.2 & 0.10 & 6.6 & 5.2 & $1.5^{* * * *}$ & 6.5 & 5.3 & $1.2^{*+*+}$ \\
\hline$[51,60]$ & 7.4 & 6.6 & $0.8^{t * *+}$ & 6.9 & 6.7 & 0.10 & 4.1 & 5.4 & $-1.3^{*+*+}$ & 4.7 & 5.0 & -0.30 & 4.7 & 4.0 & $0.7^{* * *+}$ & 5.1 & 3.9 & $1.2^{* * *}$ & 4.6 & 3.8 & $0.7^{* * *+}$ & 4.7 & 3.9 & $0.8^{*+*+}$ \\
\hline$[61+]$ & 5.2 & 4.3 & $1.0^{+*+*}$ & 5.2 & 4.4 & $0.8^{*+*}$ & 2.6 & 3.2 & $-0.5^{* * *}$ & 3.0 & 3.0 & 0.10 & 3.0 & 2.3 & $0.7^{* * * *}$ & 3.7 & 2.2 & $1.5^{2 * *}$ & 2.5 & 2.3 & 0.20 & 3.1 & 2.2 & $0.9^{m+*}$ \\
\hline Tasa de alfabetismo & 95.8 & 93.0 & $2.8^{t+*}$ & 95.3 & 93.3 & $2.0^{* * *}$ & 84.4 & 86.3 & $-1.9^{*+*+}$ & 83.8 & 86.0 & $-2.2^{2 *+*}$ & 90.3 & 83.1 & $7.2^{* * *}$ & 88.9 & 83.5 & $5.3^{2 *+*}$ & 83.9 & 80.8 & $3.1^{1 * * *}$ & 85.5 & 80.9 & $4.6^{*+*+}$ \\
\hline \multicolumn{25}{|l|}{ Asistencia escolar } \\
\hline$[3,5]$ & 58.8 & 50.4 & $8.4^{*+*+}$ & 52.5 & 51.5 & 1.00 & 36.3 & 30.0 & $6.2^{2+*+}$ & 30.6 & 31.7 & -1.10 & 0.0 & 0.0 & 0.00 & 0. & 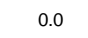 & 0.00 & 41.1 & 1.8 & $9.3^{*+*}$ & 41.4 & 32.7 & $8.6^{*+*}$ \\
\hline$[6,1$ & 98.6 & 96 & $2.1^{x+*+}$ & 99.0 & 96 & $2.3^{* * *}$ & 93.6 & 92 & $1.6^{* * *+}$ & 92 & 92.4 & 0.30 & 95.8 & 9 & $5.7^{* * *}$ & 95 & 90.4 & $4.6^{* *+*}$ & 86.8 & 81.5 & $5.3^{* * * *}$ & 89.5 & 81.6 & $7.9^{*+*}$ \\
\hline$[13,1$ & 84.2 & 74.3 & $9.9+*$ & 79.7 & 75.8 & 4.6 & 76.8 & 76.4 & 0.40 & 76.3 & 76.6 & -0.30 & 78.0 & 68.7 & $9.3^{\cdots * *}$ & 76 & 69.2 & $7.3^{* * *}$ & 75.7 & 67.3 & 8.3 & 77.2 & 67.9 & $9.3^{* * *}$ \\
\hline$[18,23]$ & 43.8 & 30.2 & $13.6^{4+10}$ & 42.5 & 31.9 & $10.6^{* *+*}$ & 30.8 & 27.6 & $3.1^{*+*}$ & 33.1 & 28.0 & $5.2^{*+*}$ & 42.0 & 28.6 & $13.4^{* * *}$ & 41.0 & 29.2 & $11.7^{+* *}$ & 34.1 & 25.5 & $8.6^{+* *+}$ & 30.2 & 27.1 & $3.1^{*}$ \\
\hline
\end{tabular}

Tabla A.1.4

Variables laborales

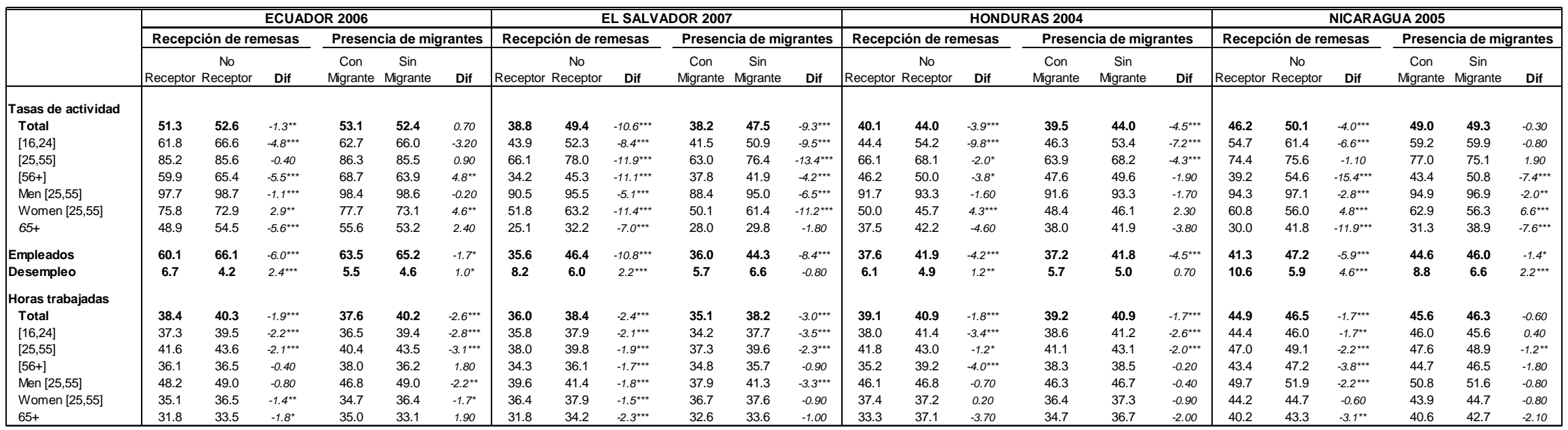




\section{Apéndice 2: Variables y modelos utilizados en la simulación}

Tabla A2.1

Descripción de variables utilizadas en las simulaciones

\begin{tabular}{|c|c|c|c|}
\hline \multicolumn{2}{|r|}{ Variables utilizadas en todos los modelos } & \multicolumn{2}{|c|}{ Variables adicionales modelo a nivel individual } \\
\hline hsize & Cantidad de miembros adultos, incluyendo los migrantes & & \\
\hline hsize2 & Cantidad de miembros adultos al cuadrado & age & Edad del individuo \\
\hline pmale & Porcentaje de hombres adultos, incluyendo migrantes & age 2 & Edad al cuadrado \\
\hline male18a65h & Número de hombres de 18 a 65 años, incluyendo migrantes & prii & Nivel educativo: primario incompleta \\
\hline fem18a65h & Número de mujeres de 18 a 65 años, incluyendo migrantes & pric & Nivel educativo: primario completa \\
\hline male18a30h & Número de hombres de 18 a 30 años, incluyendo migrantes & seci & Nivel educativo: secundario incompleto \\
\hline fem18a30h & Número de mujeres de 18 a 30 años, incluyendo migrantes & $\operatorname{secc}$ & Nivel educativo: secundario completo \\
\hline male $31 a 45 h$ & Número de hombres de 18 a 30 años, incluyendo migrantes & supi & Nivel educativo: superior incompleto \\
\hline fem31a45h & Número de mujeres de 18 a 30 años, incluyendo migrantes & supc & Nivel educativo: superior completo \\
\hline male $46 a 65 h$ & Número de hombres de 18 a 30 años, incluyendo migrantes & male & Hombre \\
\hline fem46a65 & Número de mujeres de 18 a 30 años, incluyendo migrantes & alone & Único migrante dentro del hogar \\
\hline preselder & Presencia de adultos mayores $(+65)$ & & \\
\hline meanageh & Edad media del hogar, incluyendo migrantes & & \\
\hline$m j_{-} *$ & Dummies de educativas jefe de hogar (corregidas con migrante) & & \\
\hline maxeduhh & Años de educación máximos dentro del hogar & & \\
\hline meaneduhh & Años de educación media (adultos) dentro del hogar & & \\
\hline marriedhead & Jefe del hogar casado & & \\
\hline state_r $r$ & Set de variables regionales $r=1,2, \ldots$ & & \\
\hline index & Indice de características de la vivienda & & \\
\hline mignetworks & Número de migrantes de la localidad, (exluyendo el mismo hogar) & & \\
\hline mignet_edu & Interacción index x maxeduhh & & \\
\hline ant_mig & Promedio de años de emigración promedio en la localidad & & \\
\hline pens & Recepción de jubilaciones o pensiones & & \\
\hline rural & Región rural & & \\
\hline pens & Presence of pensionated person in the household & & \\
\hline$n 7 \_17$ & Niños de 7 a 17 años dentro del hogar & & \\
\hline
\end{tabular}


Tabla A2.2

Simulación 1. Estimación del modelo de selección a nivel individual

\begin{tabular}{|c|c|c|c|c|c|c|c|c|}
\hline \multirow[t]{2}{*}{ Variable } & \multicolumn{2}{|c|}{ Ecuador 2006} & \multicolumn{2}{|c|}{ El Salvador 2007} & \multicolumn{2}{|c|}{ Honduras 2004} & \multicolumn{2}{|c|}{ Nicaragua 2005} \\
\hline & Ingreso & No emigración & Ingreso & No emigración & Ingreso & No emigración & Ingreso & No emigración \\
\hline age & $0.080 * * *$ & $-0.062 * * *$ & $0.055^{* * *}$ & $-0.074 * * *$ & $0.069 * * *$ & $-0.021^{* *}$ & $0.055^{* * *}$ & 0.005 \\
\hline age2 & $-0.001 * * *$ & $0.001^{* * *}$ & $-0.001 * * *$ & $0.001 * * *$ & $-0.001 * * *$ & $0.000 * * *$ & $-0.001 * * *$ & $0.000 * * *$ \\
\hline male & $0.595^{* * *}$ & 0.004 & $0.229 * * *$ & $-0.300 * * *$ & $0.574^{* * *}$ & $-0.221^{* * *}$ & $0.343^{* * *}$ & $0.182^{* * *}$ \\
\hline pric & $0.438^{* * *}$ & $-1.260 * * *$ & $0.234 * * *$ & $-0.308 * * *$ & $0.365^{* * *}$ & $-0.523 * * *$ & $0.211 * * *$ & $-0.392 * * *$ \\
\hline seci & $0.690 * * *$ & 5.096 & $0.201^{* * *}$ & $-0.237 * *$ & $0.539 * * *$ & $-0.294^{* * *}$ & $0.349 * * *$ & -0.044 \\
\hline secc & $0.997^{* * *}$ & $-1.826 * * *$ & $0.487 * * *$ & $-0.194 * * *$ & $0.948 * * *$ & $-0.594^{* * *}$ & $0.523 * * *$ & -0.062 \\
\hline supi & $1.276^{* * *}$ & 4.962 & $0.829 * * *$ & 0.200 & $1.219 * * *$ & 0.112 & $0.637 * * *$ & 0.061 \\
\hline supc & $1.703^{* * *}$ & $-1.587^{* * *}$ & $1.259 * * *$ & 0.264 & $1.692 * * *$ & $-0.417^{*}$ & $1.103^{* * *}$ & $0.279 * *$ \\
\hline rural & $-0.503^{* * *}$ & $-1.652^{* * *}$ & $-0.052 * * *$ & $0.622 * * *$ & $-0.505^{* * *}$ & $1.306 * * *$ & $-0.198 * * *$ & -0.020 \\
\hline hsize & & $-0.157^{* *}$ & & $-0.277 * * *$ & & $-0.116 * *$ & & -0.017 \\
\hline pmale & & -0.135 & & $-0.376 * *$ & & 0.185 & & -0.102 \\
\hline male18a65h & & 0.008 & & $0.189 * * *$ & & 0.083 & & -0.055 \\
\hline fem18a65h & & -0.055 & & $0.116^{*}$ & & 0.047 & & -0.042 \\
\hline preselder & & $0.353^{* * *}$ & & $0.318^{* * *}$ & & -0.051 & & 0.060 \\
\hline meanageh & & $-0.104^{* * *}$ & & $-0.056 * * *$ & & $-0.057 * * *$ & & $-0.037 * * *$ \\
\hline meanageh2 & & $0.001 * * *$ & & 0.000 & & $0.000^{* *}$ & & 0.000 \\
\hline maxeduhh & & $-0.024^{*}$ & & $-0.043 * * *$ & & $-0.054^{* * *}$ & & $-0.040 * * *$ \\
\hline meaneduhh & & $0.092^{* * *}$ & & 0.023 & & 0.020 & & 0.006 \\
\hline headedu & & 0.008 & & -0.012 & & $-0.030^{* * *}$ & & -0.003 \\
\hline marriedhead & & $0.445^{* * *}$ & & $0.908^{* * *}$ & & $0.362 * * *$ & & $0.353^{* * *}$ \\
\hline index & & $-0.892^{* * *}$ & & $-0.337 * * *$ & & $-0.131 * * *$ & & $-0.052 * *$ \\
\hline mignetworks & & -0.002 & & $0.424 * * *$ & & $0.532 * * *$ & & -0.001 \\
\hline index_mignet & & 0.000 & & $0.097^{* * *}$ & & $0.089 * * *$ & & 0.001 \\
\hline alone & & $-1.571 * * *$ & & $-1.932 * * *$ & & $-1.317^{* * *}$ & & $-1.773 * * *$ \\
\hline Constant & $2.543^{* * *}$ & $7.355^{* * *}$ & $3.800 * * *$ & $3.901^{* * *}$ & $5.724 * * *$ & $1.814^{* * *}$ & $5.630 * * *$ & $2.954^{* * *}$ \\
\hline$\lambda$ & $0.366 * * *$ & & -0.026 & & $-0.134 * * *$ & & -0.057 & \\
\hline$\rho$ & & 0.33 & & -0.04 & & -0.14 & & -0.07 \\
\hline Observations & 22526 & & 25007 & & 14676 & & 12862 & \\
\hline
\end{tabular}

${ }^{*}$ signif. $10 \%$; ${ }^{* *}$ signif. $5 \%$; ${ }^{* * *}$ signif. $1 \%$

(1)En todas las ecuaciones se incluyeron dummies por provincia o estado

(2) Ingreso en logaritmos 
Tabla A2.3

Simulaciones 2 y 3. Estimación del modelo de selectividad doble a nivel de hogares

\begin{tabular}{|c|c|c|c|c|c|c|c|c|c|c|c|c|}
\hline Variable & & cuador 2006 & & & Salvador 200 & & & nduras 200 & & & icaragua 200 & \\
\hline & $\begin{array}{c}\text { No } \\
\text { migración }\end{array}$ & $\begin{array}{c}\text { No } \\
\text { remesas }\end{array}$ & Ingreso & $\begin{array}{c}\text { No } \\
\text { migración }\end{array}$ & $\begin{array}{c}\text { No } \\
\text { remesas }\end{array}$ & Ingreso & $\begin{array}{c}\text { No } \\
\text { migración }\end{array}$ & $\begin{array}{c}\text { No } \\
\text { remesas }\end{array}$ & Ingreso & $\begin{array}{c}\text { No } \\
\text { migración }\end{array}$ & $\begin{array}{c}\text { No } \\
\text { remesas }\end{array}$ & Ingreso \\
\hline hsize & $-0.393 * * *$ & $-0.262^{* * *}$ & $0.320^{* * *}$ & $-0.583^{* * *}$ & $-0.300 * * *$ & $0.231^{* * *}$ & $-0.540 * * *$ & $-0.271^{* * *}$ & $0.247^{* * *}$ & $-0.365 * * *$ & $-0.180^{* * *}$ & $0.210^{* * *}$ \\
\hline hsize2 & & & $-0.025^{* * *}$ & & & $-0.024^{* * *}$ & & & $-0.019 * * *$ & & & $-0.014^{* * *}$ \\
\hline pmale & -0.235 & $0.231^{* * *}$ & & $-0.349 * * *$ & 0.051 & & $-0.350^{* *}$ & 0.068 & & 0.051 & $0.643 * * *$ & \\
\hline male18a65h & $-0.255^{* * *}$ & 0.045 & & $-0.085^{* *}$ & -0.031 & & -0.007 & 0.020 & & $-0.213^{* * *}$ & 0.063 & \\
\hline fem18a65h & $-0.376 * * *$ & 0.007 & & $-0.094 * * *$ & -0.004 & & $-0.132 * * *$ & -0.027 & & $-0.269 * * *$ & 0.061 & \\
\hline male18a30h & & & $0.061^{* * *}$ & & & 0.007 & & & $0.079 * * *$ & & & $0.056^{* *}$ \\
\hline fem18a30h & & & -0.004 & & & -0.008 & & & 0.024 & & & 0.027 \\
\hline male31a45h & & & $0.106^{* * *}$ & & & $0.069 * * *$ & & & $0.127^{* * *}$ & & & $0.142^{* * *}$ \\
\hline fem $31 a 45 h$ & & & 0.019 & & & $0.097^{* * *}$ & & & $0.058^{* *}$ & & & $0.092^{* * *}$ \\
\hline male $46 a 65 h$ & & & 0.045 & & & 0.002 & & & $0.126^{* * *}$ & & & $0.120^{* * *}$ \\
\hline fem $46 a 65$ & & & $-0.108^{* * *}$ & & & -0.036 & & & -0.005 & & & 0.042 \\
\hline preselder & & -0.004 & $-0.196^{* * *}$ & & $-0.117^{* *}$ & $-0.114 * *$ & & -0.060 & -0.023 & & -0.028 & -0.009 \\
\hline n_elder2 & & & 0.049 & & & -0.009 & & & -0.034 & & & -0.027 \\
\hline marriedhead & $0.643^{* * *}$ & $0.293^{* * *}$ & & $1.030^{* * *}$ & $0.614^{* * *}$ & & $0.502^{* * *}$ & $0.341^{* * *}$ & & $0.729^{* * *}$ & $0.612^{* * *}$ & \\
\hline meanageh & $-0.012 * * *$ & $-0.009 * * *$ & $0.035^{* * *}$ & $-0.010 * * *$ & $-0.008 * * *$ & $0.021 * * *$ & $-0.018^{* * *}$ & $-0.006 * * *$ & $0.020 * * *$ & $-0.025 * * *$ & $-0.018^{* * *}$ & 0.010 \\
\hline meanageh2 & & & $-0.000^{* * *}$ & & & $-0.000 * * *$ & & & $-0.000^{* * *}$ & & & 0.000 \\
\hline mj_pric & $-2.006^{* * *}$ & $-0.417^{* * *}$ & $0.089 * * *$ & $-1.049 * * *$ & $-0.544 * * *$ & $-0.060 * *$ & $-1.415^{* * *}$ & $-0.625 * * *$ & -0.054 & $-1.218^{* * *}$ & $-0.099 *$ & -0.008 \\
\hline mj_seci & $-1.677^{* * *}$ & $-0.464 * * *$ & $0.061^{*}$ & $-1.542^{* * *}$ & $-0.829 * * *$ & $-0.096 * *$ & $-1.904^{* * *}$ & $-0.945^{* * *}$ & -0.068 & $-1.677^{* * *}$ & $-0.461 * * *$ & 0.056 \\
\hline mj_secc & $-3.570 * * *$ & $-0.827^{* * *}$ & 0.061 & $-1.576 * * *$ & $-0.697 * * *$ & 0.005 & $-2.283^{* * *}$ & $-0.956 * * *$ & 0.003 & $-2.072 * * *$ & $-0.611 * * *$ & 0.020 \\
\hline mj_supi & $-2.790 * * *$ & $-0.633^{* * *}$ & $0.145^{* * *}$ & $-1.649 * * *$ & $-0.643 * * *$ & $0.164^{* * *}$ & $-2.121^{* * *}$ & $-0.856 * * *$ & $0.160^{* *}$ & $-2.457^{* * *}$ & $-0.752 * * *$ & 0.141 \\
\hline mj_supc & $-3.696 * * *$ & $-0.603^{* * *}$ & $0.256^{* * *}$ & $-1.726 * * *$ & $-0.481 * * *$ & $0.353^{* * *}$ & $-2.757^{* * *}$ & $-0.937 * * *$ & $0.240 * * *$ & $-2.294 * * *$ & $-0.389 * * *$ & $0.272^{* * *}$ \\
\hline acumschool & $0.023^{* * *}$ & $0.004^{*}$ & $0.006^{* * *}$ & $0.024 * * *$ & $0.011^{* * *}$ & $0.014^{* * *}$ & $0.026 * * *$ & $0.011 * * *$ & $0.007^{* * *}$ & $0.030 * * *$ & 0.001 & $0.006^{* * *}$ \\
\hline maxeduhh & $0.058^{* * *}$ & $-0.011^{*}$ & $0.038^{* * *}$ & 0.002 & -0.003 & $0.032 * * *$ & $0.038^{* * *}$ & -0.011 & $0.020 * * *$ & -0.001 & $0.016^{*}$ & $0.025^{* * *}$ \\
\hline meaneduhh & & & $0.060^{* * *}$ & & & $0.021 * * *$ & & & $0.083^{* * *}$ & & & $0.053^{* * *}$ \\
\hline rural & $-1.153^{* * *}$ & $-0.151^{* * *}$ & $-0.328^{* * *}$ & $-0.986 * * *$ & $-0.249 * * *$ & $-0.151^{* * *}$ & $-0.169 * *$ & -0.013 & $-0.310 * * *$ & 0.042 & $0.079 *$ & $-0.215^{* * *}$ \\
\hline mignetworks & -0.001 & & & $-0.016^{* * *}$ & & & 0.000 & & & $-0.006 * * *$ & & \\
\hline mignet_edu & 0.000 & & & $0.000^{* *}$ & & & 0.000 & & & $0.000^{* *}$ & & \\
\hline ant_mig & $-0.168^{* * *}$ & & & $-0.032 * * *$ & & & $-0.021^{* *}$ & & & $0.013^{*}$ & & \\
\hline index & $-0.148^{* * *}$ & $-0.119 * * *$ & & $-0.080 * * *$ & $-0.071 * * *$ & & $-0.050 *$ & $-0.074 * * *$ & & 0.010 & -0.023 & \\
\hline pens & & -0.020 & & & $0.197^{* * *}$ & & & -0.126 & & & $-0.137^{*}$ & \\
\hline n5_17 & & $-0.030 * * *$ & & & $-0.017^{* *}$ & & & -0.018 & & & $0.020^{*}$ & \\
\hline Constante & $5.675^{* * *}$ & $1.916 * * *$ & $3.534^{* * *}$ & $4.341 * * *$ & $1.986 * * *$ & $4.200^{* * *}$ & $3.769 * * *$ & $1.668^{* * *}$ & $6.603 * * *$ & $4.022 * * *$ & $1.217^{* * *}$ & $6.548^{* * *}$ \\
\hline$\lambda 1$ & & & $0.173^{*}$ & & & $0.133^{* *}$ & & & 0.024 & & & -0.024 \\
\hline$\lambda 2$ & & & $0.319^{* * *}$ & & & $0.245^{* * *}$ & & & $0.258^{*}$ & & & $-0.334 * * *$ \\
\hline$\rho 12$ & 0.7 & & & 0.8 & & & 0.7 & & & 0.5 & 84 & \\
\hline Observaciones & 13176 & 13176 & 10947 & 14913 & 14913 & 11662 & 7941 & 7941 & 6240 & 6821 & 6821 & 4975 \\
\hline$R-2$ & & & 0.54 & & & 0.47 & & & 0.57 & & & 0.41 \\
\hline
\end{tabular}

*signif. $10 \% ;{ }^{* *}$ signif. $5 \% ;{ }^{* * *}$ signif. $1 \%$

(1) Se incluyeron controles a nivel estatal o provincial para todos los países en las 3 ecuaciones

(2) En la ecuación de migración se incluyó la presencia de inmigrantes nacionales y extranjeros dentro del hogar para los países que contaban con la información.

(3) En la ecuación de recepción de remesas se incluyó la recepción de remesas a nivel local para los países que contaban con la información.

(4) Ingreso familiar en logaritmos 


\section{Apéndice 3: Distribuciones observadas y contrafácticas}

Gráfico A.3.1

Distribuciones de ingreso percápita familiar para toda la muestra (Simulación 3)

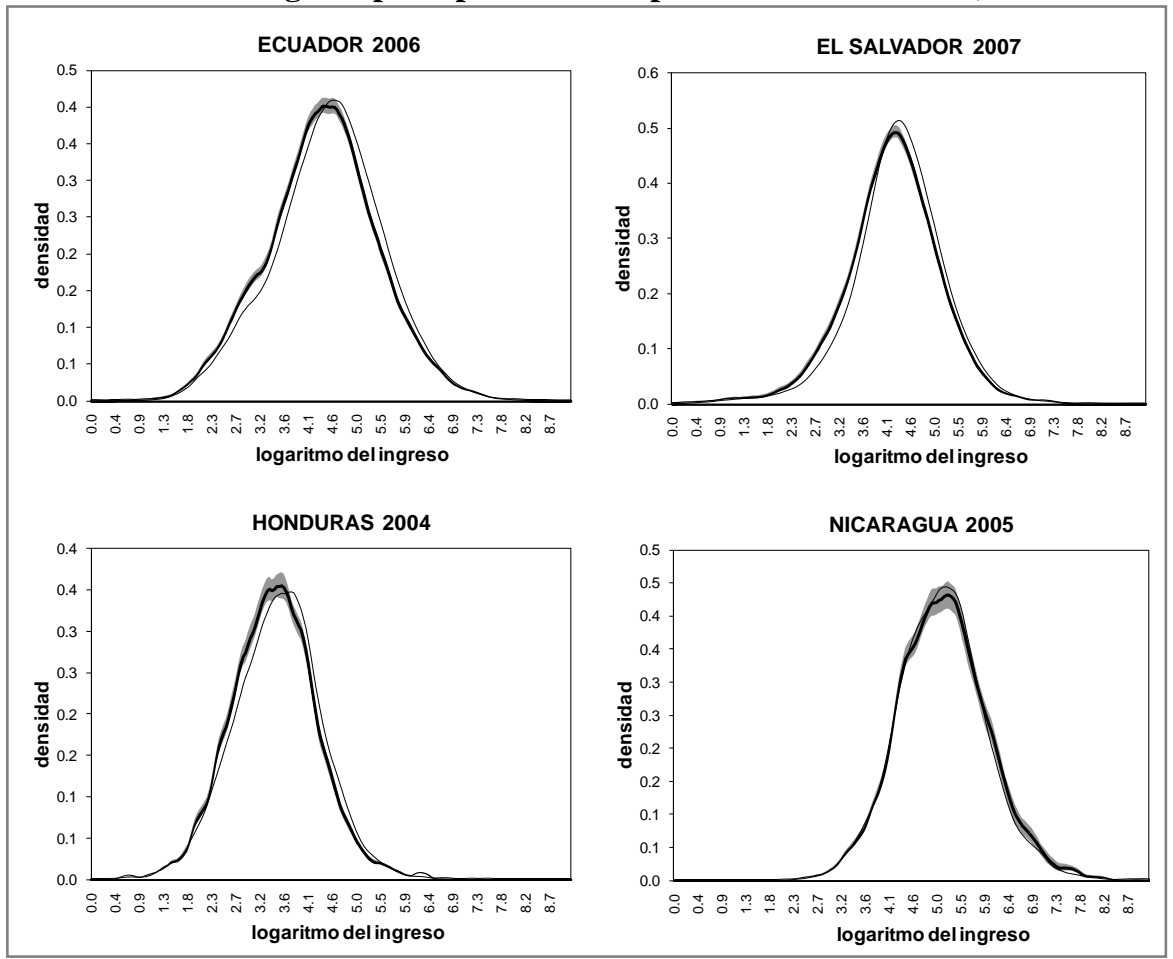

Gráfico A.3.2

Distribuciones de ingreso percápita familiar hogares con migrantes o remesas (Simulación 1)
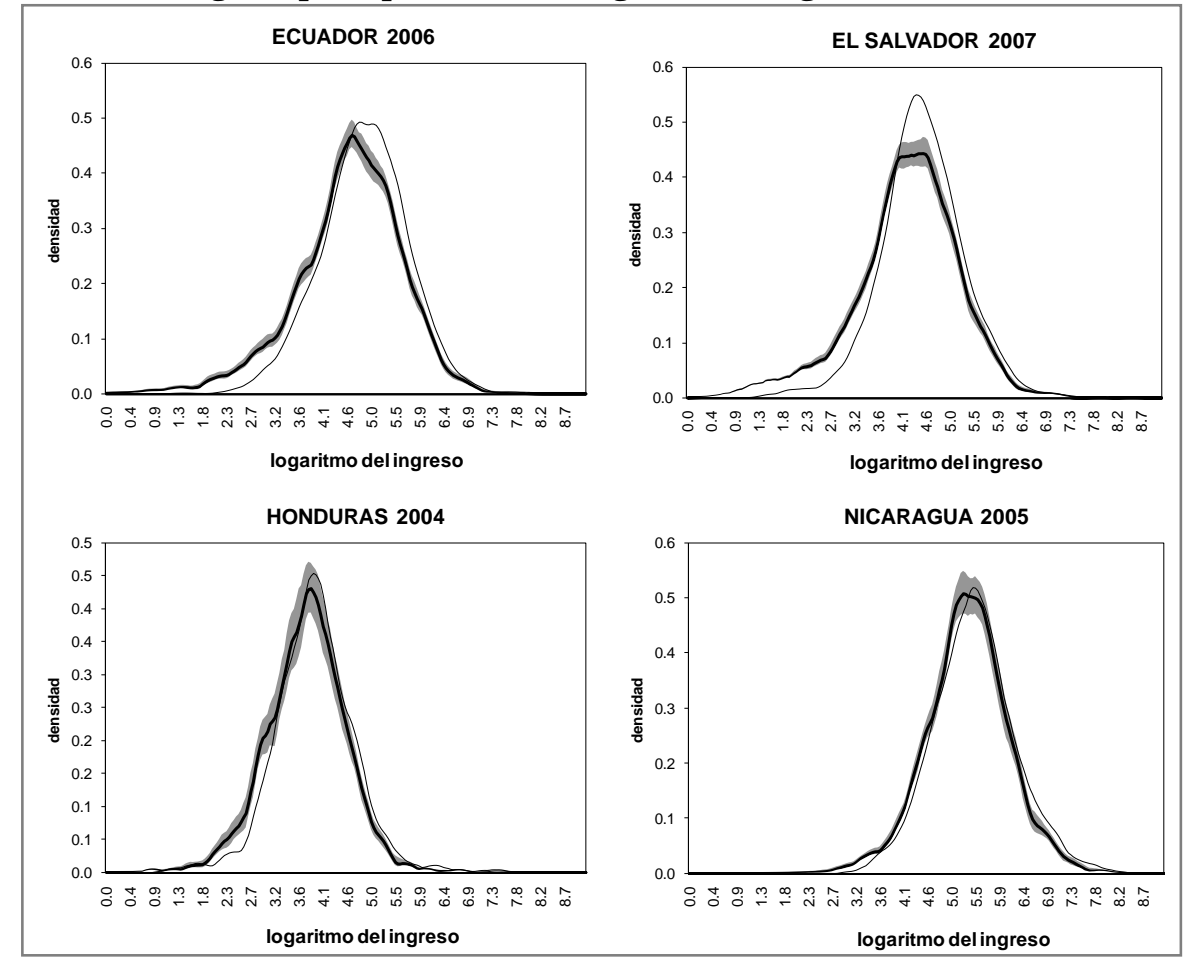
Gráfico A.3.3

Distribuciones de ingreso percápita familiar hogares con migrantes o remesas (Simulación 3)

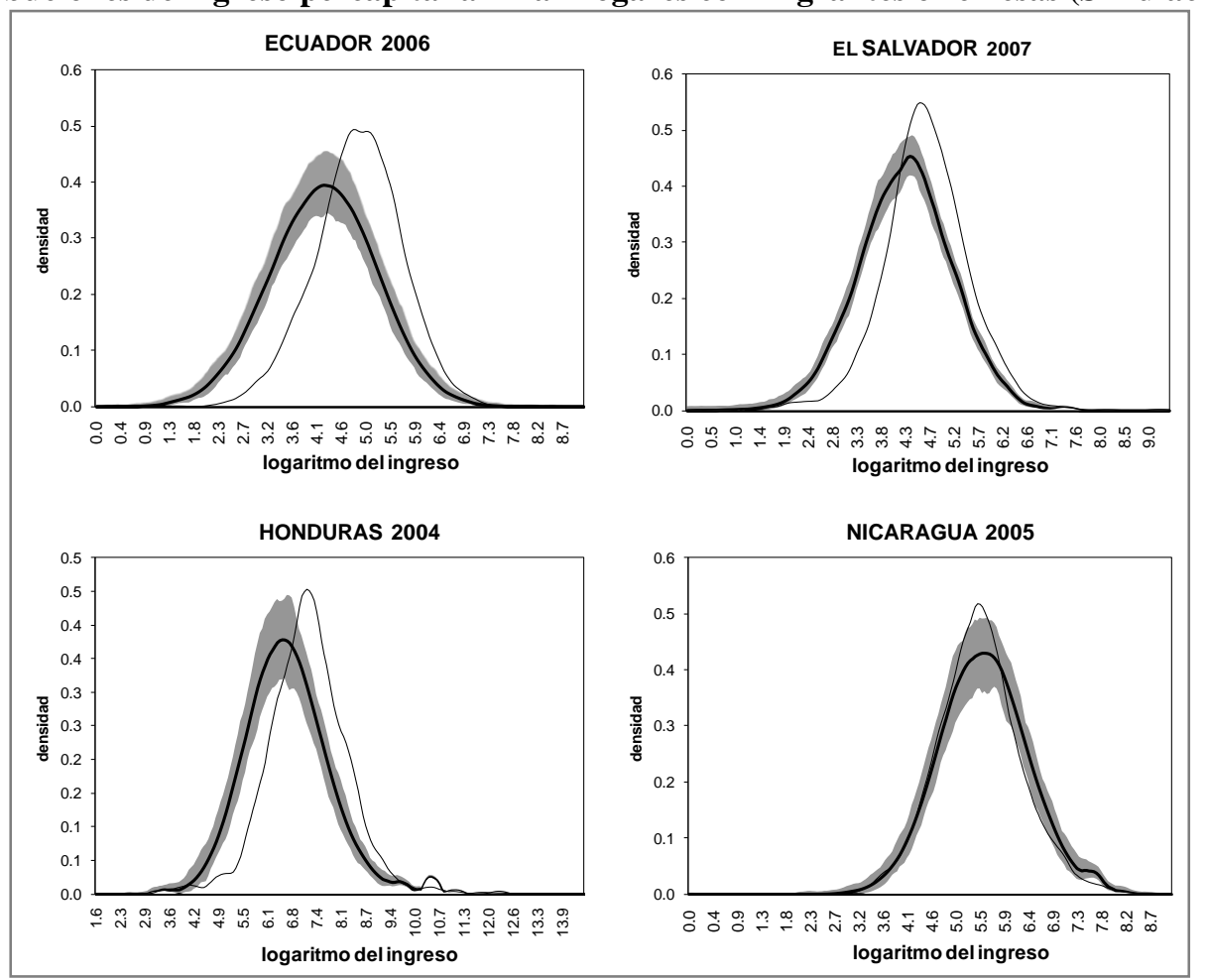

Gráfico A.3.4

Distribución de los hogares según status de migración y remesas

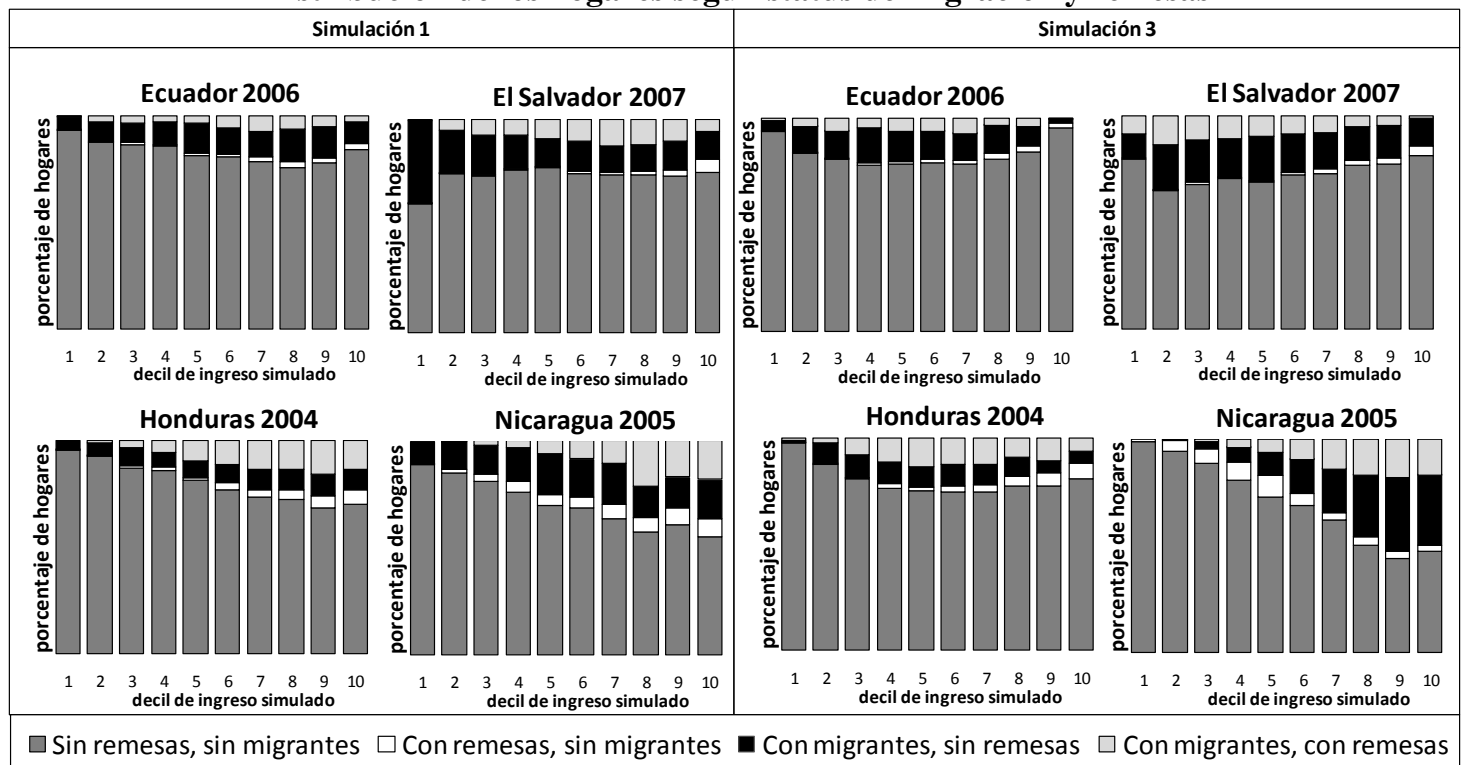

